\title{
ANALYSIS OF PROTEIN PRE-COATINGS AND THEIR EFFECT ON ENDOTHELIAL CELL ADHESION IN A TISSUE ENGINEERED BLOOD VESSEL MIMIC
}

\author{
A Thesis \\ presented to \\ the Faculty of California Polytechnic State University, \\ San Luis Obispo \\ In Partial Fulfillment \\ of the Requirements for the Degree \\ Master of Sciences in Biomedical Engineering
}

By

Rachel A. Gohres

May, 2013 
(C)2013

Rachel A. Gohres

\section{ALL RIGHTS RESERVED}




\section{COMMITTEE MEMBERSHIP}

TITLE:

AUTHOR:

DATE SUBMITTED:

COMMITTEE CHAIR:

COMMITTEE MEMBER:

COMMITTEE MEMBER:
Analysis of Protein Pre-Coatings and Their Effect on Endothelial Cell Adhesion in a Tissue Engineered Blood Vessel Mimic

Rachel A. Gohres

May 13, 2013

Kristen O'Halloran Cardinal, PhD, Associate Professor, BMGE

Trevor Cardinal, PhD, Associate Professor, BMGE

Lily Laiho, $\mathrm{PhD}$, Associate Professor, BMGE 


\section{ABSTRACT \\ ANALYSIS OF PRE-COATINGS AND THEIR EFFECT ON ENDOTHELIAL CELL ADHESION IN A TISSUE ENGINEERED BLOOD VESSEL MIMIC}

Rachel Gohres

Cardiovascular disease is the leading cause of death in developing countries. Because thousands of people are affected by this disease, medical device companies are constantly developing new intravascular devices in attempt to cure or alleviate the symptoms of the disease. However, before these devices can be brought to market or implanted in to patients, they must complete three stages of testing to receive FDA approval. These testing stages include: in vitro testing, in vivo testing, and clinical trials. Currently, there is a large gap between in vitro and in vivo testing because it is difficult to obtain physiologic information about a device during in vitro testing. Therefore, to obtain this information, most devices move on to in vivo testing, increasing the amount of time, money and animal models used during the approval process. In attempt to overcome this limitation of the approval process, Dr. Kristen Cardinal developed a tissue engineered blood vessel mimic (BVM) to bridge the gap between in vitro and in vivo testing to efficiently test intravascular devices. However, before the BVM can be utilized to test intravascular devices, key limitations must be overcome. The limitation addressed in this thesis is the lack of endothelial cell adhesion to the PLGA scaffold used in the BVM. In attempt to overcome this limitation, protein pre-coatings were characterized in 6-well plates and then implemented in to the BVM to determine if endothelial cell adhesion could be increased.

The aim of this thesis was to analyze and compare the effects of different protein precoatings coatings on endothelial cell adhesion in 6-well plates and the BVM. The first phase of this thesis sought to characterize the coatings and their effects on cell attachment in a controlled and efficient setting. Different aspects of coating protocols were developed during this phase including the optimization of incubation periods and analysis protocols. The second phase of this 
thesis included the implementation of the most effective pre-coatings from the 6-well plate studies (Conditioning Media and ProNectin-F) in to the BVM to determine which coating was most effective in increasing cell attachment and reducing cell loss after flow exposure. Using fluorescent staining and image analysis, it was concluded that Conditioning Media was as effective as ProNectin-F in increasing cell attachment and retention in the BVM. While both coatings significantly increased the number of cells adhered compared to a non-coated scaffold, the endothelial lining in the lumen was not $100 \%$ confluent. Therefore, other coatings and/or combinations of coatings can be studied in the future to continue to improve cell attachment in the BVM system. 


\section{ACKNOWLEDGEMENTS}

I would like to begin by thanking Dr. Kristen Cardinal for her continual support, encouragement and guidance, for without you, this thesis would not have been possible. It was you and your excitement for tissue engineering that ignited my passion for this field of research. I have been so fortunate to have you as my advisor for the last two years and have learned countless valuable lessons that I know I will take with me in all my future endeavors. Thank you for always pushing me to go above and beyond in all aspects of my college career. I would also like to thank my thesis committee members, Dr. Trevor Cardinal and Dr. Lily Laiho. You have both provided endless support and encouragement throughout this process.

I would also like to thank previous and current members of the Tissue Engineering Lab, Mike Gibbons, Sara Ur, Marcus Foley, Aubrey Dryer as well the rest of the team. It has been such a wonderful experience working with all of you the last two years. I would especially like to thank Aubrey for encouraging me to get involved in the lab, teaching me your ways and laying the foundation for my thesis project. Marcus, thank you for all the lessons and knowledge that you provided me with while you were in the lab. Sara, thank you for all your help, support and training with the BVM system. Finally, Mike, thank you for being my best friend and providing me with constant support, encouragement and laughs.

Finally I would like to thank my parents, Jim and Christine Gohres who have always encouraged me to make the world and better place and be the best I can be. I am so thankful to have had your constant love and support. I would also like to thank my brother and sisters, Kevin, Nicole and Heather for always cheering me on. Eric, thank you for your support and love through everything, it means the world to me. 


\section{TABLE OF CONTENTS}

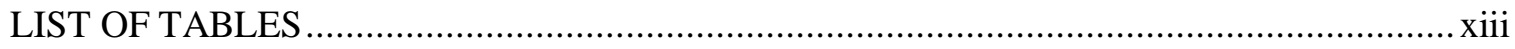

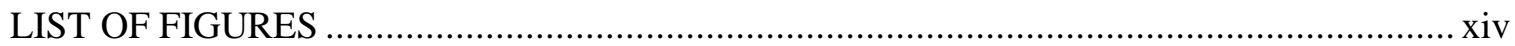

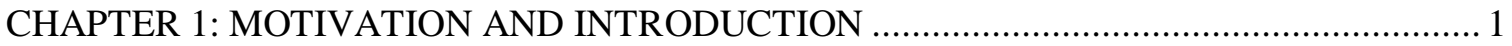

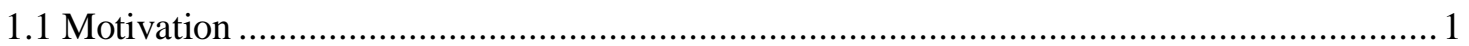

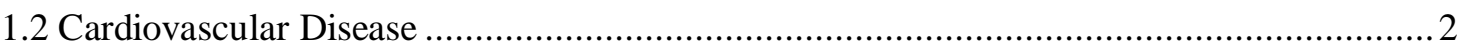

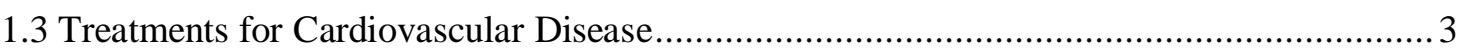

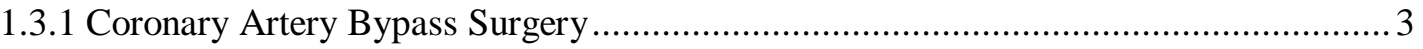

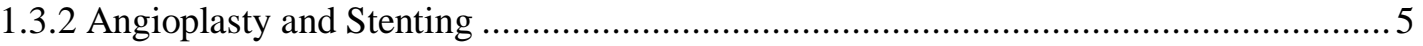

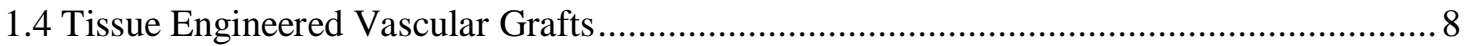

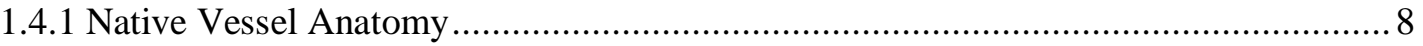

1.4.2 Requirements and Limitations of a Tissue Engineered Vessel Graft......................... 9

1.4.3 Developing Solutions for TEVG Limitations ......................................................... 10

1.4.4 Molecular Mechanisms of Cell Adhesion on Artificial Materials .............................. 11

1.4.5 Pre-Coatings Used to Enhance Cell Adhesion in Tissue Engineered

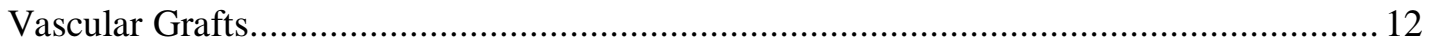

1.4.5.1 Serum/Serum Enhanced Cell Culture Medium ................................................. 12

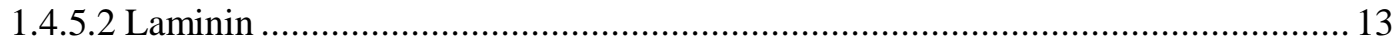

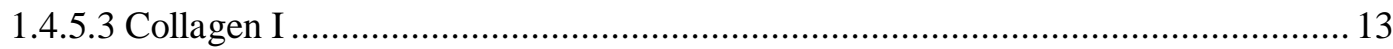

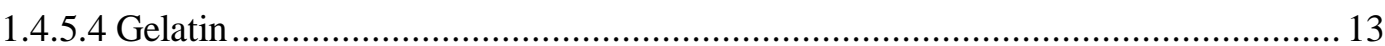

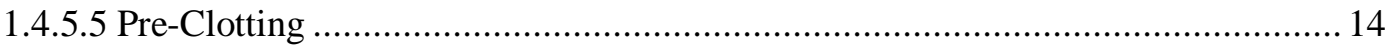

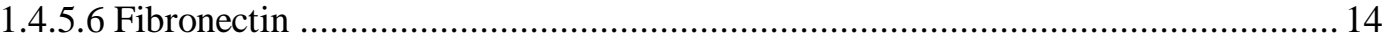

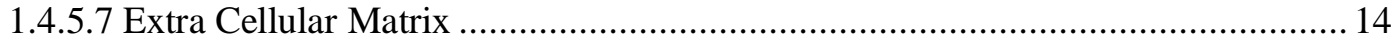

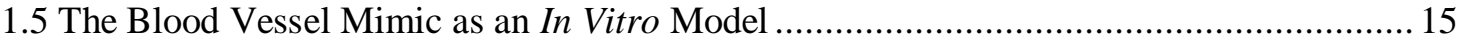

CHAPTER 2: PROTOCOL DEVELOPMENT FOR 6-WELL PLATE COATING

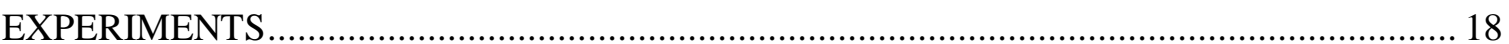

2.1 Cost-Analysis of Coatings for 6-Well Plate Experiments ............................................. 18

2.1.1 Cost Analysis of ProNectin-F in 6-Well Plate Experiments .................................... 18

2.1.2 Cost Analysis of Conditioning Media in 6-Well Plate Experiments.......................... 19

2.1.3 Cost Analysis of HUVEC Media Alone for 6-Well Plate Experiments .....................20

2.2 Protocol Development for the Analysis of Pre Coatings in 6-Well Plate Experiments ...... 20

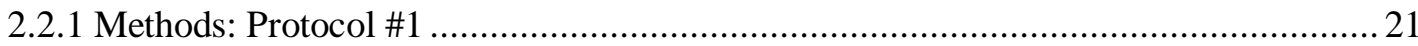

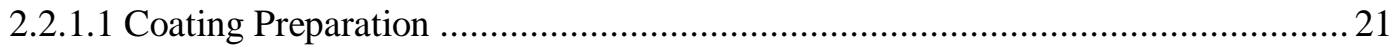




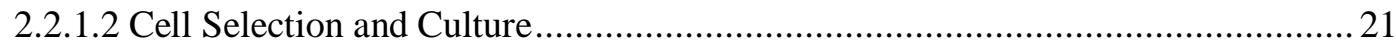

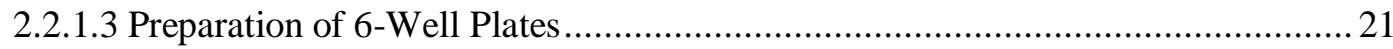

2.2.1.4 Quantifying the Number of Cells Adhered to Wells ...........................................22

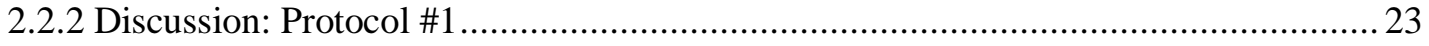

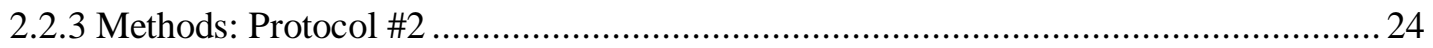

2.2.3.1 Coating Preparation and Cell Culture ............................................................... 24

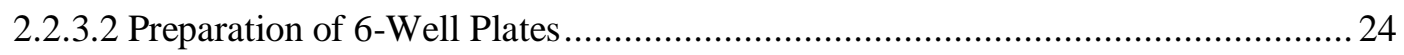

2.2.3.3 Quantifying the Number of Cells Adhered to Wells ........................................ 24

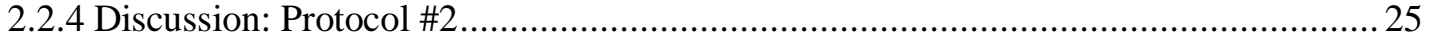

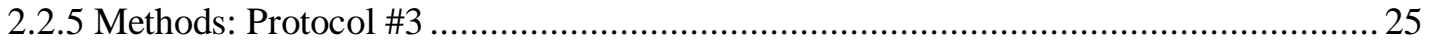

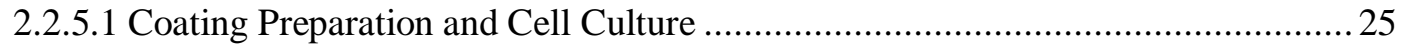

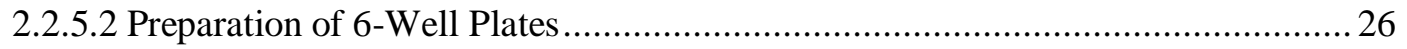

2.2.5.2 Quantifying the Number of Cells Adhered to Wells ...........................................26

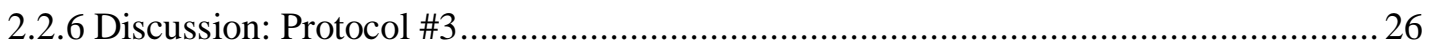

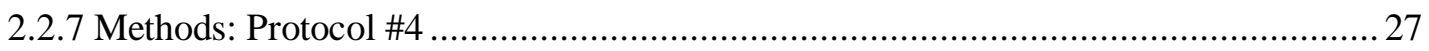

2.2.7.1 Coating Preparation and Cell Culture …...................................................... 27

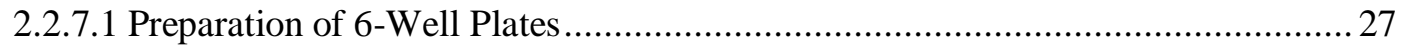

2.2.7.2 Quantifying the Number of Cells Adhered to Wells ...........................................2 27

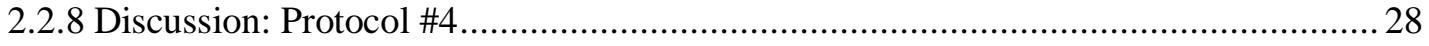

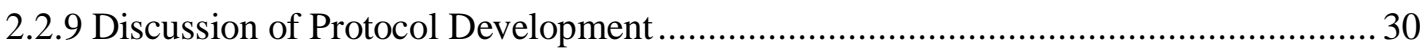

CHAPTER 3: INCUBATION TIME AND COMPARISON STUDIES OF

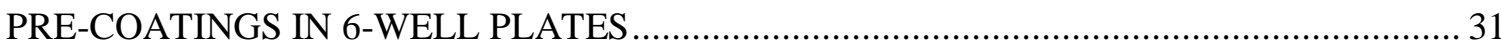

3.1 Analysis of the Effects of Coating and Cell Incubation Times on Endothelial

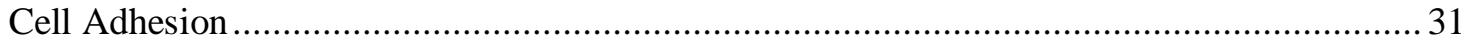

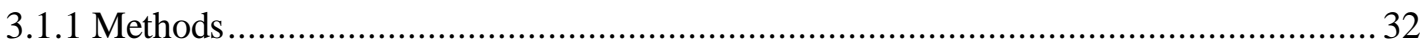

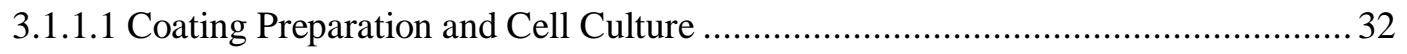

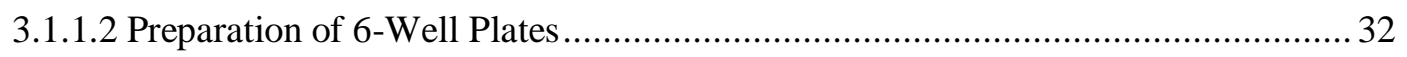

3.1.1.3 Quantifying the Number of Cells Adhered to Wells ........................................ 33

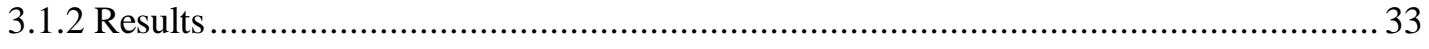

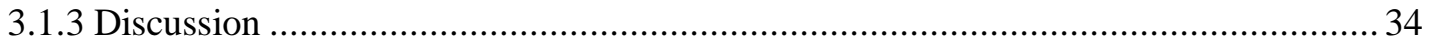

3.2 Comparison of ProNectin-F and Conditioning Media as a Pre-Coating in 6-Well Plates .. 34

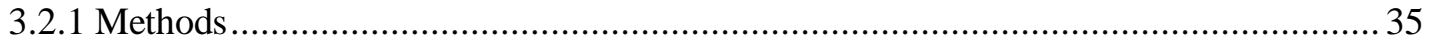

3.2.1.1 Coating Preparation and Cell Culture …......................................................... 35

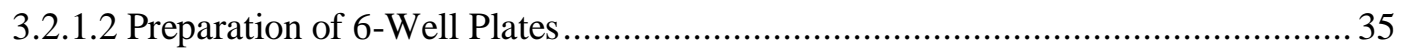




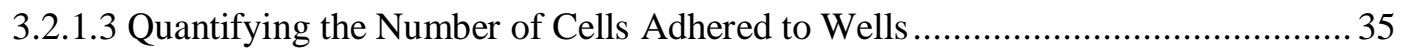

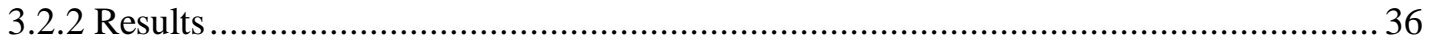

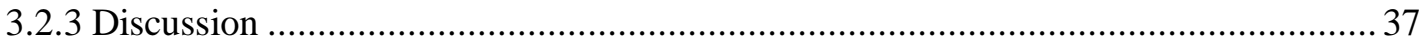

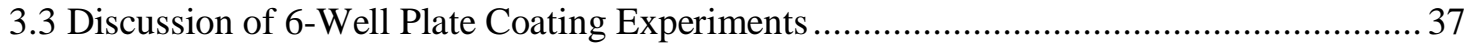

CHAPTER 4: PROTOCOL DEVELOPMENT FOR THE ANALYSIS OF

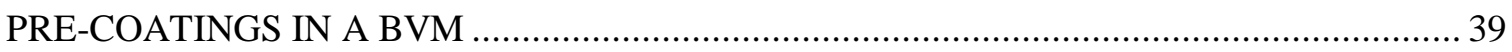

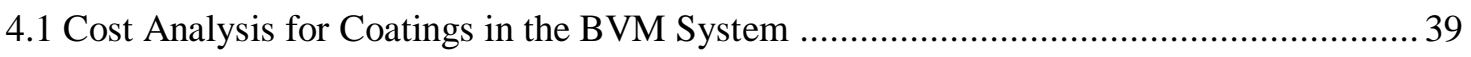

4.1.1 Cost Analysis of ProNectin-F in BVM Setups ....................................................... 39

4.1.2 Cost Analysis of Conditioning Media in BVM Setups ........................................... 40

4.2 Protocol Development for Analysis of Pre-Coatings in a BVM.................................... 41

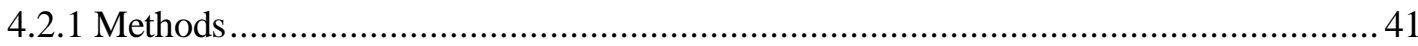

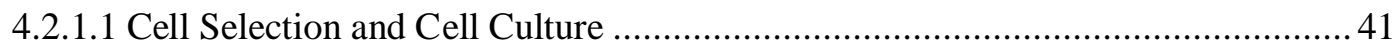

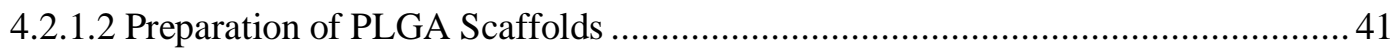

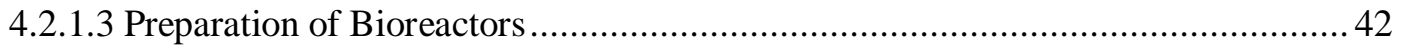

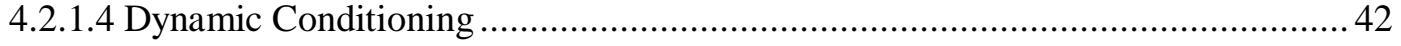

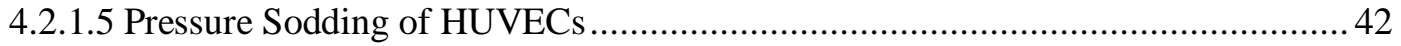

4.2.1.6 Harvesting of Scaffolds and Non-Adhered Cells from Bioreactors...................... 43

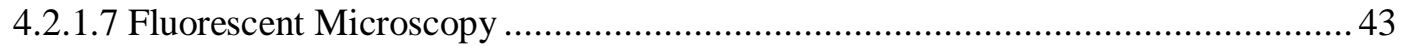

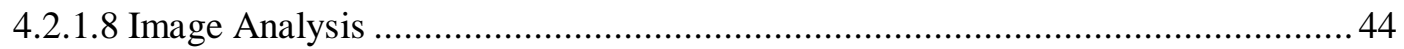

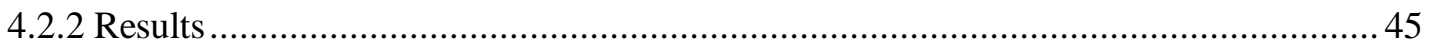

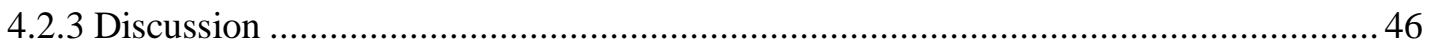

4.3 Investigation of BVM Cell Harvest and Cell Sodding Efficiency ................................. 47

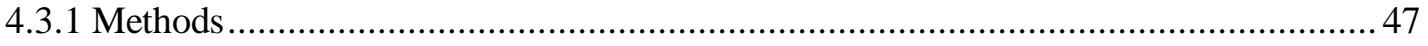

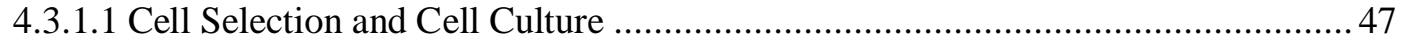

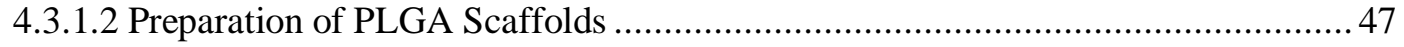

4.3.1.3 Preparation of Bioreactors and Dynamic Conditioning ..................................... 48

4.3.1.4 Pressure Sodding of HUVECs and Quantifying Lost Cells ............................... 48

4.3.1.5 Harvesting of Scaffolds and Non-Adhered Cells from Bioreactors..................... 48

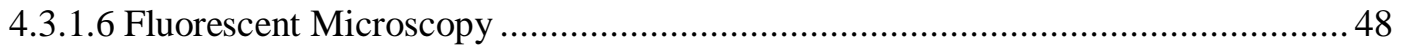

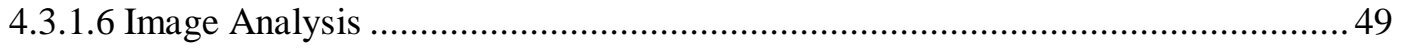

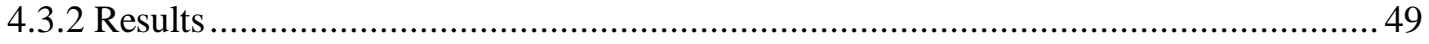

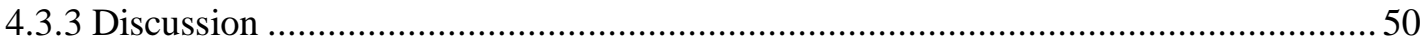

4.4 Proof of Concept Study: Protocol Verification for BVM Coating Comparison Studies ..... 51 


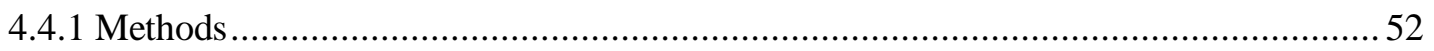

4.4.1.1 Cell Selection and Cell Culture …................................................................5 52

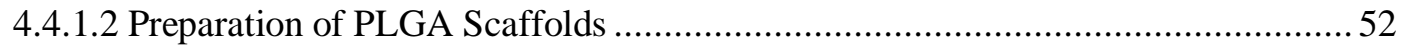

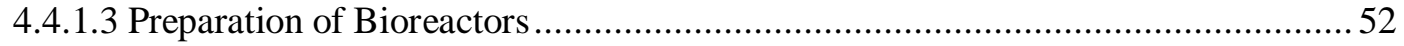

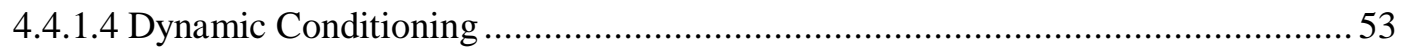

4.4.1.5 Pressure Sodding of HUVECs .................................................................. 53

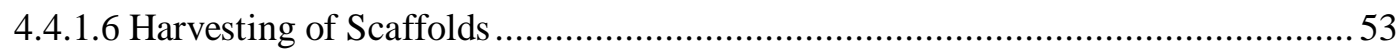

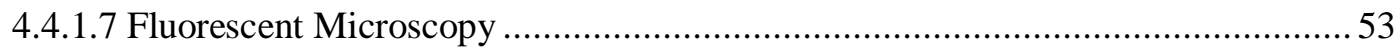

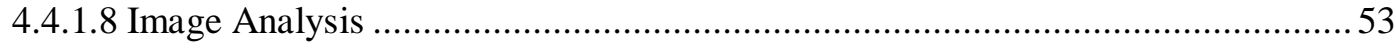

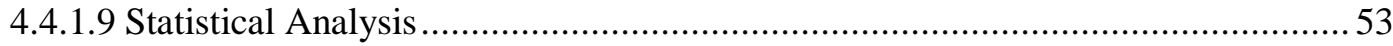

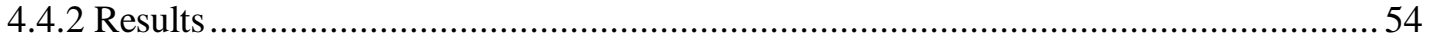

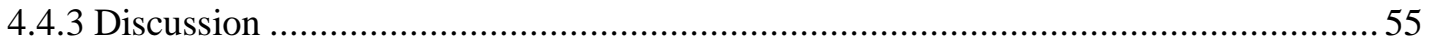

CHAPTER 5: BVM PRE-COATING COMPARISON STUDIES ......................................... 57

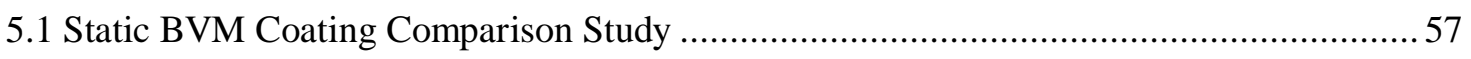

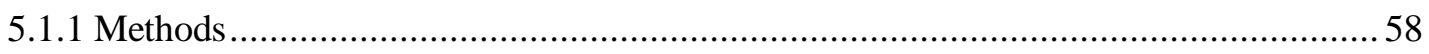

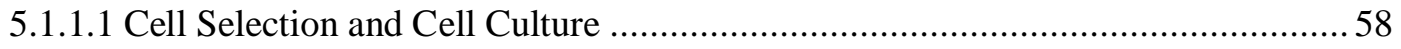

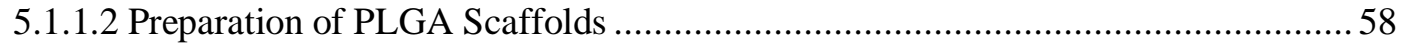

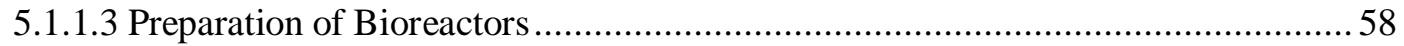

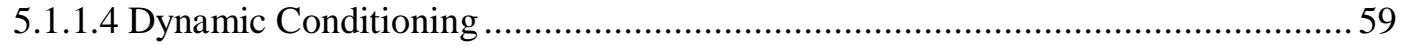

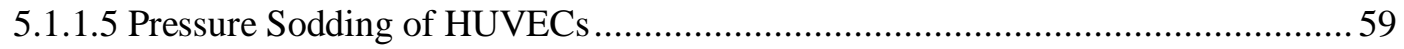

5.1.1.6 Static Incubation and Harvesting of Scaffolds .................................................59

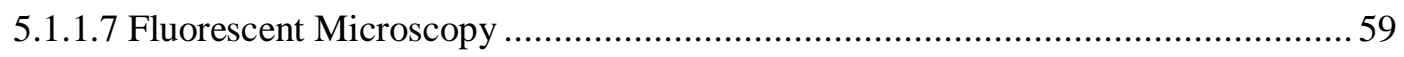

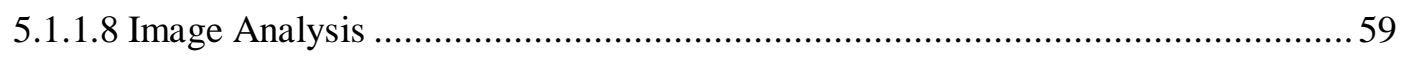

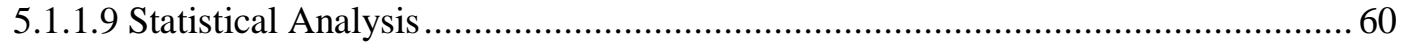

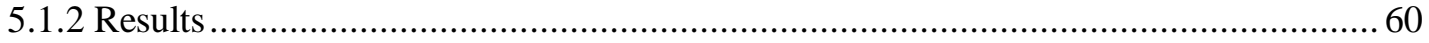

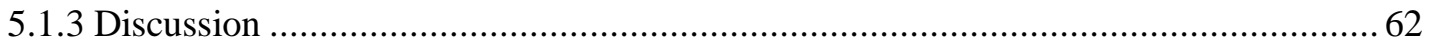

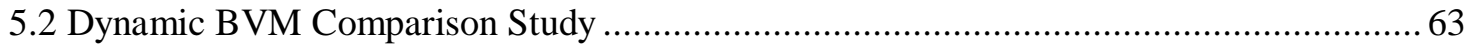

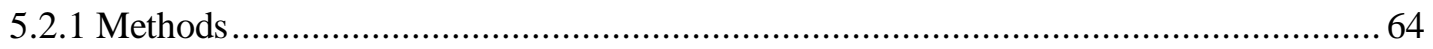

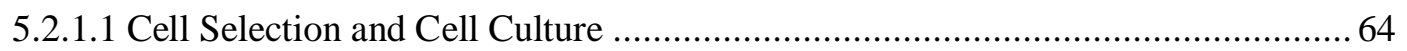

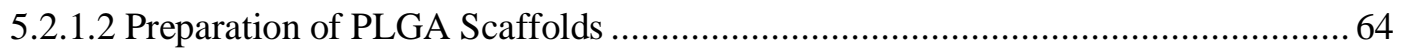

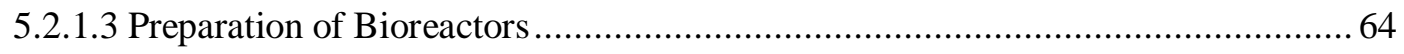

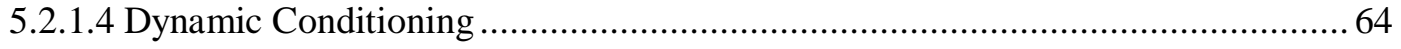

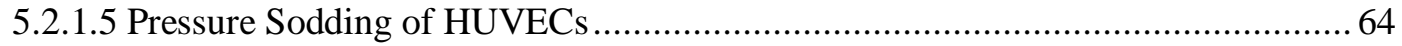




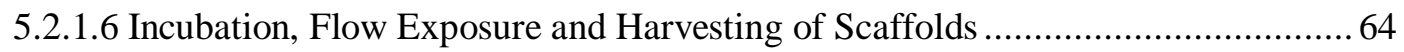

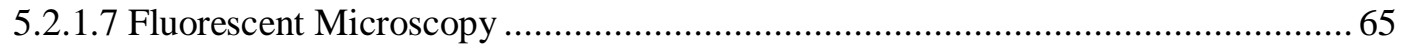

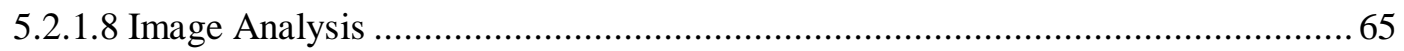

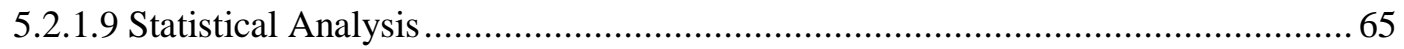

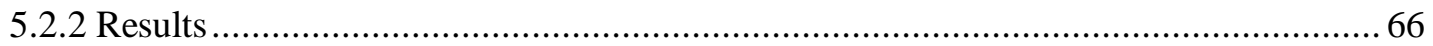

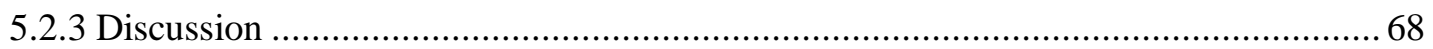

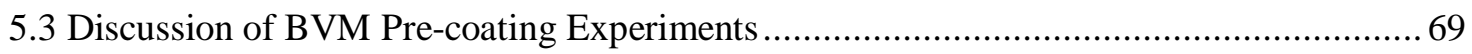

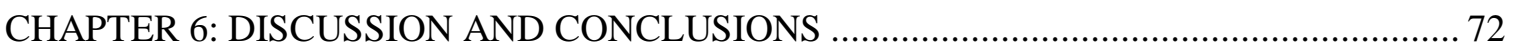

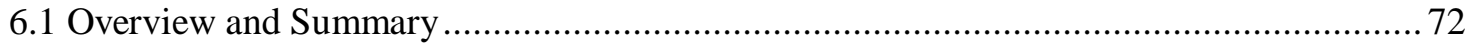

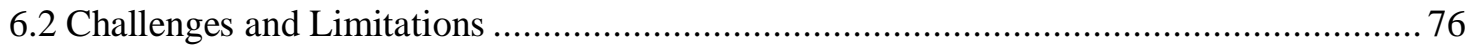

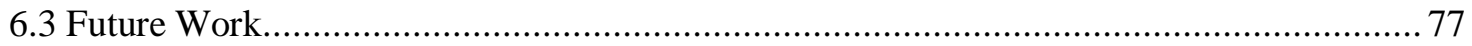

6.3.1 Comparison Studies with Coating Combinations ….............................................. 77

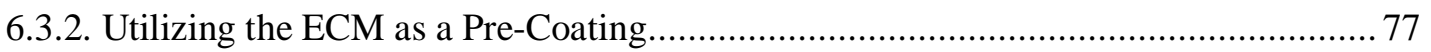

6.3.3 Rhodamine phalloidin Stain and Imaging Protocol for PLGA …............................ 78

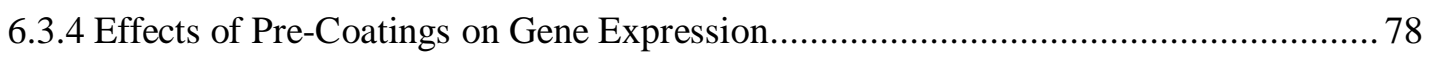

6.3.5 Evaluating Receptor Mediated Cell Adhesion..................................................... 78

6.3.6 Effects of Pre-Coatings on Smooth Muscle Cells..................................................... 79

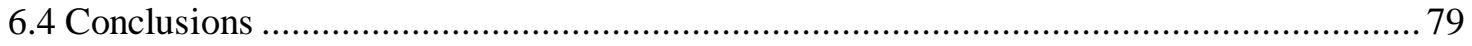

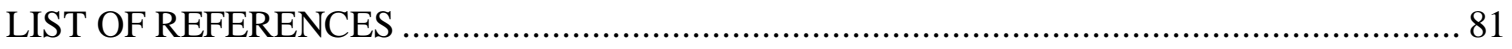

APPENDIX A: 6-WELL PLATE PROTOCOLS AND EXPERIMENTAL DETAILS .............. 86

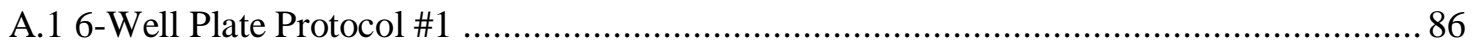

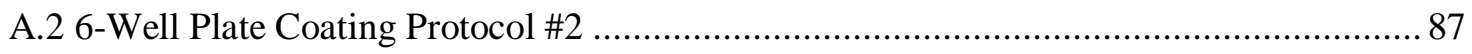

A.3 6-Well Plate Coating Protocol \#3 …..................................................................... 88

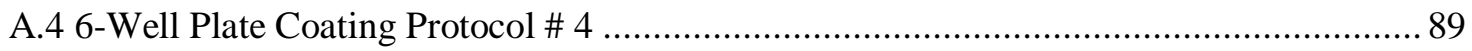

A.5 6-Well Plate Experiment: Varying Coating and Cell Incubations Protocol ...................... 90

A.6 6-Well Plate Experiments: Comparison Study Protocol ............................................... 92

APPENDIX B: BVM PROTOCOLS AND EXPERIMENTAL DETAILS …........................... 94

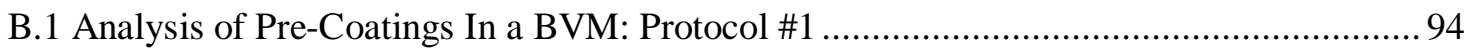

B.2: Analysis of Pre-Coatings In a BVM: Protocol \#2 ................................................... 96

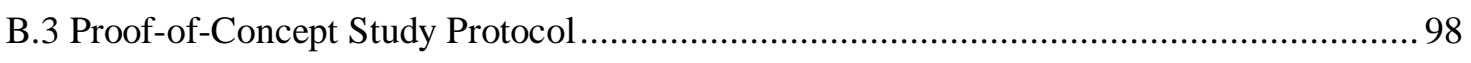

B.4 Static BVM Pre-Coating Comparison Study ........................................................ 100

B.5 Dynamic BVM Pre-Coating Comparison Study ….............................................. 102

APPENDIX C: STAINING PROTOCOLS AND EXPERIMENTAL DETAILS ..................... 104 


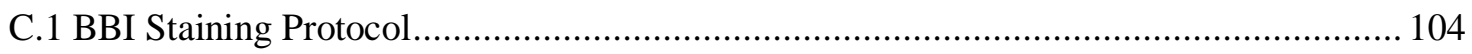

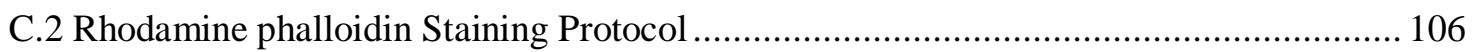




\section{LIST OF TABLES}

Table 1: Summary of the Cost-Analysis for Pro-Nectin F, Conditioning Media

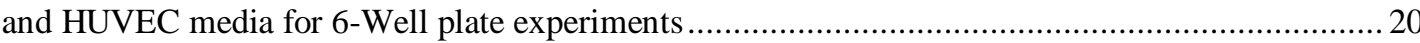

Table 2: Summary of the process in establishing a protocol for the analysis of 6-well plate experiments... 29

Table 3: Summary of the cost-analysis for Pro-Nectin F and Conditioning Media for a BVM setup.......... 40

Table 4: Summary of number of adhere and non-adhered cells following 60 minute static BVM incubation

Table 5: Summary of results obtained from Nexcelom Cellometer non-adhered cells counts and ImageJ adhered cell counts....

Table 6: Summary of the number of cells found on surfaces throughout the BVM setup........................... 49

Table 7: Summary of the number of cells traced in rhodamine phalloidin images for non-coated, Conditioning Media and ProNectin-F rhodamine phalloidin images

Table 8: Summary of cell coverage scores of non-coated, Conditioning Media and ProNectin-F rhodamine phalloidin images 


\section{LIST OF FIGURES}

Figure 1: Atherosclerosis is characterized by the buildup of plaque along the inner wall of the vessel.

When the plaque becomes unstable, it can rupture causing thromboembolisms that can lead to

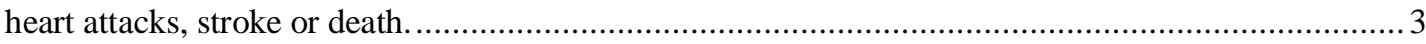

Figure 2: Illustration the re-routing of blood flow due to blockage in a coronary artery bypass surgery ....... 4 Figure 3: Illustrates the insertion of the catheter in to the vessel, followed by balloon inflation and removal to ultimately re-widen the artery and restore blood flow. http://www.medicinenet.com/coronary_angioplasty/article.htm

Figure 4: Illustrates the insertion of a catheter that includes a stent mounted on to a balloon.

(A) The balloon is inflated, expanding the stent pushing back the plaque that is blocking the artery. (B) The balloon and catheter are removed while the stent remains as a support for the vessel. (C) http://bcsheart.com/services_coronary_stenting.php.....

Figure 5: Illustration of the anatomy of a native blood vessel including the tunica intima, tunica media and tunica adventitia.

Figure 6: Bioreactor and BVM system configuration first utilized by Cardinal et al. in 2006. ................. 16

Figure 7: Solid model of the BVM system utilized by Cardinal et al. as well as the studies conducted for this thesis. Includes the rectangular bioreactor chamber, media reservoir and pump. http://digitalcommons.calpoly.edu/cgi/viewcontent.cgi?article=1085\&context=theses .................... 16

Figure 8: Diagram of the 6-well plates and applied coatings used in Protocol \#1.

Figure 9: Illustration of the Nexcelom Cellometer and the Cell Counting Process.

A: Nexcelom Cellometer. B: Process Utilized to Count Cells C: Example of Nexcelom Cellometer

Cell Tracing and Counting.

Figure 10: Diagram of the 6-well plate and applied coatings used in Protocol \#2 .......................................25

Figure 11: Diagram of the 6-well plate and applied coatings used in Protocol \#3..................................... 26

Figure 12: Diagram of the 6-well plate and applied coatings used in Protocol \#4..................................... 27

Figure 13: Well assignments for the assessment of the effects of coating and cell incubation time on cell adhesion

Figure 14: Results of incubation time experiment. Cells adhered after varying cell and coating incubation periods. Represented as a percentage of the initial number of cells counted in the well.... 34

Figure 15: Coating and incubation well assignment for the ProNectin F - Conditioning Media comparison experiment.

Figure 16: Percent of total cells adhered to wells pre-coated with Conditioning Media and ProNectin-F after 60 and 90 minute incubation periods. * $\mathrm{p}<0.05$ for percent cells adhered after 90 minutes of incubation compared to 60 minutes of incubation for individual coatings including non-coated. $* * \mathrm{p}<0.05$ for percent cells adhered to a coated surface compared to non-coated control after 90 minute incubation period.

Figure 17: Illustration of PLGA scaffolds inserted in to the BVM. The BVM and media reservoirs were then hooked up to a peristaltic pump in a large incubator.

Figure 18: Illustration of the BBI image analysis using the Cell Counter in ImageJ. 4 boxes were drawn throughout the image and each cell was counted by manual clicking

Figure 19: Illustration of image analysis technique. The four squares that had the most cells in focus were used to count cells for each image.

Figure 20: Representative BBI image of PLGA scaffold with HUVECs after 60 minutes of static incubation

Figure 21: Representative BBI image of PLGA scaffold cross-section. Image was taken at 4x.................50

Figure 22: Representative en face BBI image of BVM. Image was taken at $4 x$... 50 
Figure 23: Number of counted cells adhered to coated and non-coated scaffolds from BBI images. $\mathrm{n}=3 . * \mathrm{p}<0.05$

Figure 24: Representative images of Conditioning Media coated and non-coated scaffolds at 10x.

The scaffolds coated with Conditioning Media had better cell coverage that scaffolds that were not pre-coated.

Figure 25: Illustration of rhodamine phalloidin image analysis using freehand tracing in ImageJ.

Figure 26: Number of endothelial cells adhered to scaffolds that were non-coated, coated with

Conditioning Media or coated with ProNectin-F after 60 minutes of static incubation

in a BVM. $n=3 . * p<0.05$ compared to non-coated

Figure 27: Representative BBI images of non-coated, Conditioning Media coated and

ProNectin-F coated scaffolds after 60 minutes static incubation in a BVM

Figure 28: Endothelial cell perimeters of cells adhered to non-coated, Conditioning Media coated and ProNectin-F coated scaffolds after 60 minutes of static incubation in a BVM. $n=3$. *p<0.05 compared to non-coated scaffolds. $* * \mathrm{p}<0.05$ compared to Condition

Figure 29: Representative rhodamine phalloidin images of non-coated, Conditioning Media coated and ProNectin-F coated scaffolds after 60 minutes of static incubation in a BVM

Figure 30: Rhodamine phalloidin images representing a 1,5 and 10 on the qualitative cell coverage scale.

Figure 31: Results of BBI image analysis for cells adhered to non-coated, Conditioning Media coated and ProNectin-F coated scaffolds after 60 minutes of transluminal flow at 90rpm. $n=3$. ${ }^{*} \mathrm{p}<0.05$ compared to non-coated control.

Figure 32: Representative BBI images of non-coated, Conditioning Media coated and ProNectin-F coated scaffolds after 60 minutes of transluminal flow at $90 \mathrm{rpm}$

Figure 33: Results of traced cell perimeters from rhodamine phalloidin image analysis for non-coated, Conditioning Media coated and ProNectin-F coated scaffolds after 60 minutes of transluminal flow at $90 \mathrm{rpm} . \mathrm{n}=3$. $* \mathrm{p}<0.05$ compared to non-coated control

Figure 34: Representative rhodamine phalloidin images of non-coated Conditioning Media coated and ProNectin-F coated scaffolds after 60 minutes of trasnluminal flow at 90rpm 


\section{CHAPTER 1: MOTIVATION AND INTRODUCTION}

\subsection{Motivation}

Since their introduction in 1987, stents have significantly improved the outcomes of percutaneous coronary interventions (PCI) [1]. Not only have stents dramatically reduced the need for invasive coronary bypass grafting, but they have proven to reduce restenosis post PCI by up to $40 \%$ [2]. Although stents have been one of the most crucial medical breakthroughs in this century, they are still being constantly re-developed to improve their mechanical properties, biocompatibility and hemocompatibility $[2,3]$. As more advanced designs are introduced, the need for cost and time efficient methods of testing escalates with the desire to present a successful design to the market [3]. Currently, in vivo models are the main source of testing and obtaining data for new stent designs. However the time, money and number of animals used for testing new stents could be significantly reduced if there were a way to acquire reliable data from a physiologically relevant in vitro model [3].

Such an in vitro model, in the form of a "blood vessel mimic" (BVM), is based on the capabilities gained from the creation of tissue engineered vascular grafts, which are used as a replacement for a diseased vessel in bypass surgeries [3]. By mimicking the properties of these grafts, a BVM could be applied as a tool for pre-clinical evaluation of the endothelial response to stents and other intravascular devices [3]. Therefore, the ultimate goal of the BVM is to bridge the gap between in vitro and in vivo environments to efficiently test new intravascular device designs [3].

Although the BVM provides many advantages, there are still crucial limitations of the design that should be addressed. Currently, the BVM scaffold is made of either an expanded poly(tetrafluoroethylene) [ePTFE] or poly(lactic-co-glycolic acid) [PLGA] scaffold [4]. Although both of these materials have shown to be biocompatible, the cell adhesion rates are still relatively low. During BVM assembly, it has been found that the number of cells that adhere to the scaffold 
during the sodding stage is much less than the number of cells that are applied [unpublished work]. Also, imaging of scaffolds post sodding has illustrated an in-consistent layer, or endothelium, on the lumen of the scaffold [5]. Therefore, not only is the sodding phase of the BVM assembly inefficient, but the lack of the consistent layer of endothelial cells is an obstacle that needs to be overcome to successfully simulate a native blood vessel lining. Hence, the aim of this thesis is to implement the use of different protein pre-coatings on synthetic polymer scaffold materials to optimize cell adhesion and create a consistent endothelium in the lumen of the scaffold.

The subsequent Introduction serves to provide the necessary background information from which this thesis was based. It will include an overview of coronary heart disease and current treatments, specifically tissue engineered blood vessels and the coatings that are currently used on them to enhance cell adhesion. It will also include the foundation of a successful BVM construct and its potential role in in vitro device evaluations, concluding with a specific statement of the objectives of this thesis.

\subsection{Cardiovascular Disease}

The American Heart Association estimates that 82,600,000, people, or more than 1 in 3 adults, currently have one or more types of cardiovascular disease [6]. Of these 82,600,000 people, it is estimated that $16,300,000$ currently have coronary heart disease [6]. Coronary heart disease is the leading cause of death for men and women in the United States, causing 1 in 6 deaths in 2006 [7]. It was projected that the cost for treating coronary heart disease was 156.4 billion dollars in 2008 [8].

There is a strong correlation between coronary heart disease and atherosclerosis, the result of plaque buildup in the arteries that vascularize the heart [9] (Figure 1). The buildup of plaque in these vessels results in reduced blood flow to the heart causing angina, fatigue, shortness of breath, heart attack, stroke, or even death [10] . Many of the most successful 
treatments of this disease are device-based and include: bypass grafting, angioplasty, and stenting [10].

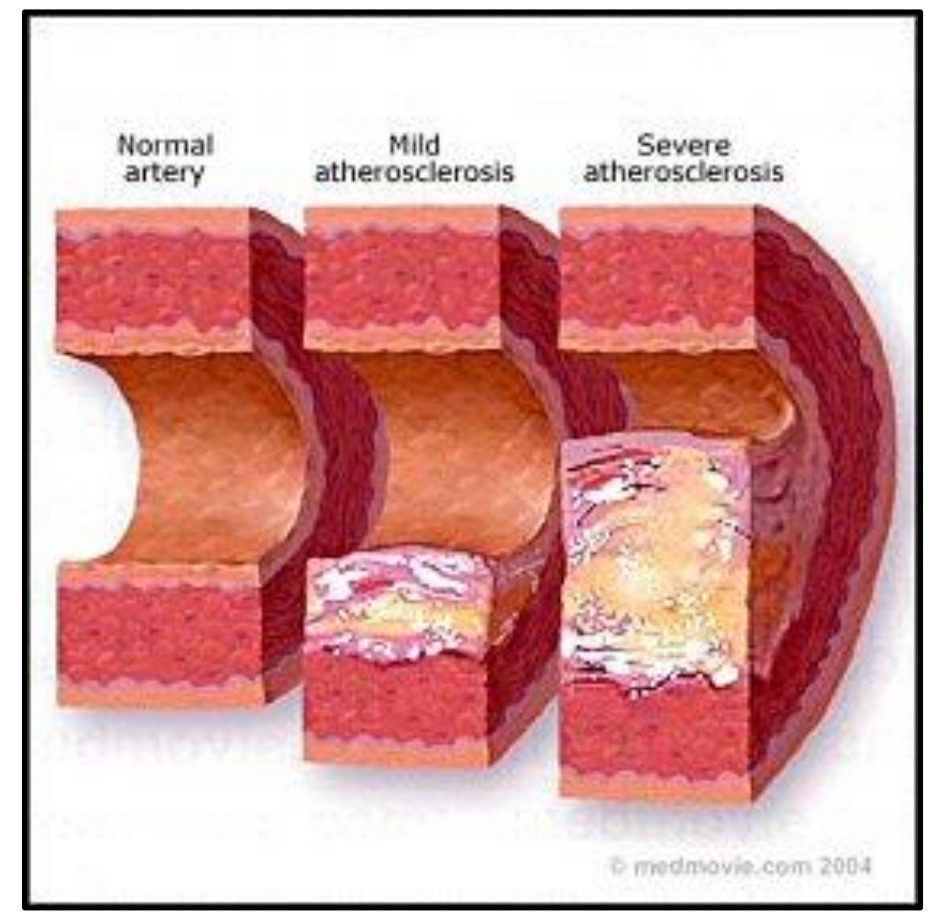

Figure 1: Atherosclerosis is characterized by the buildup of plaque along the inner wall of the vessel. When the plaque becomes unstable, it can rupture causing thromboembolisms that can lead to heart attacks, stroke or death. http://www.newbhc.com/topics/cardiovascular-risk-support/atherosclerosis/

\subsection{Treatments for Cardiovascular Disease}

The current treatments that are implemented to treat cardiovascular disease include: lifestyle modifications, pharmaceuticals, and medical procedures [10]. All of these options share the ultimate goal of relieving the patient of their symptoms, slowing or stopping the progression of the disease or repairing any damaged tissue. The following sections provide a brief introduction to medical techniques used in coronary bypass surgery, angioplasty and stenting.

\subsubsection{Coronary Artery Bypass Surgery}

Coronary and peripheral bypass surgeries are performed more than one million times annually in the seven major industrialized countries [11]. This procedure treats atherosclerosis by 
providing a graft that allows the bypassing of the diseased area and re-routes blood flow [12]

(Figure 2). Benefits of this procedure include the long term success in preventing restenosis (the re-narrowing of a coronary artery), low rates of mortality and low rates of revascularization procedures [13]. However, some major disadvantages are that this procedure is invasive, expensive, and requires a long recovery period. In most cases, the patients' own veins or arteries are the conduits of choice to avoid an unwanted immune response [13]. Unfortunately, a suitable vessel is not always available or suitable for grafting, in these cases, a synthetic graft is used [14].

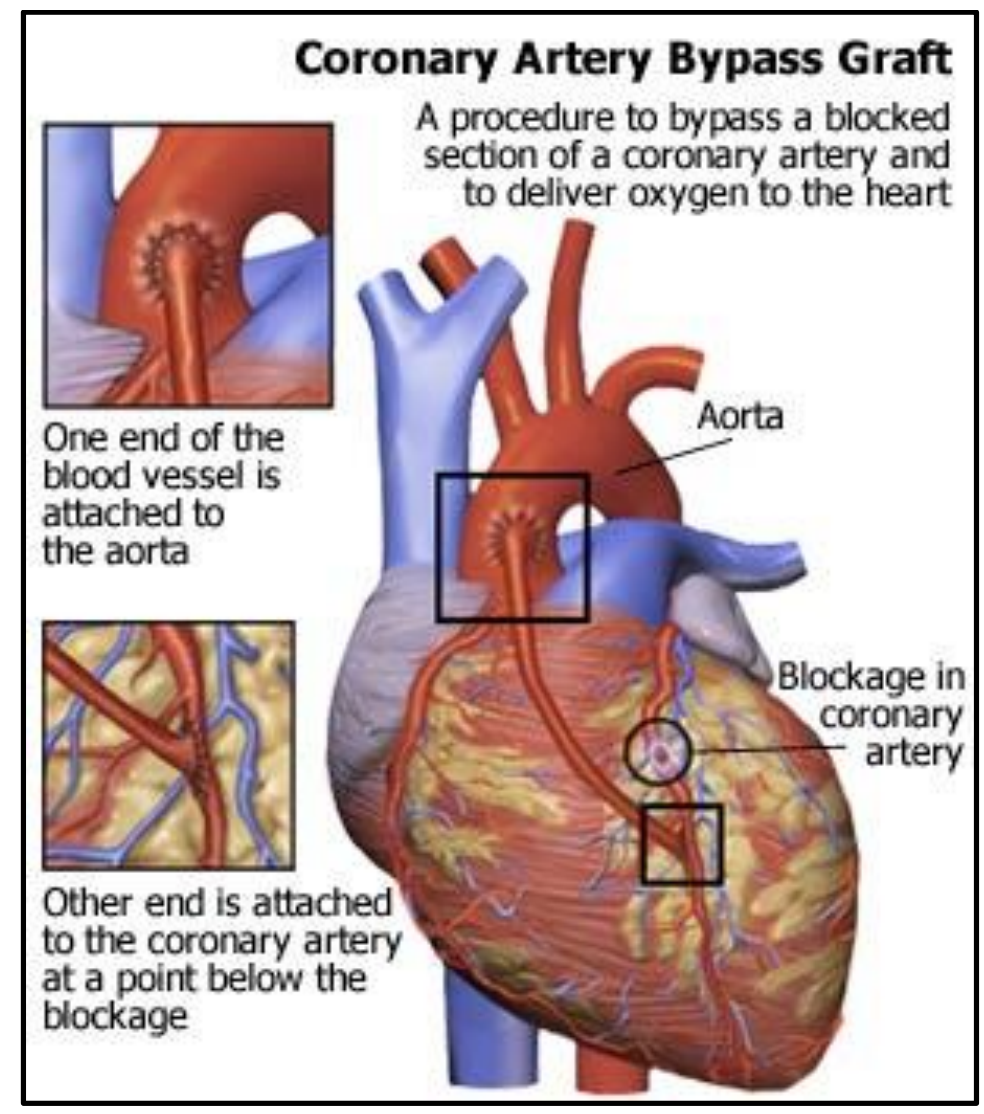

Figure 2: Illustration the re-routing of blood flow due to blockage in a coronary artery bypass surgery

http://dmzwww.metrohealth.org/body.cfm?id=1321

Advantages of synthetic grafts over other options when an autologous vein is unavailable include low cost, high availability, and the ability to easily alter their mechanical and physical 
properties [15]. Currently, the most commonly used materials for a synthetic graft include poly(ethylene terephthalate) ]PET] and expanded poly(tetrafluoroethylene) [ePTFE] [16-19]. Both materials have proven to be successful in grafts for large diameter vessels $(>6 \mathrm{~mm})$, however, when applied to smaller diameter vessels, thrombosis rates increase dramatically with the decreased blood flow $[19,20]$. The thrombosis that is responsible for the failure of these grafts is attributed to the lack of an endothelium on the lumen of the graft and a mismatch in compliance when compared to native vessels [19]. A solution to this problem is the in vitro endothelialization of the lumen of the scaffolds prior to implantation [21]. This technique has proven to drastically reduce the rates of thrombosis in synthetic grafts in vivo [21]. However, these limitations in addition to the invasiveness of coronary artery bypass grafting, cause other options such as angioplasty to be a more favorable procedure in some cases [22].

\subsubsection{Angioplasty and Stenting}

Angioplasty treats atherosclerosis by inserting a catheter and inflating a balloon inside the blocked region of the vessel to push back or break the clot [23] (Figure 3). Balloon angioplasty is favored because it is a minimally invasive procedure compared to bypass surgery [23]. However, a major disadvantage is the high rate of restenosis, or the re-narrowing of the vessel wall due to the formation of scar tissue due to injury form the balloon inflation [24-26]. 


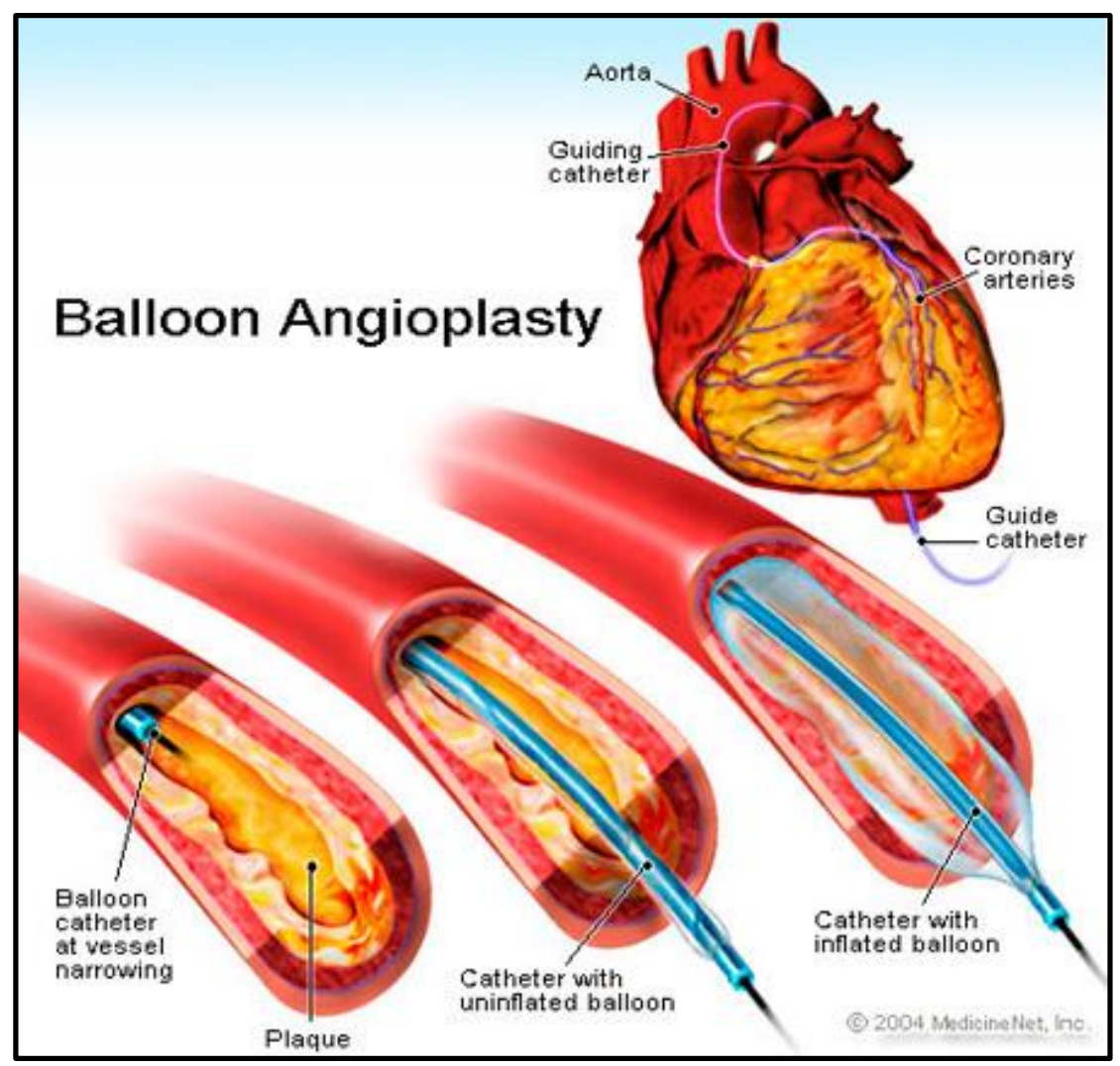

Figure 3: Illustrates the insertion of the catheter in to the vessel, followed by balloon inflation and removal to ultimately re-widen the artery and restore blood flow. http://www.medicinenet.com/coronary_angioplasty/article.htm

Stenting is a procedure that treats atherosclerosis by deploying a permanent or semipermanent wire mesh tube to open an artery during balloon angioplasty [27] (Figure 4). Unlike balloon angioplasty, the stent usually remains in the artery to open the lumen and support continued blood flow and re-endothelialization [27]. This procedure has resulted in much higher success rates; consequently $80 \%$ of all angioplasties are now combined with stenting [28]. 


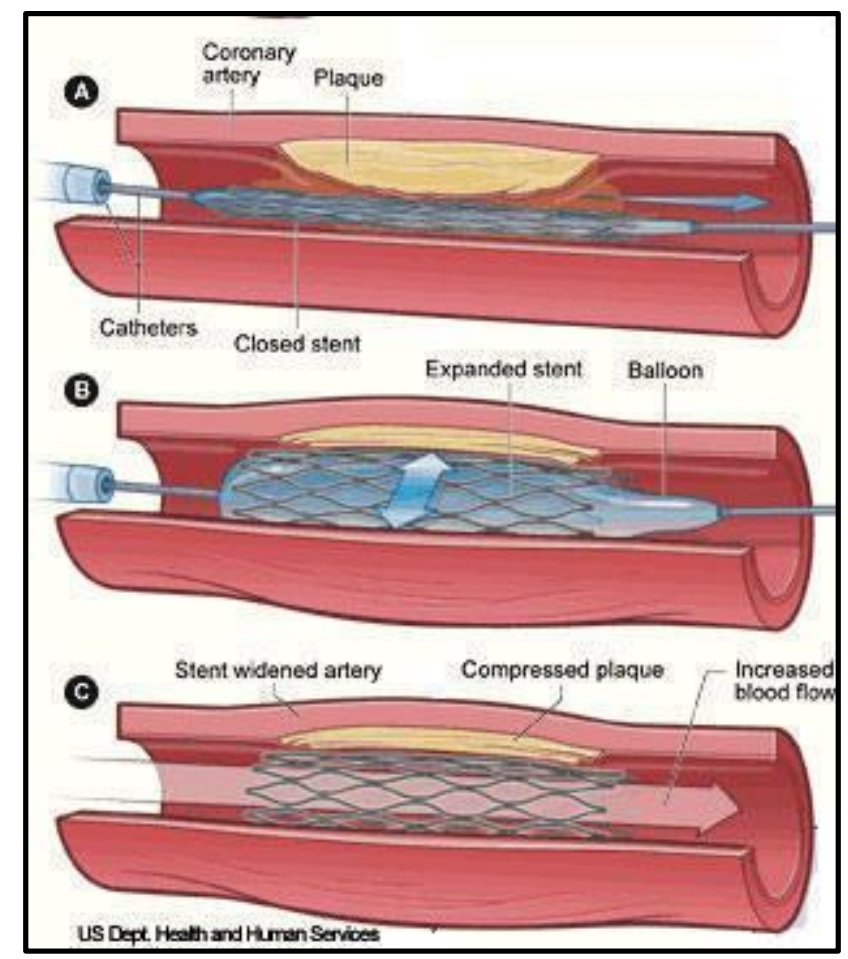

Figure 4: Illustrates the insertion of a catheter that includes a stent mounted on to a balloon. (A) The balloon is inflated, expanding the stent pushing back the plaque that is blocking the artery. (B) The balloon and catheter are removed while the stent remains as a support for the vessel. (C) http://bcsheart.com/services_coronary_stenting.php

As successful as stenting has proven to be in the last 30 years, serious complications still remain an issue [29-31]. Complications include thrombosis and in-stent restenosis due to vessel damage during stent expansion. [30, 31] Also, because the stent is meant to be permanent, it gives rise to the body's inflammatory response and other reactions that can also ultimately lead to restenosis [32]. These issues have been addressed with the introduction of drug eluting stents [33]. These stents serve to prevent restenosis by releasing medications or bioactive agents in to the blood stream and surrounding tissues [33]. This has been a very promising advancement in stent technology and is currently being intensely studied and developed [34-36]. With each new development in bettering the stent design, the importance of intravascular device testing increases. As previously stated, the high costs and time consuming limitations of in vivo testing validate the need for a physiologically relevant in vitro testing system. 
Clinically, tissue engineering has been utilized to develop a physiologic blood vessel graft for bypass patients that do not have a viable graft. These grafts, known as Tissue Engineered Vascular Grafts (TEVGs), combine autologous cells and a tubular, biocompatible polymer scaffold to mimic the function of a native blood vessel. However, in addition to functioning as a clinical therapy, the methods utilized in the construction of a Tissue Engineered Vascular Graft can be applied to the development of the previously described BVM in vitro testing system. Therefore, it is important to understand the development and requirements of a Tissue Engineered Vascular Graft. It is also important to understand the current limitations of Tissue Engineered Vascular Grafts, for those limitations are shared by the BVM system. Finally, techniques that are utilized to overcome the limitations of Tissue Engineered Vascular Grafts will be discussed.

\subsection{Tissue Engineered Vascular Grafts}

The ultimate goal of a Tissue Engineered Vascular Graft (TEVG) is to mimic at least some aspects of the anatomy and function of the native blood vessel [37]. Through the use of autologous cells, a TEVG can be implemented as an autologous vascular graft [37]. In order to appreciate the advancements made in creating TEVGs, it is important to understand the basic anatomy of a native vessel, the basic requirements that a TEVG must meet, and the limitations of the TEVG (which are shared by the BVM) that can be improved upon.

\subsubsection{Native Vessel Anatomy}

The native artery consists of three distinct layers: the tunica intima, tunica media, and tunica adventia (Figure 5) [38]. The tunica intima is the blood contacting layer that consists of a consistent layer of endothelial cells that function to prevent thrombosis and is separated from the tunica media by the internal elastic lamina [38]. The tunica media consists of smooth muscle cells within a surrounding extra-cellular matrix (ECM) consisting of collagen and elastin [38]. The tunica media is responsible for constriction and dilation of the vessel [38]. The tunica adventia mainly consists of fibroblasts and ECM. The purpose of the tunica adventia is to provide structural integrity to the vessel [38]. 


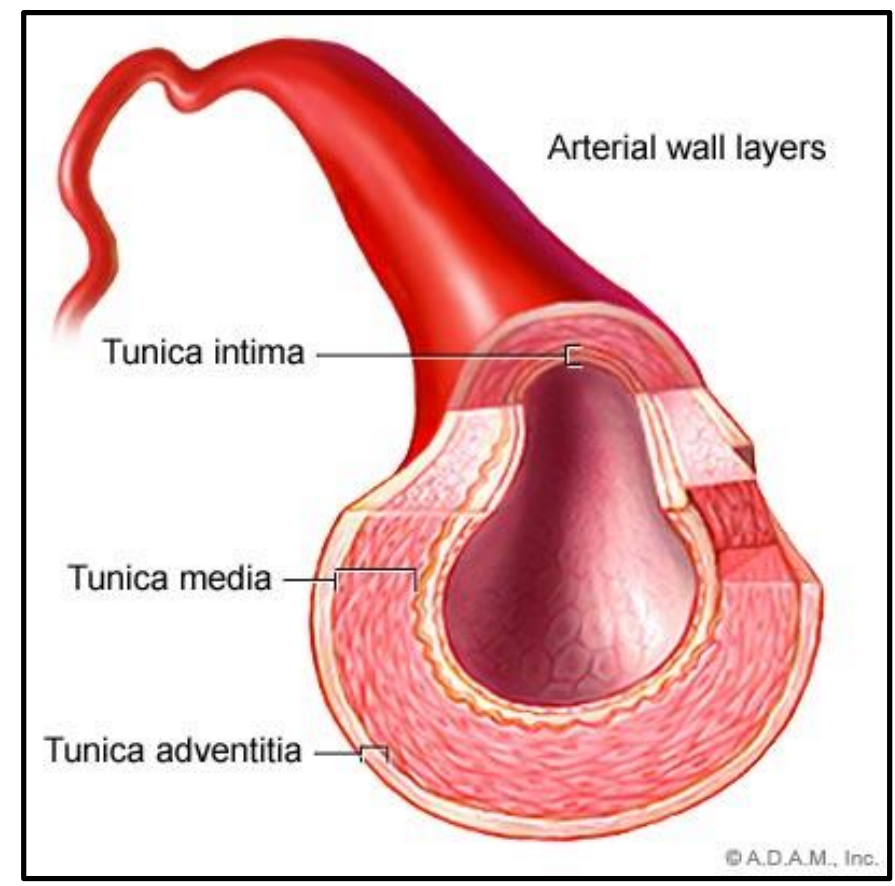

Figure 5: Illustration of the anatomy of a native blood vessel including the tunica intima, tunica media and tunica adventitia. http://bme.ccny.cuny.edu/faculty/jtarbell/SMC\% 20images.htm

A TEVG is created to mimic the native anatomy of a vessel by harvesting endothelial cells from native vessels or as derivatives of endothelial progenitor cells, which are then seeded on to the lumen of a scaffold [39-41]. The synthetic scaffold makes up the internal elastic media separating the tunica intima from the tunica media [41]. In most cases for TEVGs, the scaffold is able to provide the structural properties of the tunica media and adventia of a native vessel [41]. However, there are cases in which this is taken one step further and vascular smooth muscle cells are added to the scaffold surface, prior to endothelial cells, creating a true tunica media [41].

\subsubsection{Requirements and Limitations of a Tissue Engineered Vessel Graft}

To truly mimic the anatomy and basic functionality of a human blood vessel, the TEVG must have a confluent layer of endothelial cells lining the entire lumen of the scaffold [37]. In addition to a confluent endothelium, the TEVG must also have adequate mechanical properties in order to maintain the correct compliance once it is exposed to pulsatile flow [37]. Finally, the 
TEVG must be cost efficient, easy to store, resistant to degradation, resistant to infection and be able to be constructed in a reasonable amount of time [37].

As promising as the design of a Tissue Engineered Vascular Graft is, there are still some important limitations that current research is focused on overcoming [39-42]. One important limitation is surface thrombogenicity of the TEVG due to an inconsistent layer of endothelium in the lumen of the scaffold [39-42]. The second major limitation of the TEVG design is the compliance mismatch between the engineered and native vessels [39-43]. This mismatch can contribute to a hyperplasic response leading to anastomic intimal hyperplasia and eventually restenosis [42].

\subsubsection{Developing Solutions for TEVG Limitations}

As stated previously, the construction of a BVM utilizes the similar methods as the construction of a TEVG. Therefore, the limitations of the TEVG that were described in the previous section, mainly the lack of cell adhesion, are shared by the BVM. Therefore, to create a physiologically relevant in vitro model using these methods, this limitation must be overcome.

Enhanced graft patency occurs when the surface is lined with a consistent endothelium, making it resistant to platelet aggregation [43]. In order to develop a consistent endothelium in the lumen of the scaffold, a process known as two-stage seeding, or sodding, is currently used [44-46]. Sodding consists of the extraction of endothelial cells followed by the prolonged culture (2-3 weeks) to increase the cell numbers [45]. Once the cell count is high enough, the cells are then seeded on to the polymeric luminal surface [45].

In recent trials, when the sodding of autologous endothelial cells was implemented with ePTFE scaffolds, up to $70 \%$ of the cells were washed away once the graft was exposed to pulsatile flow [47]. In other cell adhesion studies utilizing ePTFE scaffolds, only $14 \%-40 \%$ of the applied cells remained adhered to the scaffold after exposure to pulsatile flow [48]. However, new techniques that involve the engineering of the lumen of the scaffold to improve cell 
attachment and retention have been developed and have proven to be much more successful [21, 48-57]. These techniques include shear stress preconditioning, electrostatic charging, and most successfully to date, pre-coating with endothelial specific glues [47-56]. Coatings that have been examined to date include collagen, fibronectin, gelatin, laminin, extra cellular matrix (ECM), serum, RGD peptide fragments and pre-clotting the grafts with blood and plasma $[21,51-53,55$, $56,58,59]$. The goal of the use of these coatings is the development of a compliant, selfendothelializing, non-thrombogenic, polymeric available off-the-shelf small diameter cardiovascular graft [52]. While all of these coatings have proven to increase cell adhesion when compared to a non-coated scaffold, some of them have much higher relative adhesion rates [48, 50, 52-56, 58-60]. In the following sections the molecular mechanisms of cell adhesion will be explained in addition to the comparison and analysis of the coatings listed above. These mechanisms and coatings will also be important when cell retention in the BVM system is addressed in later sections.

\subsubsection{Molecular Mechanisms of Cell Adhesion on Artificial Materials}

When cells adhere to an artificial surface there are two possible mechanisms that are utilized: direct (non-receptor mediated) binding or receptor mediated binding [58]. Direct cell adhesion is the non-specific interactions between the molecules on the cell membrane and the functional chemical groups on the polymer [58]. These interactions consist of weak chemical bonding including: hydrogen bonds, electrostatic interactions, and polar interactions [58]. This type of cell adhesion lacks the transmission of signals between the extra cellular environment and the cells to initiate receptor-mediated adhesion or ECM synthesis and deposition [58]. It has been determined that without these signals, anchorage dependent cells, such as endothelial cells, will undergo apoptosis after 24-48 hours [61].

In contrast to direct non-receptor mediated cell adhesion, receptor mediated cell adhesion to a surface is mediated by molecules within the ECM such as fibronectin, collagen or laminin [58]. When these ECM proteins are adsorbed on a synthetic material surface, the cells bind 
specific amino acid sequences of these proteins via integrin receptors [58]. The minimum adhesion motif of these molecules includes three amino acids: Arg-Gly-Asp or the RGD sequence [58].

The actual process of receptor mediated cell adhesion consists of a cascade of four different partly overlapping events: initial cell attachment, cell spreading, organization of actin cytoskeleton, and formation of focal adhesions [62]. In the initial attachment step the cell contacts the surface and some ligand binding occurs that allows the cell to withstand gentle shear forces [62]. Secondly, the cell body begins to flatten and its plasma membrane spreads over the surface [62]. Thirdly, actin filaments organize into microfilament bundles, referred to as stress fibers to aid in adhesion maturation [62]. Finally, integrin receptors are recruited in to microdomains on the cell membrane forming "focal adhesions" [62]. In these domains the integrins communicate with structural and signaling molecules to stabilize the cells attachment and initiate cell proliferation and differentiation as well as inhibit apoptotic pathways [62].

With these mechanisms in mind, many studies have attempted to utilize receptormediated binding to enhance the endothelialization of TEVGs by pre-coating the scaffold material with various proteins [43-52].

\subsubsection{Pre-Coatings Used to Enhance Cell Adhesion in Tissue Engineered Vascular Grafts}

The following subsections serve to examine the various coating techniques and technologies used to enhance endothelial cell attachment on to the surface of the scaffolds used as vascular bypass grafts. The success of each coating was quantified by calculating the cell loss after incubation from the initial number of cells seeded using counting techniques such as electron microscopy or viability assays such as almar blue [43-55].

\subsubsection{Serum/Serum Enhanced Cell Culture Medium}

Serum is a part of blood that is made up of non-clotting proteins, glucose, nutrients, electrolytes, hormones, antigens, antibodies, and other particles [56, 57, 63-65]. Albumin and $\gamma-$ globulin are the highest concentrated proteins in serum while fibronectin and laminin have a 
much lower concentration in serum [64]. While albumin and $\gamma$-globulin are known to inhibit cell adhesion, the adsorption of fibronectin, laminin on to surfaces has been shown to increase cell adhesion [64]. Many studies that involved the pre-coating of scaffolds with serum have found a significantly increased cellular attachment in comparison with non-coated grafts $[51,52,57,58]$. However, when coating a surface with serum, there is a competitive adsorption of proteins that both inhibit and encourage cell adhesion on to the surface [64]. Therefore, studies have found that while a serum coating increased cell adhesion when compared to a non-coated surface, it was inferior to fibronectin, collagen and laminin alone [52-54, 56, 57, 63-65].

\subsubsection{Laminin}

Laminins are major proteins found in the basal lamina of blood vessels [59]. Laminins are an important and biologically active part of the basal lamina influencing cell differentiation, migration and adhesion [59]. When laminin is used as a pre-coating, cellular attachment can be increased by up to three times when compared to a non-coated graft $[55,59,65]$. However, it too was found to be inferior to other coatings such as fibronectin, collagen and pre-clotting with blood or plasma. $[50,54,60]$

\subsubsection{Collagen I}

Collagen I is the major insoluble protein in the extracellular matrix and connective tissue [52]. When used as a pre-coating, collagen was found to significantly increase cell attachment when compared to non-coated grafts, however the increase was not significant when compared to other fibronectin, laminin or pre-clotting with plasma or blood [52, 53, 66].

\subsubsection{Gelatin}

Gelatin is a translucent, colorless solid substance that is extracted from collagen containing only the RGD binding site $[67,68]$. In studies, it was confirmed that gelatin coatings increased cell adhesion when compared to controls, and was also shown to be superior to the use of laminin as a pre-coating $[52,69]$. However, gelatin required a much longer incubation period 
for optimal cell attachment ( $>2$ hours as compared to 60 minutes for other coatings) and it was also found that up to $40 \%$ of adhered cells were washed away once exposed to pulsatile flow [67].

\subsubsection{Pre-Clotting}

The use of pre-clotting with the patients' own blood or plasma is appealing as a precoating to enhance cell adhesion because it is a simplistic surgical alternative that is more time and cost efficient when compared to chemical coatings [66]. To date, there have been a very small number of studies analyzing pre-clotting with plasma, however the results of these studies have been very promising and have shown to significantly increase cell adhesion to ePTFE scaffolds when compared to non-coated scaffolds [66]. Pre-clotting with blood, however, has been studied more intensely and has been found to have superior cell attachment rates when compared to serum and collagen, but inferior attachment rates compared to fibronectin and laminin $[54,66,70]$.

\subsubsection{Fibronectin}

Fibronectin is an extracellular matrix protein that is known to promote cellular attachment and spreading [54] . Fibronectin is the peptide sequence that has been most successfully used clinically for improving cellular attachment and retention [53, 54]. In comparative studies using ePTFE grafts, fibronectin had superior cell adhesion rates when compared to adhesion rates of collagen, gelatin laminin, albumin and gelatin [52-54, 71]. However, in other studies when fibronectin was used in combination with any of these other coatings, cell attachment was found to be far superior to fibronectin used as a coating on its own [52].

\subsubsection{Extra Cellular Matrix}

The use of the extra cellular matrix (ECM) in its entirety, composed of collagen, laminin, fibronectin, and elastin has been found to have far superior attachment and retention rates than fibronectin, collagen or laminin used alone [72]. 
As previously stated, the most crucial limitation of the tissue engineered blood vessel is the inability to create a consistent layer of endothelial cells in the lumen of the scaffold during seeding in order to prevent thrombosis. Therefore, a large amount of research has been dedicated to engineering the vessel lumen to increase endothelial cell attachment prior to implantation. The in vitro testing system in the form of a Blood Vessel Mimic shares this limitation of inefficient cell adhesion and retention. Hence, the use of pre-coatings such as fibronectin, collagen and other ECM components can be utilized in the BVM system to enhance cell attachment resulting in a more consistent endothelium creating a more accurate model of the native vessel.

\subsection{The Blood Vessel Mimic as an In Vitro Model}

The possibility of implementing a TEVG in vitro to examine the response of the intimal lining of the endothelium to stent implantation was introduced by the work of Kristen Cardinal in 2006 [3]. The use of the in vitro system would provide a more physiological, cost effective, high throughput and convenient way to assess new stent designs and their interactions with the endothelium prior to animal testing [3]. This particular study utilized the extraction of human endothelial cells from adipose tissue that were then sodded on to the lumen of an ePTFE scaffold [3]. The cells and scaffold were then allowed to grow within a flow bioreactor until a consistent endothelium was formed [3]. The system consisted of 2 chambers connected by tubing. One chamber housed the scaffold and cells while the other served as a media reservoir[3]. The tubing was connected to a peristaltic pump such that the BVM could be exposed to fluid flow (Figure 6) [3]. The stents were then deployed in the scaffold within the bioreactor and its effects on the endothelium were observed [3]. The success of this study shows that the possibility of using a Blood Vessel Mimic as an in vitro testing system is definitely feasible. 


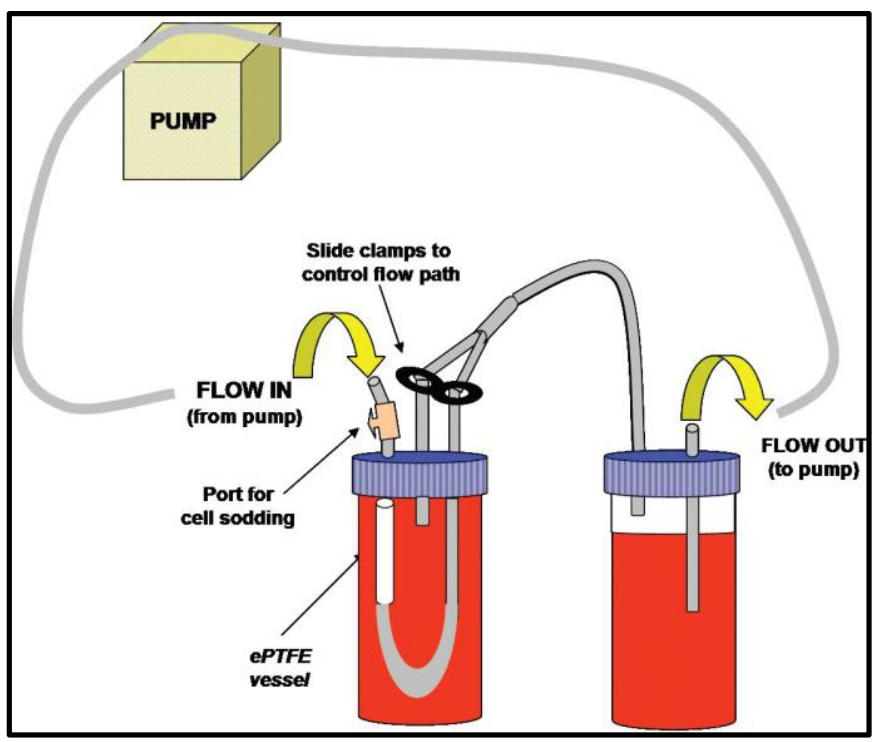

Figure 6: Bioreactor and BVM system configuration first utilized by Cardinal et al. in 2006. www.ncbi.nlm.nih.gov/pubmed/17518679

This system was further developed by Cardinal et al. to consist of a rectangular vessel chamber, media reservoir, and a peristaltic pump (Figure 7). This system was then utilized to evaluate the endothelialization of modified stent designs as compared to bare metal stents. The success of this study also supports the feasibility of developing an in vitro testing system for intravascular devices.

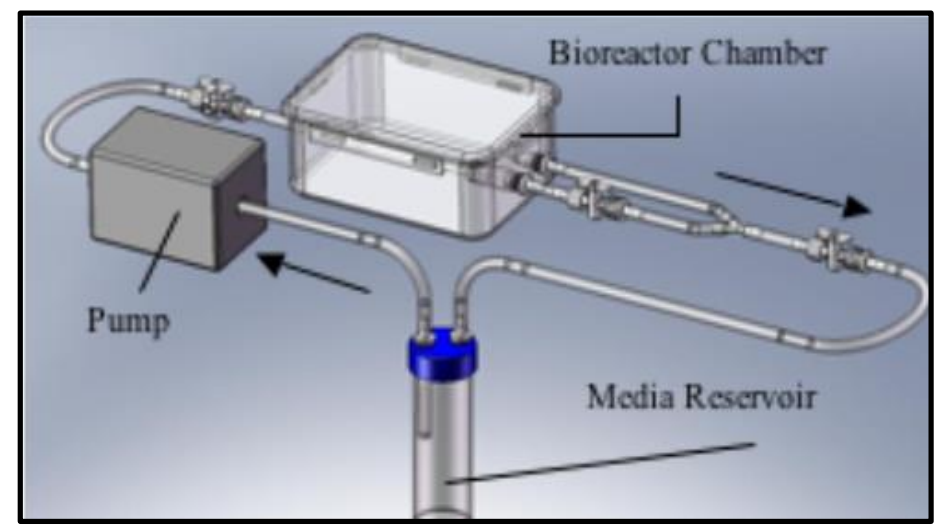

Figure 7: Solid model of the BVM system utilized by Cardinal et al. as well as the studies conducted for this thesis. Includes the rectangular bioreactor chamber, media reservoir and pump. http://digitalcommons.calpoly.edu/cgi/viewcontent.cgi?article=1085\& context=theses 
The biggest advantage of the BVM is that it provides the potential to produce consistent reliable data for stent implantation in a controlled model such that stent designs can be compared directly [4]. However, improvements are still being made to this system because there are still several physiological and mechanical limitations of the system that still need to be overcome. Under the guidance of Dr. Kristen Cardinal, many lab researchers are working hard to adjust the original BVM design to better simulate the in vivo conditions of the native blood vessel. Future designs hope to include the introduction of pulsatile flow [73], incorporation of smooth muscle cells to mimic the tunica media [5], and finally increasing the efficiency during the sodding stages of the BVM set-up. This thesis will address the final limitation of the BVM design with the ultimate goal of optimizing the BVM's sodding efficiency and creating a consistent endothelium.

Overall, the goal of this thesis is to improve the endothelial lining in the BVM by using protein pre-coatings to improve cell retention. To accomplish this goal, several specific aims were pursued. The first aim was to characterize, compare and asses pre-coatings and their effects on endothelial cell adhesion in six well plates. The second aim was to then utilize pre-coatings in the BVM system to compare and assess pre-coatings and their effects on endothelial cell adhesion to a PLGA scaffold. Preceding both of these aims, protocol development was also necessary. Results from these aims will be provided in the subsequent chapters. 


\section{CHAPTER 2: PROTOCOL DEVELOPMENT FOR 6-WELL PLATE COATING EXPERIMENTS}

As previously stated, pre-coatings have been utilized to modify the lumen of TEVGs to overcome limited endothelial cell adhesion. Because the BVM system shares this same limitation, pre-coatings could also be utilized to increase endothelial cell retention. However, before these coatings could be implemented in a full BVM system, they first needed to be characterized in a more controlled and efficient setting, in this case, 6-well plates.

One of the noted advantages of the BVM is that it is a cost effective system for testing stent deployment when compared to animal testing in vivo. Therefore, it is important that the precoatings used in this system also be as cost-effective. Hence, before experiments began, a costanalysis was first performed. Next, to compare the effectiveness of these coatings in increasing endothelial cell adhesion in 6-well plates, a protocol was developed to consistently quantify the number of cells adhered to each well.

\subsection{Cost-Analysis of Coatings for 6-Well Plate Experiments}

In the current BVM system, the polymer scaffold is allowed to incubate in "Conditioning Media" (serum enhanced cell culture medium) for twenty minutes prior to cell sodding. Also, during cell culture, HUVEC Media is allowed to incubate on the culture flask surface for thirty minutes prior to adding cells. For this reason, both of these solutions were examined as precoatings to enhance HUVEC attachment in the BVM in addition to ProNectin-F(engineered fibronectin protein) from Sigma-Aldrich due to its success in literature. Therefore, cost analysis was performed for Conditioning Media, HUVEC media and ProNectin-F for 6-well plate experiments. A summary of the cost analysis can be found in Table 1 and will be explained below.

\subsubsection{Cost Analysis of ProNectin-F in 6-Well Plate Experiments}

The ProNectin-F ordered from Sigma-Aldrich is $\$ 114.50$ for $1 \mathrm{mg}$ of the fibronectin that is diluted in to $1 \mathrm{~mL}$ of the provided diluting solution. To coat two wells in the 6-well plate 
coating analysis, $50 \mu \mathrm{L}$ of ProNectin-F is diluted in $5 \mathrm{~mL}$ of HUVEC media (Lonza). The calculations for the number of 6-well plate experiments that can be performed for each bottle of ProNectin-F are as follows:

$$
\frac{1.0 \mathrm{E} 3 \text { Lper bottle }}{5.0 \mathrm{E}-6 \mathrm{~L} \text { per set up }}=20 \text { 6-well plate experiments for } \$ 114.50
$$

A bottle of HUVEC media contains $500 \mathrm{~mL}$ of volume, and $5 \mathrm{~mL}$ are required for diluting the ProNectin-F in each 6-well plate experiment. Therefore, for twenty 6-well plate experiments (2wells coated in each experiment) with $5 \mathrm{~mL}$ of HUVEC media will constitute of one fifth of the total volume $(100 \mathrm{~mL})$. The cost to complete twenty 6-well plate experiments with ProNectin-F diluted in HUVEC media is calculated below:

$$
\begin{gathered}
(\$ 122 \text { per bottle })((0.20))=\$ 24.40 \\
\$ 24.40+\$ 114.50=\$ 138.90 \text { for } 20 \text { setups }
\end{gathered}
$$

\subsubsection{Cost Analysis of Conditioning Media in 6-Well Plate Experiments}

For the six well plate coating experiments, $1.5 \mathrm{~mL}$ of Conditioning Media was required to coat one well. Conditioning Media requires both fetal bovine serum (FBS) and base media (M199), ordered from Sigma-Aldrich. The calculations for twenty 6-well plate set-ups for Conditioning Media are as follows:

$$
500 \mathrm{~mL} \text { of } \mathrm{FBS}=\$ 124.50
$$

One bottle of Conditioning Media contains $83 \mathrm{~mL}$ of FBS

$$
\$ 124.50(83 / 500)=\$ 20.67
$$

One bottle of M199= $\$ 8.24$

Cost of one bottle of Conditioning Media: $\$ 20.67+\$ 8.24=\$ 28.91$

For twenty setups, $30 \mathrm{~mL}$ of the $500 \mathrm{~mL}$ bottle is consumed, therefore the cost to complete twenty 6-well plate experiments with Conditioning Media is: 


$$
(\$ 28.91)(0.06)=\$ 1.73
$$

\subsubsection{Cost Analysis of HUVEC Media Alone for 6-Well Plate Experiments}

To coat two wells with HUVEC media, $3.0 \mathrm{~mL}$ of media is required. The calculations of the cost to complete twenty 6-well plate experiments with HUVEC media are as follows.

$500 \mathrm{~mL}$ of HUVEC Media $=\$ 122$.

20 experiments require $60 \mathrm{~mL}$ of the $500 \mathrm{~mL}$ bottle $=12 \%$.

$$
(\$ 122)(0.12)=\$ 14.64
$$

Table 1: Summary of the Cost-Analysis for Pro-Nectin F, Conditioning Media and HUVEC media for 6-Well plate experiments

\begin{tabular}{|l|l|l|}
\hline \multicolumn{1}{|c|}{ Coating } & \multicolumn{1}{|c|}{$\begin{array}{c}\text { Volume Required for 20 } \\
\text { Setups }\end{array}$} & \multicolumn{1}{c|}{ Cost for 20 Setups } \\
\hline $\begin{array}{l}\text { ProNectin-F diluted in } \\
\text { HUVEC media }\end{array}$ & $100 \mathrm{~mL}$ & $\$ 138.90$ \\
\hline Conditioning Media & $30 \mathrm{~mL}$ & $\$ 1.73$ \\
\hline HUVEC Media & $60 \mathrm{~mL}$ & $\$ 14.64$ \\
\hline
\end{tabular}

It is obvious that of these three pre-coatings, Conditioning Media is the most cost efficient option. However, the efficiency of the coating in enhancing cell attachment in a BVM is also an important property of the coating. There are many variables in the BVM system that can affect cell adhesion in addition to the coatings, such as the cell sodding procedure and fluid flow exposure. Therefore, in order to accurately evaluate the efficiency of each coating for HUVEC attachment, a protocol was developed for to compare them in 6-well plates.

\subsection{Protocol Development for the Analysis of Pre Coatings in 6-Well Plate Experiments}

In order to determine the ability of Pro-Nectin F, Conditioning Media, and HUVEC media to promote cell adhesion in a 6-well plate experiment, it was necessary to establish a protocol that could be utilized for each experiment to determine the number of cells that adhered 
to each well. In the following sub-sections, a summary of the protocols that were used will be provided along with a discussion of what was successful and what was altered in subsequent protocols. The full protocols can be found in Appendix A. A summary of the conclusions that were drawn from each protocol can be found in Table 2 .

\subsubsection{Methods: Protocol \#1}

\subsubsection{Coating Preparation}

HUVEC Media was prepared following the Lonza Bullet Kit instructions (Lonza: CC3162). ProNectin-F (Sigma: F5022) was prepared by diluting 50 $\mu \mathrm{L}$ of the stock ProNectin-F solution into $5 \mathrm{~mL}$ of HUVEC media. Conditioning Media was prepared by combining $83 \mathrm{~mL}$ of FBS (Sigma: F4135) with 500mL of M199 (Lonza: 181474).

\subsubsection{Cell Selection and Culture}

Human umbilical vein endothelial cells (HUVECs) were purchased from Lonza (Lonza: CC-2517) and stored in vials in a liquid nitrogen dewar. Vials of P6 HUVECs were thawed and cultured according to standard practices. Cells were maintained at $37^{\circ} \mathrm{C}$ and $5 \% \mathrm{CO}_{2}$ for the culture and expansion process.

\subsubsection{Preparation of 6-Well Plates}

Once each pre-coating was prepared, $1.5 \mathrm{~mL}$ of each coating was added to previously specified and labeled wells in three VWR 6-well plates and allowed to incubate for 20 minutes (Figure 8). The incubation occurred at $37^{\circ} \mathrm{C}$ and $5 \% \mathrm{CO}_{2}$. During this incubation, HUVECs were detached from a $225 \mathrm{~mL}$ cell culture flask using trypsin. After 20 minutes of incubation, the coatings were aspirated and $1 \mathrm{~mL}$ of HUVEC media was added to each well along with $1.5 \mathrm{~mL}$ of the suspended cell solution from the culture flask. The wells, now containing cells, were then incubated for 15 minutes except for wells 6,12 and 18 that were only allowed to incubate for 5 minutes (full protocol in Appendix A.1). 


\subsubsection{Quantifying the Number of Cells Adhered to Wells}

Cell counts were obtained using a Nexcelom Bioscience Cellometer (Figure 9). The

Nexcelom Bioscience Cellometer utilizes bright field imaging and pattern-recognition software to quickly and accurately identify and count individual cells suspended in a solution[74]. Cell count, concentration, diameter, and \% viability are automatically calculated and reported [74]. An initial cell count prior to adding the cells to the 6-well plates was obtained from the Nexcelom Bioscience Cellometer. The initial number of cells counted was $6.3 \times 10^{6}$. This value was then divided by 18 to obtain an initial cell count per well (see sample calculation below). After the allotted incubation time, the solution was removed from each well in to individual petri dishes. This solution contained the cells from each well that did not adhere to the surface. Therefore, to calculate the number of cells that did adhere to the wells, this number would be subtracted from the initial number of cells that were assumed to be in each well (see sample calculation below).

$$
\text { Initial Cell Count }=6.3 \times 10^{6}
$$

Number of Cells Added to Each Well $=\frac{6.3 \times 10^{6}}{18}=3.5 \times 10^{5}$ cells in each well Sample Number of Counted Non - Adhered Cells From Well $1=1.2 \times 10^{3}$ cells Number of Adhered Cells in Well $1=3.5 \times 10^{5}-1.2 \times 10^{3}=2.3 \times 10^{5}$ cells Percent Cells Adhered $=\frac{2.3 \times 10^{5}}{3.5 \times 10^{5}} \times 100=65.7 \%$ of applied cells adhered to the well 


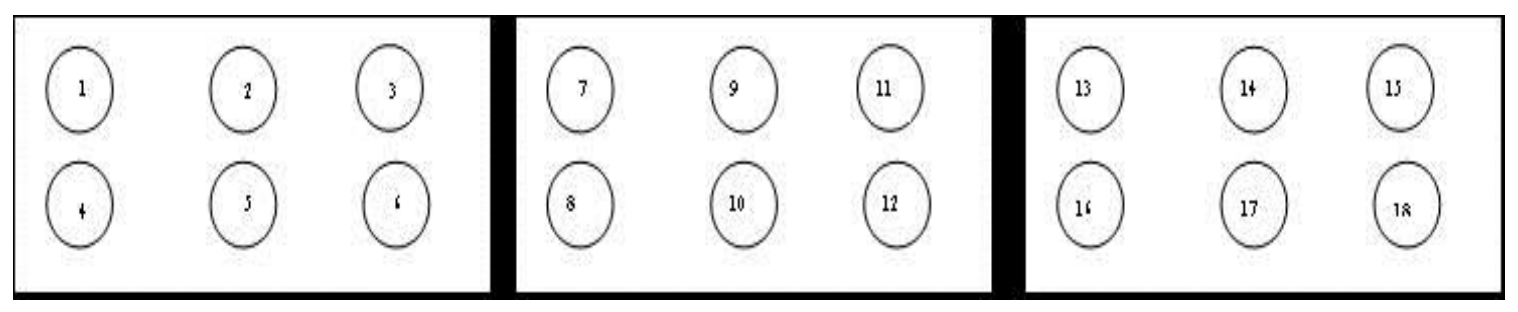

Well Legend:

1, 7, 13: No Coating

2, 8, 14: Conditioning Media

3, 9, 15: HUVEC Media

4, 10, 16: ProNectin- F+ HUVEC Media

5, 11, 17: ProNectin-[74] F+PBS

6, 12, 18: HUVEC Media with 5 Minute Cell Incubation

Figure 8: Diagram of the 6-well plates and applied coatings used in Protocol \#1.

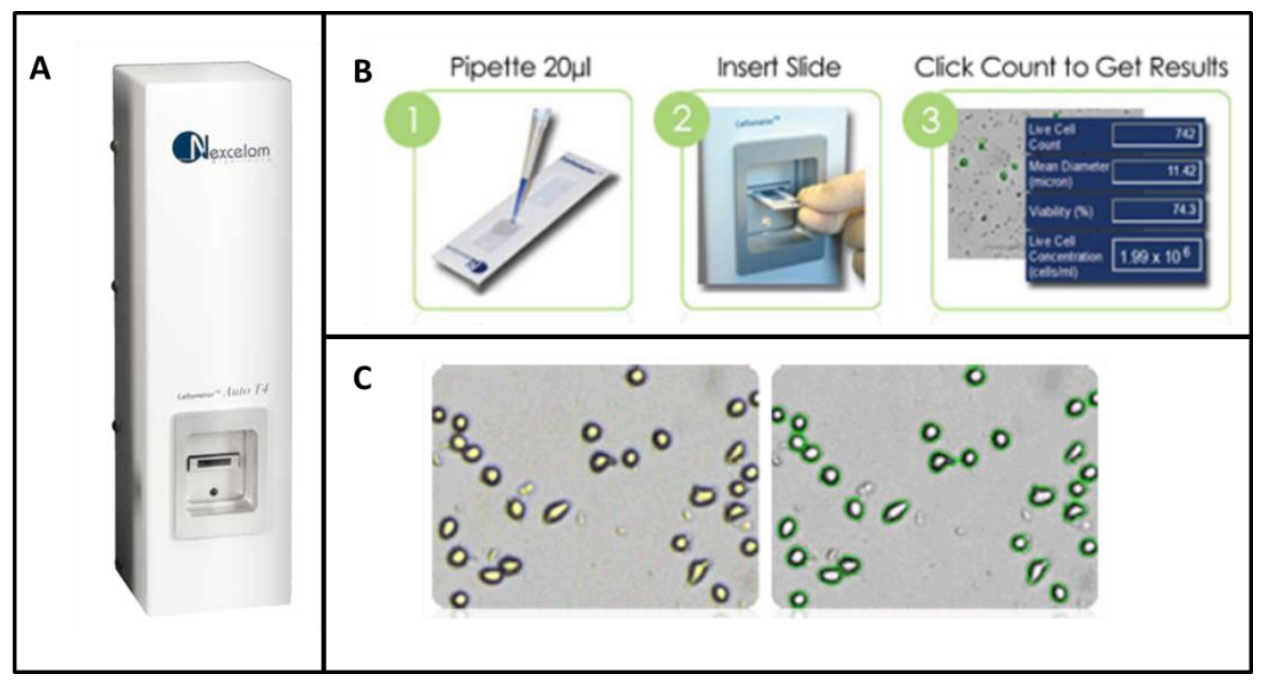

Figure 9: Illustration of the Nexcelom Cellometer and the Cell Counting Process. A: Nexcelom Cellometer. B: Process Utilized to Count Cells C: Example of Nexcelom Cellometer Cell Tracing and Counting

\subsubsection{Discussion: Protocol \#1}

During this experiment, the presence of three 6-Well plates in the tissue culture hood

simultaneously created stress for both aseptic space in the hood as well as time. In order to accurately determine the number of cells that did not adhere, the solution had to be removed from the wells quickly to avoid more cells adhering to the surface post-incubation. This was difficult to manage with 18 different wells. Also, once all of the media had been removed from the wells in 
to individual petri dishes, many of the cells had adhered to the bottom of the petri dishes during the counting stages, resulting in inaccurate cell counts. Also, due to the long incubation period (15 minutes), there were few cells in the non-adhered solution, resulting in the inability to obtain automated counts.

It was determined that in future protocol development experiments only one 6-well plate would be used and that the incubation period would be reduced to five minutes to increase the number of cells in the non-adhered solution. These changes were made in attempt to reduce time and space constraints as well as provide enough cells to produce automated cell counts. Finally, it was determined that the ProNectin-F would be more effective when diluted in HUVEC media as compared to PBS. Therefore, in future protocols ProNectin-F was diluted in HUVEC media.

\subsubsection{Methods: Protocol \#2}

\subsubsection{Coating Preparation and Cell Culture}

Completed using methods described in Protocol \#1 (Section 2.2.1.2).

\subsubsection{Preparation of 6-Well Plates}

Because only one 6-well plate was being coated for this protocol, a confluent $75 \mathrm{~mL}$ cell culture flask was used instead of a 225mL cell culture flask. Like Protocol \#1, $1.5 \mathrm{~mL}$ of each coating was applied to the specified wells and allowed to incubate for 20 minutes. An initial cell count was obtained from the T-75 culture flask like Protocol \#1; however this number was divided by six instead of eighteen to quantify the number of cells being added to each well. Each well was assigned and coating and labeled (Figure 10). As previously stated, this protocol reduced the incubation time for the cells in the coated wells from twenty minutes to five minutes (full protocol in Appendix A.2).

\subsubsection{Quantifying the Number of Cells Adhered to Wells}

Completed using the same methods described in Protocol \#1 (Section 2.2.1.4). 


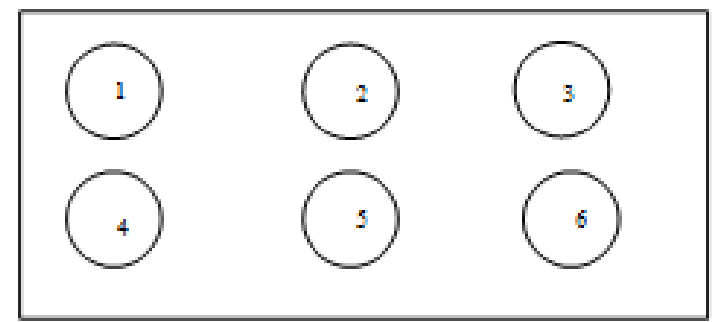

$$
\begin{gathered}
\text { Well Legend: } \\
\text { 1: No Coating } \\
\text { 2: Conditioning Media } \\
\text { 3: HUVEC Media } \\
\text { 4: Pro-Nectin F+ HUVEC Media } \\
\text { 5: Pro-Nectin F+HUVEC Media } \\
\text { 6: HUVEC Media }
\end{gathered}
$$

Figure 10: Diagram of the 6-well plate and applied coatings used in Protocol \#2.

\subsubsection{Discussion: Protocol \#2}

Reducing the number of 6-well plates used in the protocol development experiments from three to one increased to amount of aseptic space and eliminated the time constraint during the removal of non-adhered cells post incubation. However, it was still difficult to obtain automated counts for the non-adhered cells. It was determined that this was because the Nexcelom Bioscience Cellometer had a minimal threshold ratio of cells to solution. This concentration had to be met in order to automatically trace and calculate the number of cells present in a solution. Therefore, it was decided that more cells needed to be present in each well to increase the concentration. It was also concluded that it would be more efficient to directly count the adhered cells rather than the non-adhered cells in each well.

\subsubsection{Methods: Protocol \#3}

\subsubsection{Coating Preparation and Cell Culture}

The coatings and cells were prepared using the methods described in Protocol \#1 (Section

\subsubsection{2).}




\subsubsection{Preparation of 6-Well Plates}

Completed using methods described in Protocol \#2, with the exception of a confluent $225 \mathrm{~mL}$ cell culture flask of HUVECs instead of a $75 \mathrm{~mL}$ cell culture flask. Each well was assigned a coating and labeled (Figure 11).

\subsubsection{Quantifying the Number of Cells Adhered to Wells}

After the cells were incubated in the coated wells, the solution containing the non-

adhered cells was discarded and $1 \mathrm{~mL}$ of trypsin was added to each well to detach the adhered cells from the wells. Once the cells were detached, the trypsin was deactivated with $2 \mathrm{~mL}$ of HUVEC media and the solution containing the adhered cells was moved in to individual $15 \mathrm{~mL}$ conicals so that the number of adhered cells in each well could be counted (full protocol in Appendix A.3).

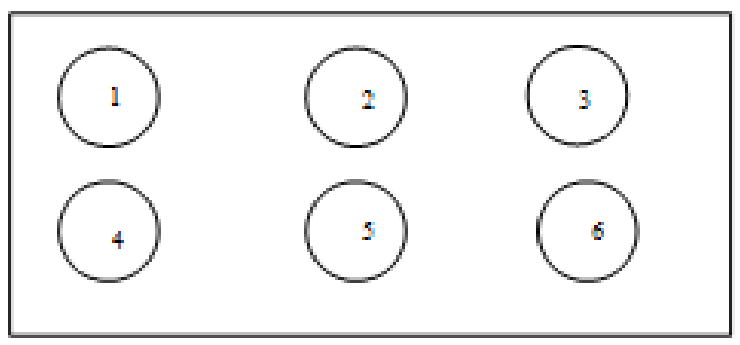

$$
\begin{gathered}
\text { Well Legend: } \\
\text { 1: No Coating } \\
\text { 2: Conditioning Media } \\
\text { 3: HUVEC Media } \\
\text { 4: Pro-Nectin F+ HUVEC Media } \\
\text { 5: Pro-Nectin F+PBS } \\
\text { 6: HUVEC Media }
\end{gathered}
$$

Figure 11: Diagram of the 6-well plate and applied coatings used in Protocol \#3.

\subsubsection{Discussion: Protocol \#3}

Although the number of cells added to the wells was increased, the threshold cell-tosolution ratio still was not met and automated cell counts were not obtained. Therefore, in order to further increase this ratio it was determined that the amount of solution that the cells were suspended in had to be decreased. 


\subsubsection{Methods: Protocol \#4}

\subsubsection{Coating Preparation and Cell Culture}

The coatings and cells were prepared using the methods described in Protocol \#1

(Sections 2.2.1.1-2.2.1.2).

\subsubsection{Preparation of 6-Well Plates}

The 6-well plates were prepared using the methods described in Protocol \#3. Each well was assigned a coating and labeled (Figure 12)

\subsubsection{Quantifying the Number of Cells Adhered to Wells}

Cell counts were performed for both the adhered and non-adhered cells to ensure that all of the cells counted initially were accounted for. After the incubation period, the non-adhered cell solution from each well was moved to a second 6-well plate and was submitted for cell-counting. Also, to increase to cell-to-solution ratio in attempt to meet the threshold for the Nexcelom Cellometer, the solution that the cells were suspended in was decreased to $0.5 \mathrm{~mL}$. This solution was then submitted for automated cell counts (full protocol in Appendix A.4).

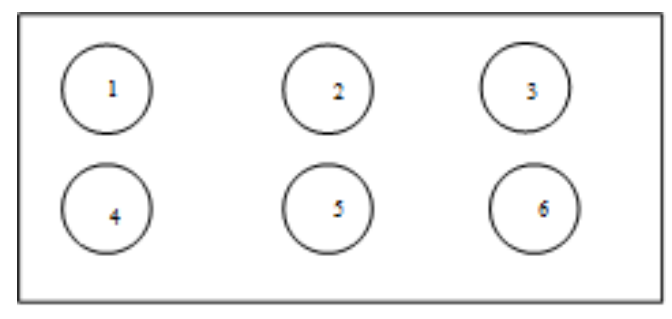

$$
\begin{gathered}
\text { Well Legend: } \\
\text { 1: No Coating } \\
\text { 2: Conditioning Media } \\
\text { 3: HUVEC Media } \\
\text { 4: Pro-Nectin F+ HUVEC Media } \\
\text { 5: Pro-Nectin F+PBS } \\
\text { 6: HUVEC Media }
\end{gathered}
$$

Figure 12: Diagram of the 6-well plate and applied coatings used in Protocol \#4. 


\subsubsection{Discussion: Protocol \#4}

Using Protocol \#4, cell counts were successfully obtained for both adhered and nonadhered cells in each well because the threshold for the cell counter was met by reducing the volume of solution that the cells were suspended in. 
Table 2: Summary of the process in establishing a protocol for the analysis of 6-well plate experiments

\begin{tabular}{|c|c|c|c|}
\hline Protocol & What Was Changed & What Worked & What Did Not Work \\
\hline Protocol \#1 & N/A & $\begin{array}{l}\text { 1. All of the coatings } \\
\text { were effective and } \\
\text { resulted in adhered cells } \\
\text { to the wells }\end{array}$ & $\begin{array}{l}\text { 1. Three six well plates } \\
\text { was too chaotic for a new, } \\
\text { un-established protocol. } \\
\text { 2. Incubation time for } \\
\text { cells in a } 6 \text { well plate was } \\
\text { too long. Too many cells } \\
\text { adhered and there were } \\
\text { not enough to meet } \\
\text { threshold for cell- counter } \\
\text { in the non-adhered } \\
\text { cell/media solution }\end{array}$ \\
\hline Protocol \#2 & $\begin{array}{l}\text { 1. Only one six well plate } \\
\text { was used. } \\
2 \text {. Cell incubation time in } \\
\text { wells was reduced from } \\
20 \text { minutes to } 5 \text { minutes. } \\
\text { 3. ProNectin-F was only } \\
\text { diluted in HUVEC media, } \\
\text { not PBS. }\end{array}$ & $\begin{array}{l}\text { 1.Only using one six well } \\
\text { plate to analyze coatings } \\
\text { was much more } \\
\text { manageable } \\
\text { 2. Five minute cell } \\
\text { incubation time was } \\
\text { enough to allow cells to } \\
\text { adhere, but also enough to } \\
\text { remain non-adhered to } \\
\text { attempt to meet threshold } \\
\text { for cell counter }\end{array}$ & $\begin{array}{l}\text { 1.Too much time for } \\
\text { counting non-adhered } \\
\text { cells, cells began to } \\
\text { adhere to surface of the } \\
\text { Petri dish } \\
\text { 2.Could not get counts of } \\
\text { non-adhered cells for all } \\
\text { of the wells }\end{array}$ \\
\hline Protocol \#3 & $\begin{array}{l}\text { 1. Decided to obtain } \\
\text { counts for adhered cells } \\
\text { instead of non-adhered } \\
\text { cells. } \\
\text { 2. Began with more cells, } \\
\text { used a T-225 culture flask } \\
\text { instead of T-75 } \\
\text { 3. Detached cells from } \\
\text { wells using trypsin and } \\
\text { deactivated with HUVEC } \\
\text { media prior to counting. }\end{array}$ & $\begin{array}{l}\text { 1. Detachment of cells } \\
\text { from individual wells } \\
\text { using trypsin, confirmed } \\
\text { by cell counter and scope } \\
\text { that the cells were } \\
\text { removed efficiently from } \\
\text { the wells. }\end{array}$ & $\begin{array}{l}\text { 1. Still unable to get } \\
\text { counts for adhered cells. }\end{array}$ \\
\hline Protocol \#4 & $\begin{array}{l}\text { 1. Decided to obtain } \\
\text { counts for both adhere } \\
\text { and non-adhered cells. } \\
\text { 2. After cells were } \\
\text { removed from wells, the } \\
\text { solution was centrifuged } \\
\text { and excess media was } \\
\text { removed such that the } \\
\text { adhered cells were } \\
\text { suspended in } ~ 0.5 \mathrm{~mL} \text { of } \\
\text { solution }\end{array}$ & $\begin{array}{l}\text { 1. Counts were } \\
\text { successfully obtained for } \\
\text { both adhered and non- } \\
\text { adhered cells. }\end{array}$ & $\begin{array}{l}\text { 1. Nothing, this protocol } \\
\text { was efficient and } \\
\text { successful }\end{array}$ \\
\hline
\end{tabular}




\subsubsection{Discussion of Protocol Development}

After implementing four different protocols, it was determined that Protocol \#4 was an

efficient and accurate procedure for examining the effects of a coating on cell attachment in a 6well plate. The analysis steps utilized in Protocol \#4 were implemented in to all future protocols that served to analyze coating efficiency concerning cell adhesion in a 6-well plate. 


\section{CHAPTER 3: INCUBATION TIME AND COMPARISON STUDIES OF PRE-COATINGS IN 6-WELL PLATES}

In the protocol development stages, the amount of time that the 6-well plates incubated both with and without cells was based on values seen in literature [50, 52, 54, 59]. However, multiple incubation periods were used for both coating and cell incubation times in different studies $[50,52,54,59]$. The coating incubation time is defined as the amount of time that the precoating is allowed to incubate on the 6-well plate prior to adding cells. The cell incubation time is defined as the amount of time that the cells are allowed to incubate on the coated surface prior to analysis. However, it was not stated how these different incubation times effected the number of endothelial cells that attached to the coated surfaces. Determining how the coating and cell incubation times affect cell adhesion allowed for the optimization of coating protocols to maximize cell adhesion.

In pre-coating cell adhesion studies, it was repeatedly found that the use of ProNectin-F as a pre-coating to enhance cell adhesion was more successful than other coatings that were implemented [52-55, 64, 67]. However, this coating is also a very expensive alternative and would need to significantly outperform Conditioning Media (the current BVM coatings) in increasing endothelial cell adhesion to be considered for use in the BVM system. As previously stated, these studies were first performed in 6-well plates to avoid factors within the BVM system that may affect cell adhesion in addition to the pre-coatings.

\subsection{Analysis of the Effects of Coating and Cell Incubation Times on Endothelial Cell Adhesion}

As previously stated, two different incubation times are required in the pre-coating protocol: coating incubation and cell incubation. This study sought to determine how varying these incubation periods affected the number of endothelial cells adhered to the coated surfaces. 


\subsubsection{Methods}

\subsubsection{Coating Preparation and Cell Culture}

Conditioning Media was prepared using the same methods described in Protocol

Development sections. Culture of P6 HUVECs, thawing and expansion was also completed using the same methods described in the Protocol Development sections (Section 2.2.1.2).

\subsubsection{Preparation of 6-Well Plates}

Because this experiment sought to only analyze the effects of different incubation times on cell adhesion, all wells were coated with $1.5 \mathrm{~mL}$ Conditioning Media. In this experiment, four 6-well plates were utilized and each well was assigned a coating incubation time of 10, 20 or 30 minutes and a cell incubation time of 2, 5 or 8 minutes. One 6-well plate was used for the staggering of varying coating incubation times. Conditioning Media was added to well 3 and 6 first and allowed to incubate for 10 minutes at $37^{\circ} \mathrm{C}, 5 \% \mathrm{CO}_{2}$. After ten minutes, Conditioning Media was added to wells 2,5, and 7-12 and placed back in the incubator for 10 more minutes. Conditioning Media was then added to wells 1 and 4 and the plate was placed back in the incubator for the final 10 minute incubation. Wells 7-12 were also incubated during the final ten minutes (20 minute total incubation time). The wells that varied in cell incubation times were in 3 separate 6-well plates. This was done because after the cell incubation time was completed, the adhered and non-adhered cells were removed from the wells. This process requires the 6-well plate to be out of the incubator for 5-7 minutes, and would result in inaccurate cell incubation times if they were all on the same plate. By utilizing three 6-well plates, the longer cell incubation periods can continue will cells are being removed from the wells assigned shorter incubation periods. The assignments of the wells can be found in Figure 13. The full protocol used for this experiment can be found in Appendix A.5. 

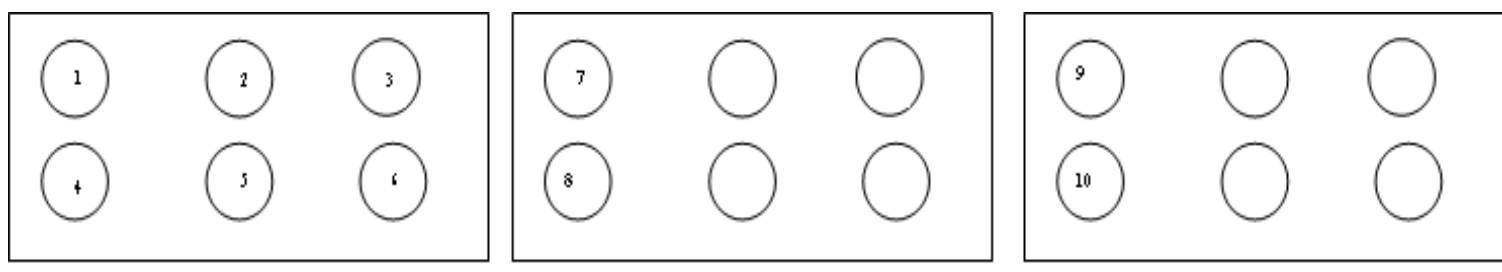

1. 10 min coating incubation. 5 min cell incubation

2. 20 min coating incubation. 5 min cell incubation

3. 30 min coating incubation. 5 min cell incubation

4. 10 min coating incubation. 5 min cell incubation

5. 20 min coating incubation. 5 min cell incubation

6. 30 min coating incubation. 5 min cell incubation

7. $20 \mathrm{~min}$ coating incubation. $2 \mathrm{~min}$ cell incubation

8. 20 min coating incubation. 2 min cell incubation

9. 20 min coating incubation. 5 min cell incubation

10.20 min coating incubation. 5 min cell incubation

$11.20 \mathrm{~min}$ coating incubation. $8 \mathrm{~min}$ cell incubation

12.20 min coating incubation. 8 min cell incubation

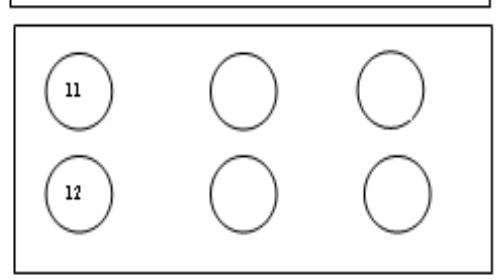

Figure 13: Well assignments for the assessment of the effects of coating and cell incubation time on cell adhesion

\subsubsection{Quantifying the Number of Cells Adhered to Wells}

The methods described in Protocol \#4 of Protocol Development were utilized in this

study to obtain cell counts for adhered and non-adhered cells in each well (Section 2.2.7.2).

\subsubsection{Results}

As illustrated in Figure 14, the results of this experiment indicated that varying the amount of time that the coated surfaces are incubated prior to adding cells did not affect the number of cells that adhered to the coated surface. However, an increasing trend was observed for the number of cells that adhered to the coated surface as the cell incubation time increased. 


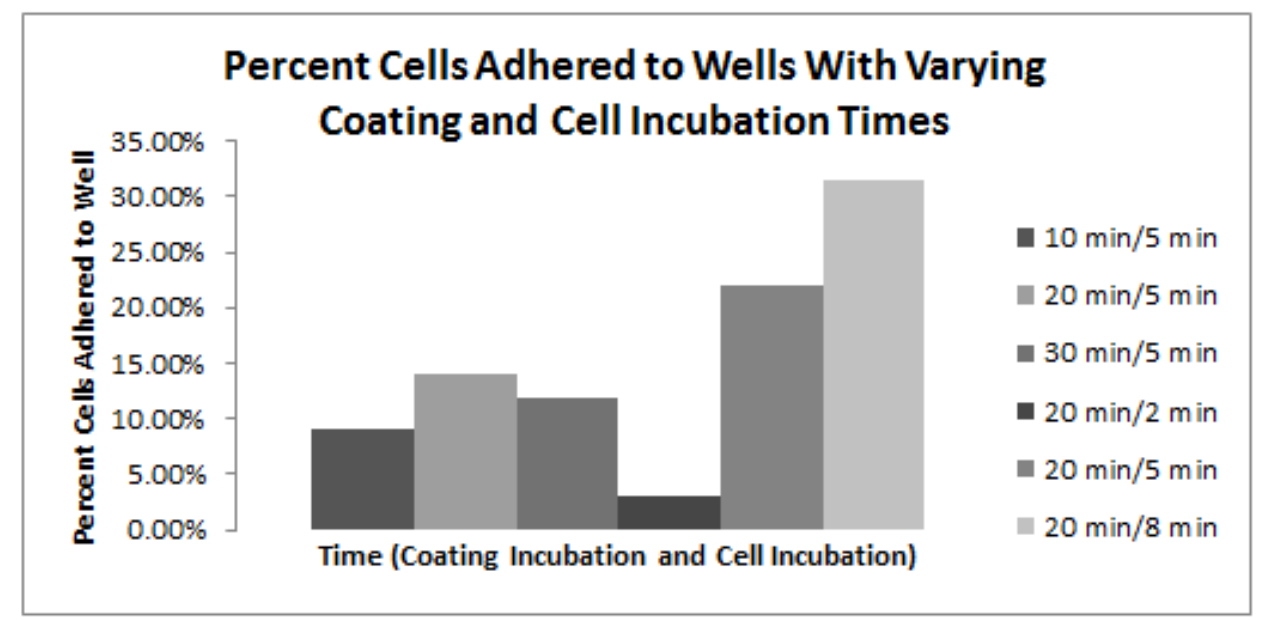

Figure 14: Results of incubation time experiment. Cells adhered after varying cell and coating incubation periods. Represented as a percentage of the initial number of cells counted in the well.

\subsubsection{Discussion}

As previously stated, it was observed that varying the coating incubation period did not result in a large variation in cell adhesion. Therefore, it was concluded that this incubation period did not have a significant effect on endothelial cell adhesion to coated surfaces and would be kept constant in future experiments. However, in contrast to coating incubation, increasing cell incubation times did result an increasing trend in percent cells adhered. Hence, it was concluded that the cell incubation period will have an effect on endothelial cell adhesion and would be considered during the BVM coating protocol development stages (Chapter 4).

\subsection{Comparison of ProNectin-F and Conditioning Media as a Pre-Coating in 6-Well Plates}

In literature, when ProNectin-F was used as a pre-coating on a TEVG, it was found that maximal cell adhesion was obtained when the cells were allowed in incubate on surface for $60-90$ minutes $[50,52,54,55,64,67]$. To determine how the successful, yet expensive, ProNectin-F pre-coating compared to Conditioning Media in increasing cell adhesion, a comparison study was designed. This study served to evaluate the efficacy of ProNectin-F and Conditioning Media compared to a non-coated surface in terms of endothelial cell adhesion after 60 and 90 minute cell incubation periods. 


\subsubsection{Methods}

\subsubsection{Coating Preparation and Cell Culture}

Conditioning Media and ProNectin-F were prepared using the same methods described in Protocol Development sections (Section 2.2.1.1). Culture of P6 HUVECs, thawing and expansion was also completed using the same methods described in the Protocol Development sections (Section 2.2.1.2)

\subsubsection{Preparation of 6-Well Plates}

Each coating (or non-coated) was assigned to three wells for each time point. The well assignments can be found in Figure 14. All 18 wells were incubated with the assigned coating for 20 minutes prior to adding cells. The endothelial cells were then added to each well and were incubated for 60 or 90 minutes. The full protocol used in this experiment can be found in Appendix A.6.

\subsubsection{Quantifying the Number of Cells Adhered to Wells}

The same methods described in Protocol \#4 of Protocol Development were utilized to obtain cell counts for adhered and non-adhered cells in each well (Section 2.2.7.2). 

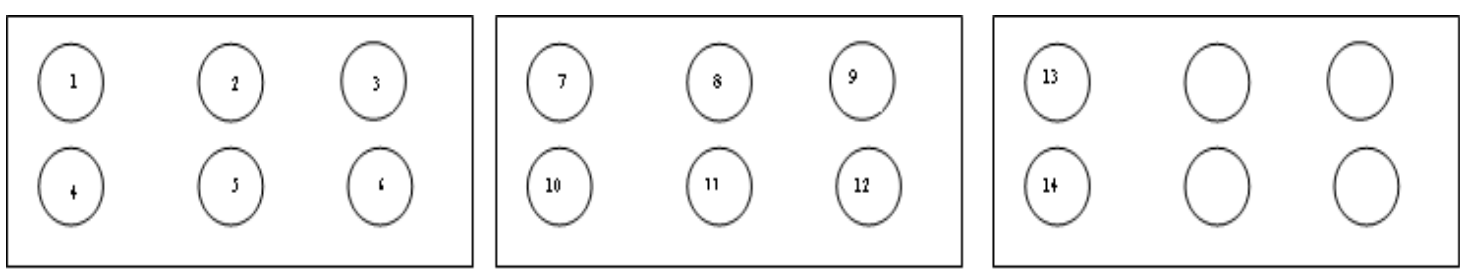

1: Conditioning Media: 60 Minute Incubation

2: Conditioning Media: 60 Minute Incubation

3: Conditioning Media: 60 Minute Incubation

4: ProNectin F: 60 Minute Incubation

5: ProNectin F: 60 Minute Incubation

6: ProNectin F: 60 Minute Incubation

7: Conditioning Media: 90 Minute Incubation

8: Conditioning Media: 90 Minute Incubation

9: Conditioning Media: 90 Minute Incubation

10: ProNectin F: 90 Minute Incubation

11: ProNectin F: 90 Minute Incubation

12: ProNectin F: 90 Minute Incubation

13: No Coating: 60 Minute Incubation

14: No Coating: 60 Minute Incubation

15: No Coating: 60 Minute Incubation

16: No Coating: 90 Minute Incubation

17: No Coating: 90 Minute Incubation

18: No Coating: 90 Minute Incubation

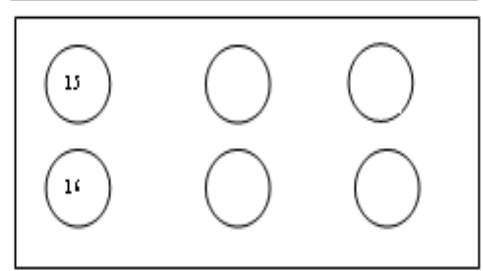

\section{Figure 15: Coating and incubation well assignment for the ProNectin F - Conditioning Media comparison experiment}

\subsubsection{Results}

As illustrated in Figure 16, the use of Conditioning Media and ProNectin-F as pre-

coatings significantly increased the number of cells that adhered to the 6-well plates when

compared to a non-coated control. The results from the experiment also indicate that significantly

more cells adhere after 90 minutes of cell incubation when compared to 60 minutes of incubation

regardless of the coating. Lastly, the results of this study indicate that there was no significant

difference between the number of cells that adhered when Conditioning Media or ProNectin-F

were used as a pre-coating. 


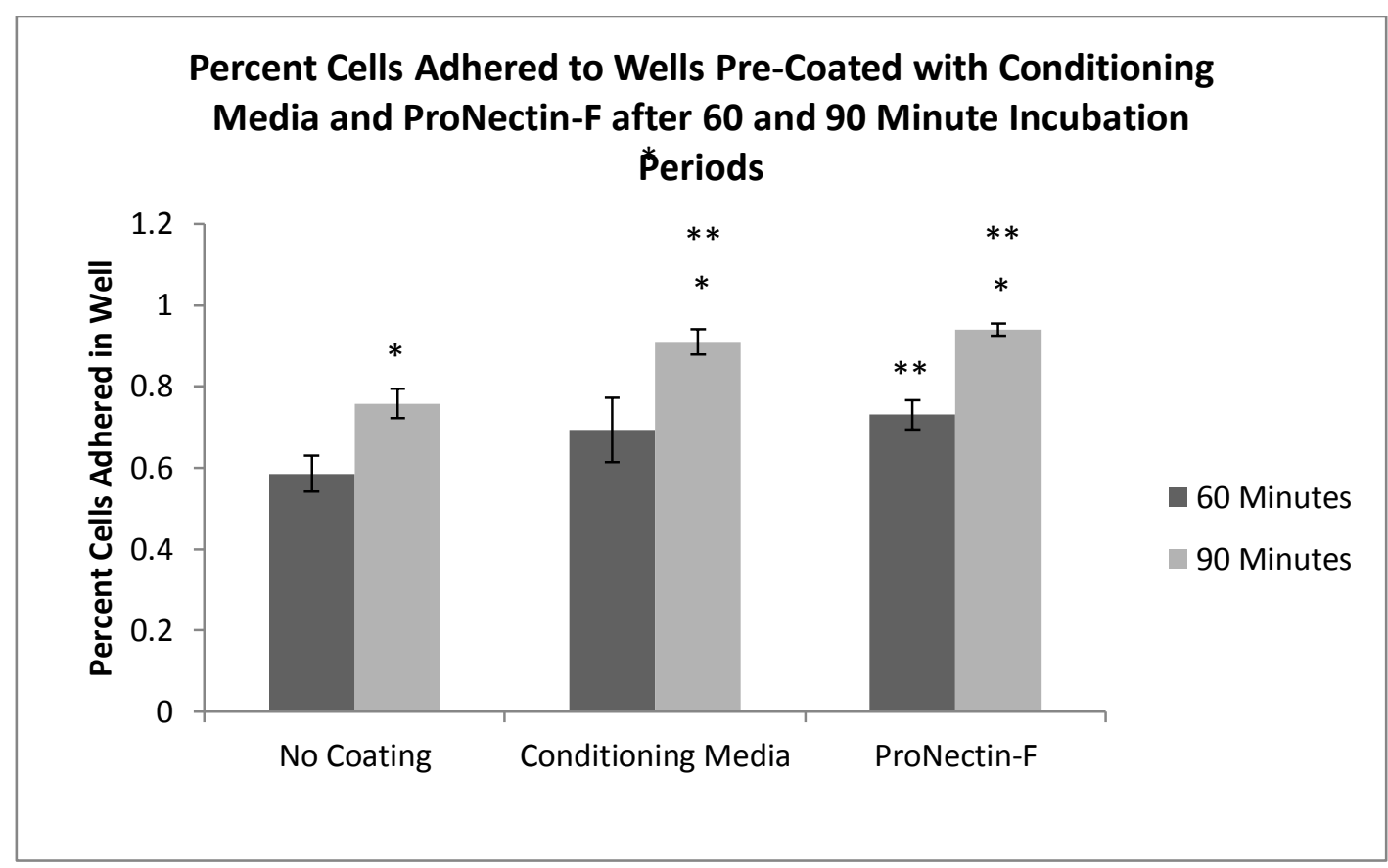

Figure 16: Percent of total cells adhered to wells pre-coated with Conditioning Media and ProNectin-F after 60 and 90 minute incubation periods. * $\mathrm{p}<0.05$ for percent cells adhered after 90 minutes of incubation compared to 60 minutes of incubation for individual coatings including non-coated. $* * \mathbf{p}<0.05$ for percent cells adhered to a coated surface compared to non-coated control after 90 minute incubation period.

\subsubsection{Discussion}

The results from this experiment supported the hypothesis that the use of pre-coatings would significantly increase the number of cells that adhered to the surface of the 6 -well plates when compared to wells that did not have a coating. In addition, there was not a significant difference in the number of cells that adhered to the Conditioning Media coated surfaces and the ProNectin-F coated surfaces. This was a beneficial finding for the BVM protocol because it indicated that the coating that is currently implemented in constructing a BVM is as effective as the much more expensive ProNectin-F alternative.

\subsection{Discussion of 6-Well Plate Coating Experiments}

The 6-well plate coating experiments resulted in two main conclusions: the coating incubation time does not significantly affect the number of cells adhered to a coated surface and that there was not a significant difference in the number of cells that adhered to the Conditioning 
Media coated surfaces and the ProNectin-F coated surfaces. However, it is important to note that 6-well plates are not composed of the same material as a BVM scaffold and are not exposed to fluid flow or shear forces.

In literature studies in which ProNectin-F was found to be a very successful pre-coating, the cells were exposed to flow either in a bioreactor or the human circulatory system [53, 54]. In these studies it was concluded that the cells were able to create a stronger attachment to the materials that were coated with ProNectin-F when compared to other materials because significantly less cells "washed off" the material once it was exposed to flow [53, 54]. Hence, it is possible that Conditioning Media and ProNectin-F cause a similar number of cells to adhere to a BVM scaffold initially, prior to flow exposure, as seen in the 6-well plate experiments; but that once the cells are exposed to flow, one coating would prove to be more effective than the other. Therefore, to further characterize these pre-coatings and their effects on endothelial cell adhesion, the coatings were implemented into BVM system. To accomplish this, modifications to the protocol that was developed in Chapter 2 were first necessary to consistently analyze the efficiency of these coatings on PLGA scaffolds. Protocol development will be presented in the next chapter, with BVM experiments presented in Chapter 5. 


\section{CHAPTER 4: PROTOCOL DEVELOPMENT FOR THE ANALYSIS OF PRE-COATINGS IN A BVM}

The efficiency of the sodding stages during BVM construction had never been quantified in this laboratory. However, it has been noted in previous work in this laboratory that a significant amount of cells are lost from sodding stages to later time-points of 3-7 days of flow exposure [5, $73,75]$. However, before developing a protocol to implement and compare pre-coatings in a BVM, it was important to perform another cost analysis of the coatings for these studies. In this chapter, a cost analysis was performed for Conditioning Media and ProNectin-F for two BVM studies and a protocol was developed using similar analysis steps from the 6-well plate experiments. PLGA was chosen as the scaffold material for the coating experiments because PLGA is currently the more common scaffold utilized for BVMs in the laboratory, and it can be electrospun in the laboratory, resulting in more availability, lower costs and no dependency on ePTFE suppliers [76].

\subsection{Cost Analysis for Coatings in the BVM System}

After the 6-well plate experiments, it was concluded that Conditioning Media and Pronectin-F were more efficient than HUVEC media in encouraging endothelial cell adhesion to a synthetic surface. Therefore, these pre-coatings were chosen to be utilized in the BVM system to determine which coating is more efficient in increasing endothelial cell adhesion in a BVM. As previously stated, one of the benefits of utilizing the BVM as an in vitro testing platform is that it is cost efficient when compared to in vivo testing. Hence, the cost of the coatings must be considered when determining which is the best coating for the BVM system. A summary of the analysis can be found in Table 8 and will be explained below.

\subsubsection{Cost Analysis of ProNectin-F in BVM Setups}

As stated in Section 2.1.1, ProNectin-F is $\$ 114.50$ for $1 \mathrm{mg}$ that is diluted in $1 \mathrm{~mL}$ of the diluting solution. A total of $450 \mu \mathrm{L}$ of ProNectin-F diluted in $45 \mathrm{~mL}$ of HUVEC media is required 
for the BVM setup (35mL for the media reservoir and $10 \mathrm{~mL}$ for priming the scaffold). The calculations for the cost of using ProNectin-F as a pre-coating in the BVM system are as follows:

$$
\begin{gathered}
\frac{1.0 \mathrm{E}-3 \text { Lper bottle ProNectin-F }}{450 \mathrm{E}-6 \mathrm{~L} \text { per set up }}=2.22 \text { BVM setups for } \$ 114.50 \\
(\$ 122 \text { per bottle of HUVEC Media })((0.18))=\$ 21.96 \\
\$ 21.96+\$ 114.50=\$ 166.46 \text { for } 2 \text { BVM setups } \\
\frac{\$ 166.46}{2}=\$ 83.23 \text { per BVM setup }
\end{gathered}
$$

\subsubsection{Cost Analysis of Conditioning Media in BVM Setups}

As stated in Section 2.1.2, the cost to make one 500mL bottle of Conditioning Media is \$28.91. A total of $45 \mathrm{~mL}$ is required for the BVM setup $(35 \mathrm{~mL}$ for the media reservoir and $10 \mathrm{~mL}$ for priming the scaffold). The calculations for the cost of using Conditioning Media as a precoating in the BVM system are as follows:

$(\$ 28.91$ per bottle of Conditioning Media $)(0.09)=\$ 2.60$ per BVM setup

Table 3: Summary of the cost-analysis for Pro-Nectin F and Conditioning Media for a BVM setup

\begin{tabular}{|l|l|l|}
\hline \multicolumn{1}{|c|}{ Coating } & \multicolumn{1}{c|}{$\begin{array}{c}\text { Volume Required for 1 } \\
\text { BVM Setup }\end{array}$} & Cost per Setup \\
\hline $\begin{array}{l}\text { ProNectin-F diluted in } \\
\text { HUVEC media }\end{array}$ & $45 \mathrm{~mL}$ & $\$ 83.23$ \\
\hline Conditioning Media & $45 \mathrm{~mL}$ & $\$ 2.60$ \\
\hline
\end{tabular}

Again, it is obvious that Conditioning Media is the most cost-efficient pre-coating for the BVM system. However, as previously stated, the coatings effectiveness in increasing endothelial cell adhesion in the BVM is also a crucial property of the coating. Therefore, to determine which coating was more suitable for the BVM system, a protocol had to be developed such that the 
efficiency of Conditioning Media and ProNectin-F in increasing cell adhesion in a BVM could be compared to one another.

\subsection{Protocol Development for Analysis of Pre-Coatings in a BVM}

Like the 6-well plate protocol development stages, a protocol had to be developed to compare the effects of different pre-coatings on endothelial cell adhesion in a BVM. In literature, pre-coatings were evaluated in TEVGs by comparing \% adhered and \% non-adhered values for each coating $[44,52,54]$. Therefore, an attempt was made to develop a protocol to quantify these values in the BVM setup. During the BVM protocol development stages, only Conditioning Media was used as a pre-coating due to the high cost of ProNectin-F. The full protocol used for this setup can be found in Appendix B.1.

\subsubsection{Methods}

\subsubsection{Cell Selection and Cell Culture}

The methods described in the 6-well plate experiments in Chapter 2 were utilized to select, and thaw P4 HUVECs (Section 2.2.1.2). The HUVECs were expanded to P6 and were used once the flasks were $80 \%$ confluent.

\subsubsection{Preparation of PLGA Scaffolds}

One 15 wt\% PLGA scaffold was electrospun by another student using previously developed methods. Two $4 \mathrm{~cm}$ sections were cut from the scaffold and sutured to luer lock fittings on each side with a silk suture. The scaffolds were then sterilized in $70 \% \mathrm{EtOH}$ for 30 minutes. After sterilization, each scaffold was syringe-rinsed with PBS followed by a syringe-prime with Conditioning Media. To accomplish this, the PBS and media were flushed through the lumen of the scaffold to remove the air. The luminal outlet was then closed and the PBS and media were forced out through the pores of the scaffold. Both of these rinsing processes were the repeated with Conditioning Media to prime the scaffolds. 


\subsubsection{Preparation of Bioreactors}

Bioreactor media and Conditioning Media were warmed to $37^{\circ} \mathrm{C}$ in a water bath. Using aseptic technique, bioreactor media was added to each bioreactor such that the scaffolds would be completely submerged when inserted. The media reservoirs were also filled with Conditioning Media (Figure 17). The rinsed and primed scaffolds were then inserted in to the bioreactors. The bioreactors with the scaffolds and media reservoirs filled with Conditioning Media were then placed in a large incubator and hooked up to a peristaltic pump (Figure 17).

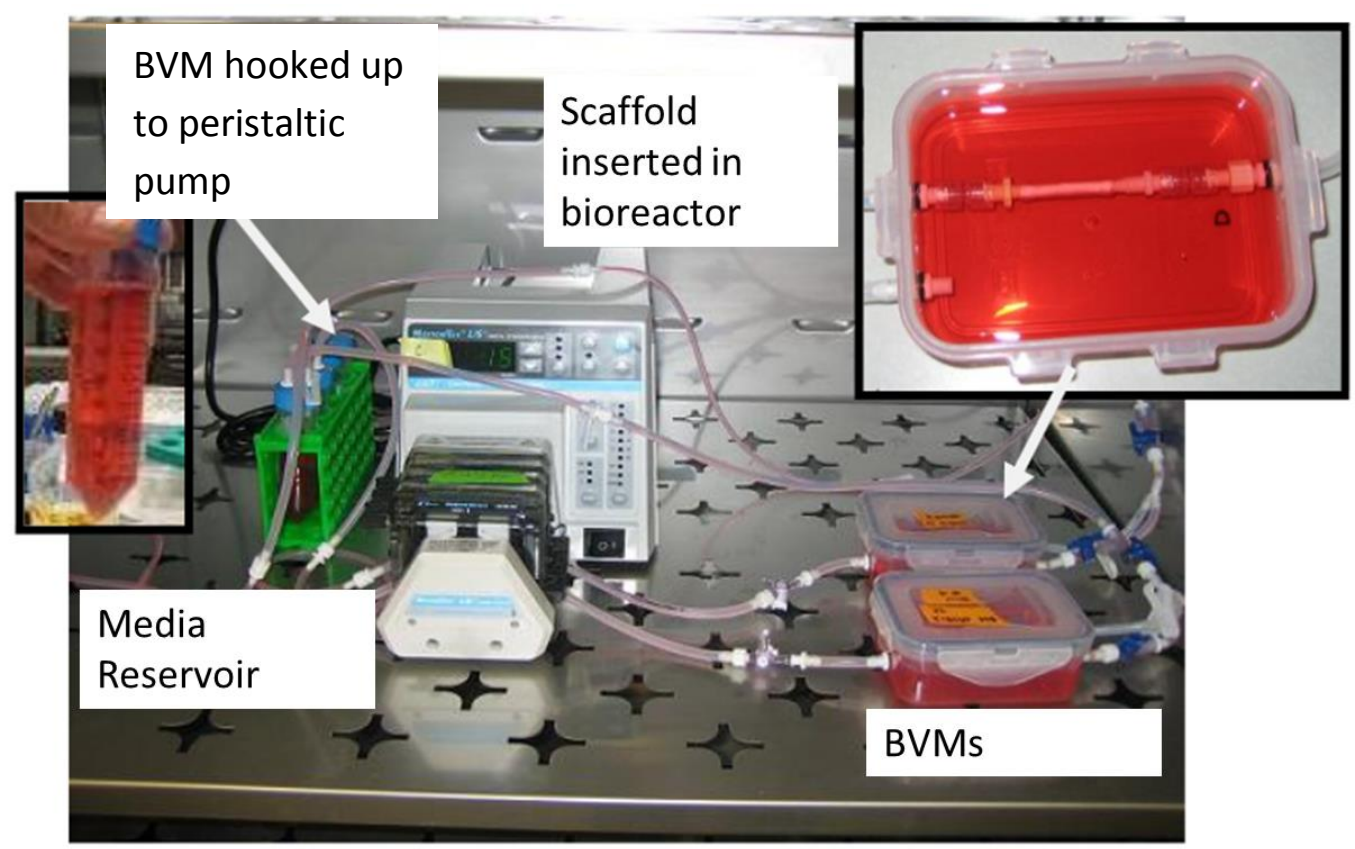

Figure 17: Illustration of PLGA scaffolds inserted in to the BVM. The BVM and media reservoirs were then hooked up to a peristaltic pump in a large incubator.

\subsubsection{Dynamic Conditioning}

Each bioreactor was primed using the peristaltic pump to remove all air from the systems. After priming, transluminal flow was restricted, forcing Conditioning Media through the pores of the scaffold at 150rpm. The dynamic conditioning of the scaffolds was continued for 20 minutes.

\subsubsection{Pressure Sodding of HUVECs}

At the end of the dynamic conditioning process, each bioreactor was removed from the incubator and placed back in the laminar flow hood for cell sodding. HUVECs were harvested from VWR $225 \mathrm{~mL}$ cell culture flasks with $1 \mathrm{X}$ trypsin and an initial cell count was obtained using 
the Bioscience Nexcelom Cellometer. The cells were centrifuged for 4 minutes and re-suspended in $6 \mathrm{~mL}$ of HUVEC media. The cell solution was moved into a trough and inserted in to the BVM via pressure sodding. Each scaffold was pressure sodded with approximately 3 million cells per scaffold using sterile techniques. Pressure sodding consists of restricting transluminal flow such that when cell solution is syringed in to the system, the cells are forced in to the wall of the scaffold, attaching to and covering the luminal surface. The cells were then chased with $3 \mathrm{~mL}$ of HUVEC media using the syringe. The bioreactors were placed back in to the large incubator and hooked up to the peristaltic pump. The pressure sodding was continued in the incubator for one hour at 10rpm transmural flow. The bioreactors were then incubated statically for one hour to allow for proper cell adhesion. The incubator was maintained at $37^{\circ} \mathrm{C}$ and $5 \% \mathrm{CO}_{2}$.

\subsubsection{Harvesting of Scaffolds and Non-Adhered Cells from Bioreactors}

Scaffold harvesting was conducted by removing each BVM from the large incubator. All valves were closed on the bioreactor and $15 \mathrm{ml} \mathrm{VWR} \mathrm{conical} \mathrm{tubes} \mathrm{were} \mathrm{labeled} \mathrm{appropriately}$ and filled with approximately 10-12 $\mathrm{ml}$ of histochoice fixative. Each HUVEC sodded PLGA scaffold was removed from the chamber and barb fittings using a surgical scalpel. Each scaffold was then transferred to one of the prepared histochoice filled tubes.

It was assumed that the cells that had not adhered to the luminal surface of the scaffolds would be found in the bioreactor media or media reservoirs. To quantify the number of nonadhered cells, the media from these locations was centrifuged for 4 minutes and re-suspended in 1 $\mathrm{mL}$ of HUVEC media. Samples from this volume were then submitted to the Nexcelom Cellometer to count the number of non-adhered cells.

\subsubsection{Fluorescent Microscopy}

To quantify the number of cells adhered to the luminal surface of the scaffold, a Bisbenzimide (BBI, Em $\lambda$ 460nm) stain was used (Appendix C.1). To maintain the integrity of this light sensitive stain, two $15 \mathrm{~mL}$ VWR conicals were wrapped in aluminum foil from base to cap to minimize light exposure. Ten $\mathrm{mL}$ of Mili-Q (non-sterile) was added to each conical tube. Ten $\mu \mathrm{L}$ 
of BBI was added to the Mili-Q in the covered tubes and shaken. The fixed scaffolds were then removed from the histochoice and cut longitudinally to expose the lumen for staining. Each half of the scaffolds was then placed in the covered conicals for a minimum of 20 minutes. Images of each scaffold were then obtained using an Olympus fluorescent microscope.

\subsubsection{Image Analysis}

The image analysis program ImageJ was utilized to quantify the number of cells adhered to the lumen of each scaffold. Four images of each scaffold half were obtained at 10X using the Olympus fluorescent microscope and camera system, resulting in eight images per scaffold. Using ImageJ, four equal sized boxes were placed throughout each image. Using the Cell Counter plug-in in ImageJ, the number of cells in each box was counted by manually clicking on each cell (Figure 18). The number of cells in the four boxes was averaged to obtain an average cell density in that image (Figure 19). This was repeated for all eight images for each scaffold. Those eight values were then averaged to obtain an average cell density per scaffold.

The counts obtained in ImageJ have a unit of cells/pixels ${ }^{2}$. To convert this density to cells $/ \mathrm{cm}^{2}$ a Ranchi Ruling was used. The final cell density of the scaffold was then multiplied by the surface area of the scaffold to obtain the number of adhered cells. 


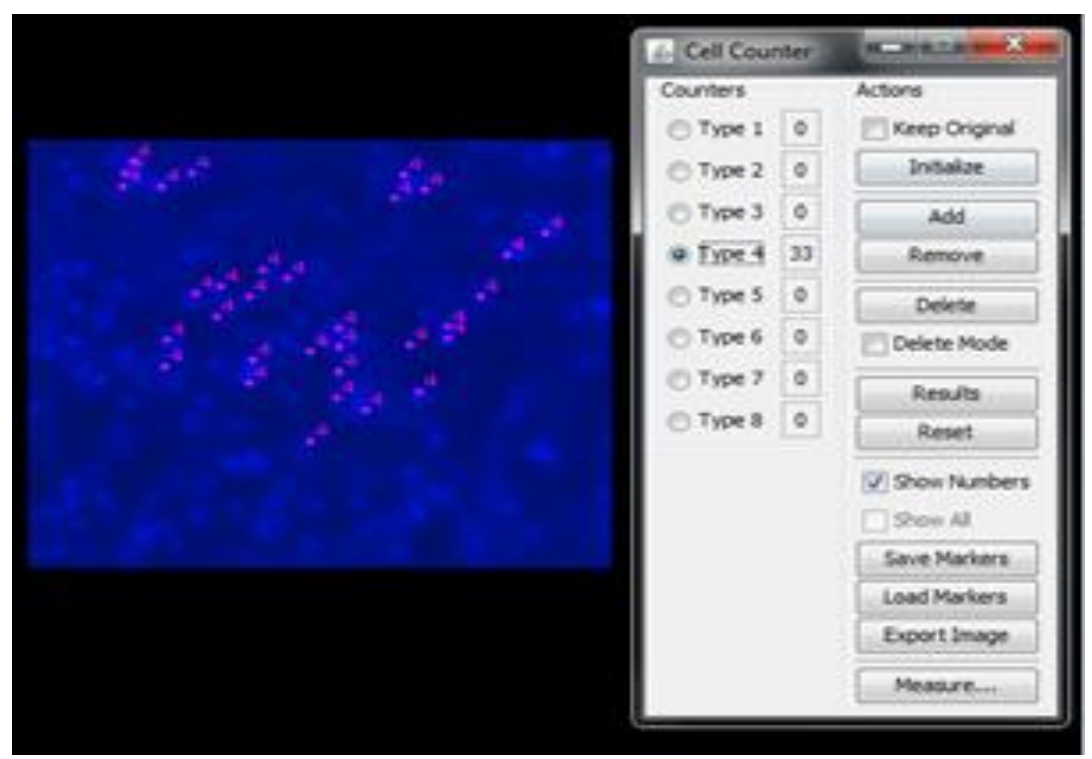

Figure 18: Illustration of the BBI image analysis using the Cell Counter in ImageJ. 4 boxes were drawn throughout the image and each cell was counted by manual clicking

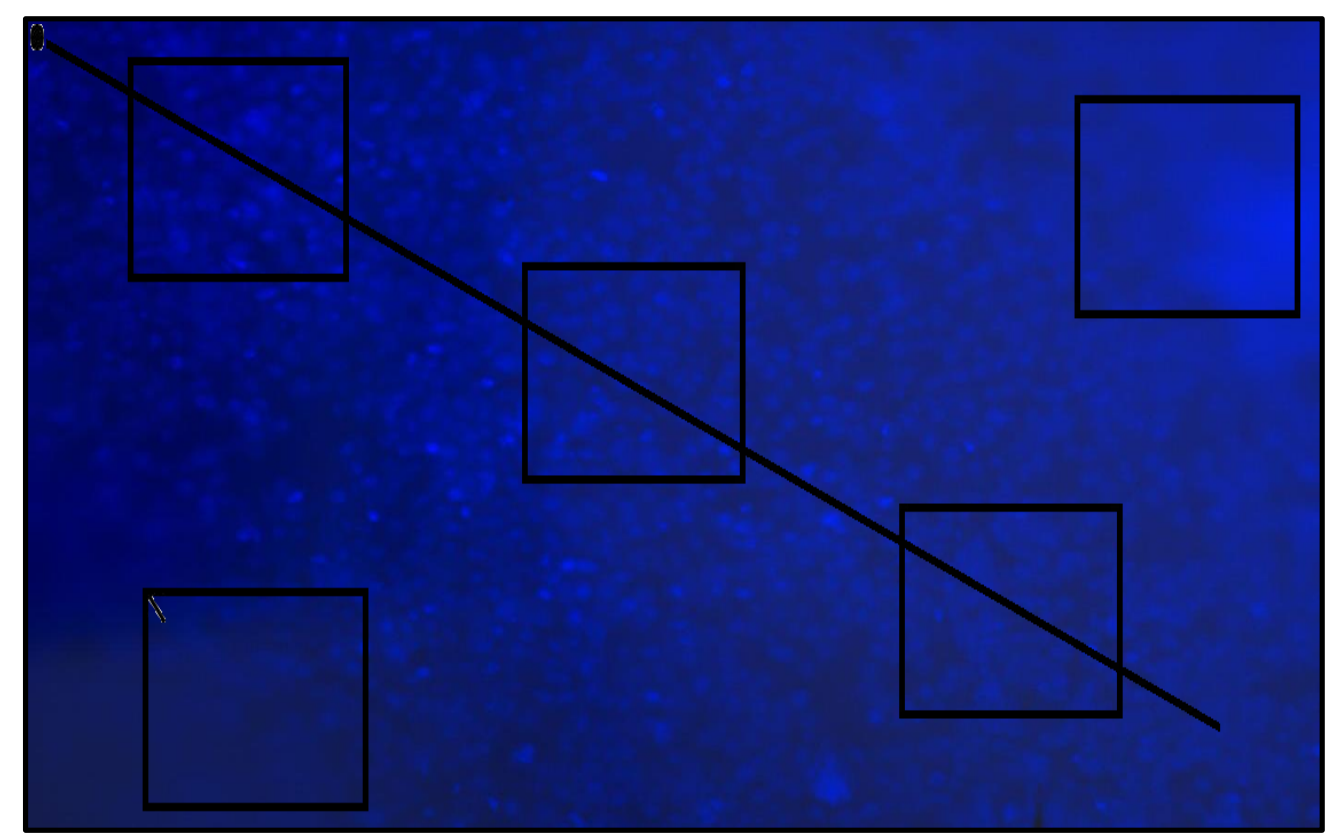

Figure 19: Illustration of image analysis technique. The four squares that had the most cells in focus were used to count cells for each image.

\subsubsection{Results}

As seen in Table 3, after one hour static incubation, only $10.68 \%$ of the applied cells were counted from the BBI images using ImageJ. However, combining this result with the number of non-adhered cells counted in the BVM media, only $17.50 \%$ of the applied cells were 
accounted for. Interestingly, the BBI images illustrated relatively well covered and confluent endothelial layers (Figure 20).

Table 4: Summary of number of adhered and non-adhered cells following 60 minute static BVM incubation

\begin{tabular}{|c|c|c|c|c|c|}
\hline & Scaffold A & $\begin{array}{c}\text { \% Initial } \\
\text { Cell } \\
\text { Count }\end{array}$ & Scaffold B & $\begin{array}{c}\text { \% Initial } \\
\text { Cell } \\
\text { Count }\end{array}$ & Average \\
\hline $\begin{array}{c}\text { Initial Cell } \\
\text { Count }\end{array}$ & $6.00 \mathrm{E}+06$ & $100 \%$ & $6.00 \mathrm{E}+06$ & $100 \%$ & $/$ \\
\hline $\begin{array}{c}\text { Total Cells } \\
\text { Counted on } \\
\text { Scaffold }\end{array}$ & $6.79 \mathrm{E}+05$ & $11.33 \%$ & $6.01 \mathrm{E}+05$ & $10.03 \%$ & $\mathbf{1 0 . 6 8 \%}$ \\
\hline $\begin{array}{c}\text { Average } \\
\text { Counted Non- } \\
\text { Adhered Cells }\end{array}$ & $3.07 \mathrm{E}+05$ & $5.13 \%$ & $5.10 \mathrm{E}+05$ & $8.50 \%$ & $\mathbf{6 . 8 2 \%}$ \\
\hline $\begin{array}{c}\text { Total Cells in } \\
\text { BMV System }\end{array}$ & $9.86 \mathrm{E}+05$ & $16.46 \%$ & $1.11 \mathrm{E}+06$ & $18.53 \%$ & $\mathbf{1 7 . 5 0 \%}$ \\
\hline
\end{tabular}

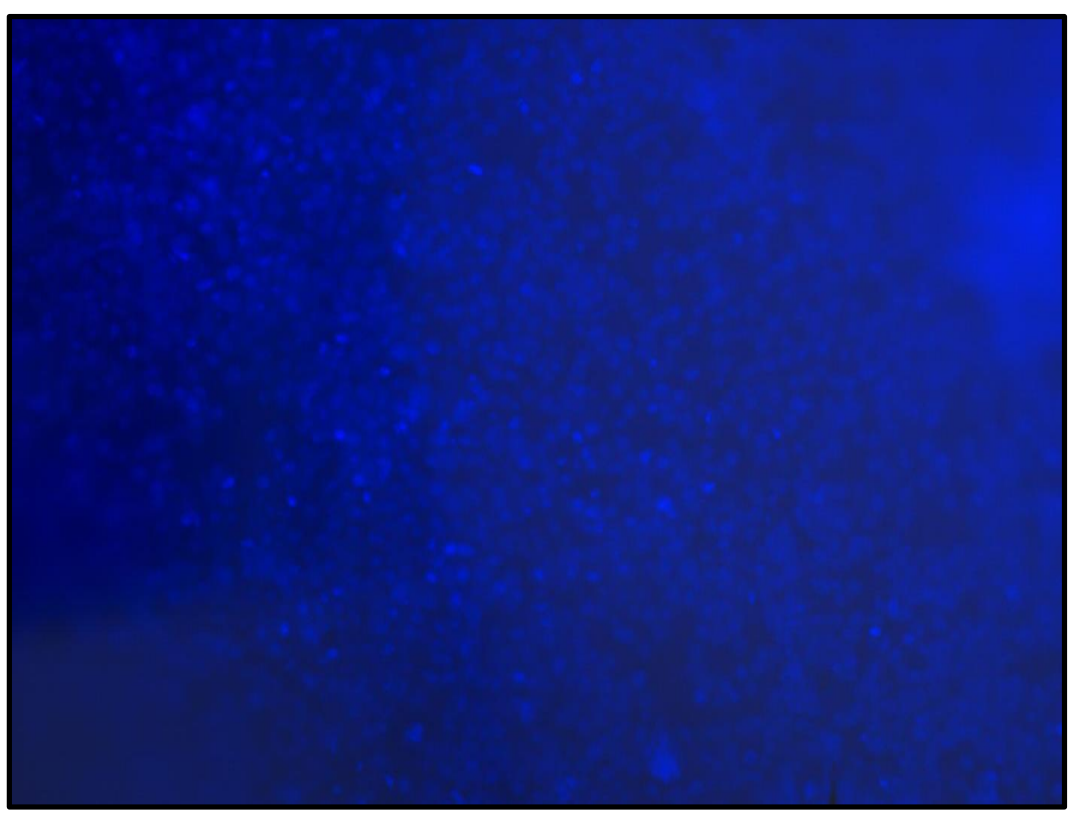

Figure 20: Representative BBI image of PLGA scaffold with HUVECs after 60 minutes of static incubation

\subsubsection{Discussion}

The results of this experiment indicated that the majority of the cells that were harvested from the cell culture flasks were not in the BVM system. As stated in the methods, once the 
HUVECs are harvested from the cell culture flasks they come in contact with a $50 \mathrm{~mL}$ centrifuge tube, a trough and a syringe. Therefore, it was hypothesized that cells may be remaining in these locations and are not added to the BVM, contributing to the low percentages that are observed. Another hypothesis to explain the lack of cells counted during analysis was that the pressure sodding process was pushing cells far in to the pores of the scaffold and hence, were not visible during en face imaging and image analysis.

\subsection{Investigation of BVM Cell Harvest and Cell Sodding Efficiency}

In attempt to explain the low number of cells accounted for after BBI image analysis and Nexcelom Cellometer non-adhered cell counts, an experiment was designed to investigate the possible locations where the cells could be lost. These locations included the centrifuge tube used to pellet the cells, the trough used to hold the cell solution before sodding, the syringe used to add the cells to the BVM and lastly, the pores of the scaffold. A study was designed to include one BVM setup in which all possible locations were analyzed to determine if all the cells could be accounted for. The full protocol for this setup can be found in Appendix B.2.

\subsubsection{Methods}

\subsubsection{Cell Selection and Cell Culture}

The methods described in the 6-well plate experiments in Chapter 2 were utilized to select, and thaw one vial of P4 HUVECs (Section 2.2.1.2). The HUVECs were expanded to P6 and were used once the flask was $80 \%$ confluent.

\subsubsection{Preparation of PLGA Scaffolds}

One $15 \mathrm{wt} \%$ PLGA scaffold was electrospun by another student using previously developed methods. One $4 \mathrm{~cm}$ section was cut from the scaffold and sutured to luer lock fittings on each side with a silk suture. The scaffold was sterilized in $70 \% \mathrm{EtOH}$, rinsed and primed as described previously (Section 4.2.1.2). 


\subsubsection{Preparation of Bioreactors and Dynamic Conditioning}

The bioreactor was prepared and the scaffolds were conditioned and coated using the same methods as the previous section (Section 4.2.1.3-4.2.1.4).

\subsubsection{Pressure Sodding of HUVECs and Quantifying Lost Cells}

At the end of the dynamic conditioning process, the bioreactor was removed from the incubator and placed back in the hood for cell sodding. HUVECs were harvested from VWR $225 \mathrm{~mL}$ cell culture flasks with $1 \mathrm{X}$ trypsin. The cells were centrifuged for 4 minutes and resuspended in $6 \mathrm{~mL}$ of HUVEC media. After the cell solution was transferred to a trough, $1 \mathrm{~mL}$ of trypsin was added to the $50 \mathrm{~mL}$ centrifuge tube to detach any remaining cells. The trypsin was deactivated with $2 \mathrm{~mL}$ of HUVEC media and samples from this solution were submitted to the Nexcelom Cellometer for cell counts. After the cell solution was syringed in to the BVM via pressure sodding, $1 \mathrm{~mL}$ of trypsin was added to the trough and syringe. After deactivation with HUVEC media, samples from these solutions were also submitted to the Nexcelom Cellometer for cell counts. Once the cells were sodded on the scaffold, the bioreactor was placed back in to the large incubator and hooked up to the peristaltic pump. The pressure sodding was continued in the incubator for one hour at 10rpm transmural flow. The bioreactor was then incubated statically for one hour to allow for proper cell adhesion. The incubator was maintained at $37^{\circ} \mathrm{C}$ and $5 \%$ $\mathrm{CO}_{2}$.

\subsubsection{Harvesting of Scaffolds and Non-Adhered Cells from Bioreactors}

The scaffold was harvested and fixed in histochoice using the previously described methods. The non-adhered cells were also obtained and counted as previously described (Section 4.2.1.6).

\subsubsection{Fluorescent Microscopy}

As before, to quantify the number of cells adhered to the luminal surface of the scaffold, a BBI stain was used (Section 4.2.1.7). One cross section was cut from the scaffold to determine 
if cells were being forced in to the pores. The remaining scaffold was cut longitudinally to image the lumen and obtain adhered cell counts.

\subsubsection{Image Analysis}

The same image analysis procedure described previously was used to quantify the number of cells adhered to the lumen of the scaffold (Section 4.2.1.8).

\subsubsection{Results}

As seen in Table 4, the percentage of the initial cell count that was accounted for after non-adhered cell counts and image analysis was $21.54 \%$. This percentage was similar to the percentage found in Section 4.2, suggesting that the lack of cells accounted for was not due to experimenter error. However, the total percentage of cells found on surfaces throughout the BVM setup was only $10.4 \%$. This plus the number of cells quantified after image analysis and nonadhered cells counts $(21.54 \%)$ resulted in a total of $32 \%$ of the cells being accounted for. The BBI images of BVM cross-sections did not indicate that cells were being forced through the pores of the scaffold (Figure 21). Finally, the en face BBI images of the scaffold indicated a well-covered lumen similar to the scaffolds imaged in Section 4.3 (Figure 22).

Table 5: Summary of results obtained from Nexcelom Cellometer non-adhered cells counts and ImageJ adhered cell counts

\begin{tabular}{|l|r|r|}
\hline Initial Cell Count & $6.46 \mathrm{E}+06$ & \\
\hline Adhered Cells on Scaffold & $8.13 \mathrm{E}+05$ & $\mathbf{1 2 . 6 0 \%}$ \\
\hline Non-Adhered Counted Cells & $5.77 \mathrm{E}+05$ & $\mathbf{8 . 9 4 \%}$ \\
\hline Total Cells in BVM & $\mathbf{1 . 3 9 E 0 6}$ & $\mathbf{2 1 . 5 4 \%}$ \\
\hline
\end{tabular}

Table 6: Summary of the number of cells found on surfaces throughout the BVM setup

\begin{tabular}{|l|l|}
\hline Location & Number of Cells \\
\hline Trough & $4.26 \mathrm{E}+05$ \\
\hline Syringe & $1.03 \mathrm{E}+05$ \\
\hline $50 \mathrm{~mL}$ Conical & $1.46 \mathrm{E}+05$ \\
\hline Total & $\mathbf{6 . 7 5 E}+\mathbf{0 5}(\mathbf{1 0 . 4 \%})$ \\
\hline
\end{tabular}




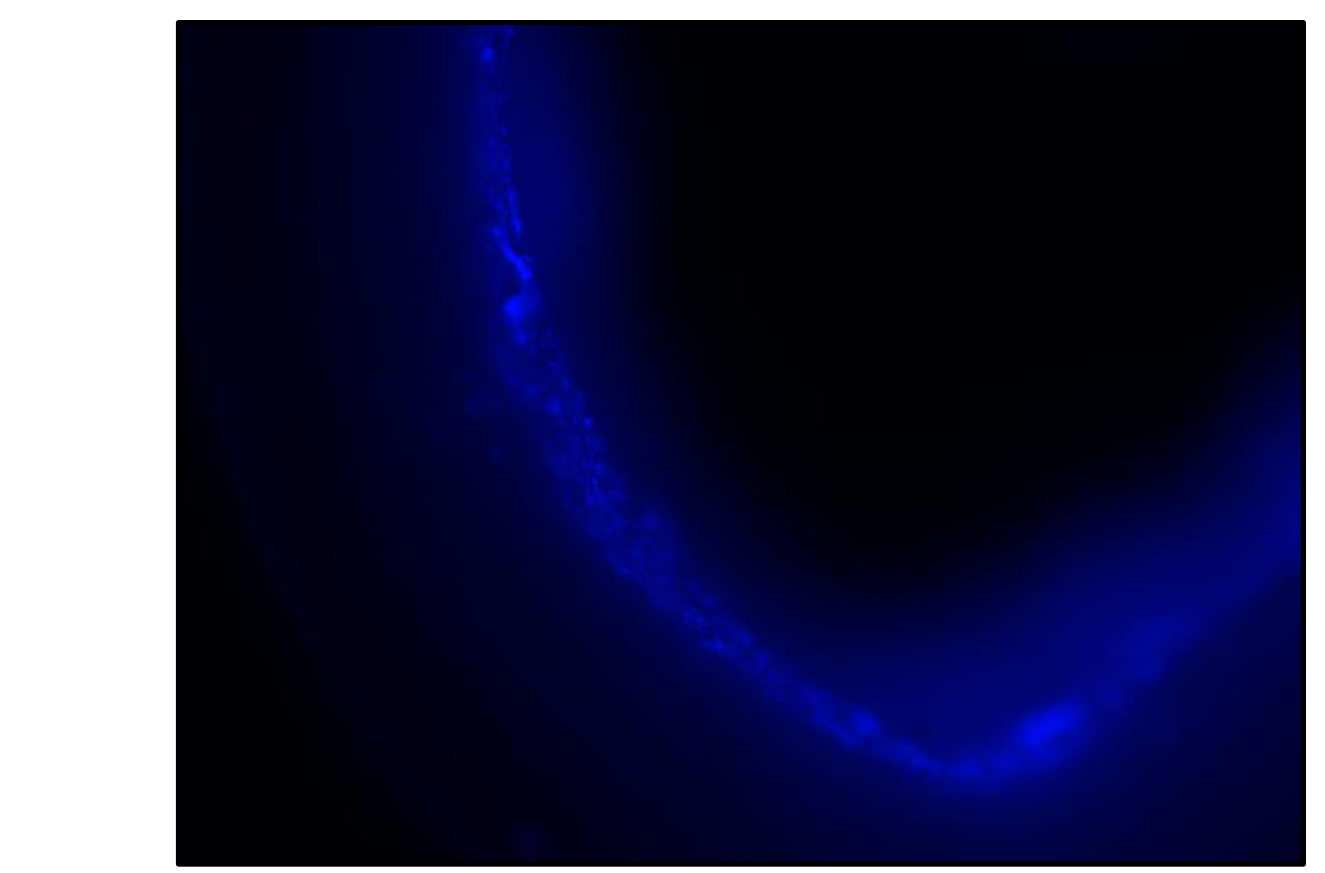

Figure 21: Representative BBI image of PLGA scaffold cross-section. Image was taken at 4x.

\section{Figure 22: Representative en face BBI image of BVM. Image was taken at 4x.}

\subsubsection{Discussion}

The goal of this study was to determine if the number of unaccounted cells observed in

Section 4.2 could be found in the $50 \mathrm{~mL}$ centrifuge tube used to pellet the cells, the trough used to hold the cells during sodding, the syringe used to transfer the cells in to the BVM, or in the pores 
of the scaffold. As seen in Tables 4 and 5, only one third of the initial cell count was accounted for after including these locations in the analysis. While the locations analyzed in this study did not contain all the unaccounted cells, the information obtained was still valuable. As seen in Table 5, there were a substantial number of cells found in each location, indicating a potential area of inefficiency in the BVM protocol. Therefore, it is important to keep these results in mind during a BVM setup to reduce the number of cells lost during these stages of the protocol and maximize the number of cells sodded on to the scaffold.

After further imaging and analysis, it was determined that the curved shape of the scaffolds resulted in an incomplete field of focus. Therefore, because not all of the cells are in focus in the images, they cannot be counted during image analysis. This conclusion helps to reconcile the differences observed between the confluent en face BBI images and the low number of cells accounted for. It was then hypothesized that the methods used to quantify the number of adhered cells (BBI staining and image analysis) would be sufficient to detect a difference in the number of cells adhered to scaffolds coated with different pre-coatings, even if all of the cells were not accounted for. Although the unaccounted for cells could provide an area of investigation for a separate project, it was determined to be outside the scope of this project. Because the aim of this thesis is to compare the coatings, only the relative number of cells adhered was important for analysis. To determine if this method was sufficient, a proof-of-concept study was developed in which this method of analysis was used to compare the number of cells adhered to a coated versus non-coated BVM.

\subsection{Proof of Concept Study: Protocol Verification for BVM Coating Comparison Studies}

In the previous study it was concluded that the analysis of en face BBI images was sufficient to determine which coating was more effective in increasing endothelial cell adhesion in a BVM. One of the aims of this thesis was the determine which coating was most effective in increasing 
cell adhesion, therefore, accounting for all the cells added to the BVM system was not as important as determining the relative number of cells adhered to coated scaffolds. To confirm that only using cell counts of the BBI images in ImageJ was adequate to determine a difference in the number of cells adhered to a scaffold, a small proof-of-concept study was designed. The goal of this study was to compare the number of endothelial cells adhered to a BVM pre-coated with Conditioning Media to a non-coated BVM using cell counts of BBI images in ImageJ. Because the goal of this study was to determine if this analysis technique for BVM coating comparison studies was appropriate, ProNectin-F was not used as a coating due to its high cost. The full protocol for this setup can be found in Appendix B.3.

\subsubsection{Methods}

\subsubsection{Cell Selection and Cell Culture}

The same methods described in the 6-well plate experiments in Chapter 2 were utilized to select, and thaw P4 HUVECs (Section 2.2.1.2). The HUVECs were expanded to P7 and were used once the flasks were $80 \%$ confluent.

\subsubsection{Preparation of PLGA Scaffolds}

Three 15 wt\% PLGA scaffolds were electrospun by another student using previously developed methods. Six $4 \mathrm{~cm}$ sections were cut from the scaffolds and sutured to luer lock fittings on each side with a silk suture. The scaffolds were the sterilized in $70 \% \mathrm{EtOH}$ for 30 minutes. After sterilization, each scaffold was syringe-rinsed with PBS. The three scaffolds to be precoated with Conditioning Media were syringe-primed (Section 4.2.1.2) with Conditioning Media. The three scaffolds that were non-coated were flushed with only DCF-PBS.

\subsubsection{Preparation of Bioreactors}

Bioreactor media and Conditioning Media were warmed to $37^{\circ} \mathrm{C}$ in a water bath. Using aseptic technique, bioreactor media was added to each bioreactor that housed a coated scaffold. DCF-PBS was added to the bioreactors that housed non-coated scaffolds. The media reservoirs for the coated scaffolds were filled with Conditioning Media, while the reservoirs for non-coated 
scaffolds were filled with DCF-PBS. The rinsed and primed scaffolds were then inserted in to the bioreactors. The bioreactors with the scaffolds and media reservoirs were then placed in a large incubator and hooked up to a peristaltic pump

\subsubsection{Dynamic Conditioning}

Each bioreactor was primed using the peristaltic pump to remove all air from the systems. After priming, transluminal flow was restricted, forcing Conditioning Media or DCF-PBS through the pores of the scaffolds at 150rpm. The dynamic conditioning of the scaffolds was continued for 20 minutes.

\subsubsection{Pressure Sodding of HUVECs}

The same methods described in Section 4.2.1.5 were utilized to sod the HUVECs to each scaffold.

\subsubsection{Harvesting of Scaffolds}

After 60 minutes of static incubation, the same methods described in section 4.2.1.6 were utilized to harvest the coated and non-coated scaffolds from the bioreactors. No non-adhered cell counts were obtained during this study.

\subsubsection{Fluorescent Microscopy}

The same methods described in Section 4.2.1.7 were utilized to stain and image the scaffolds.

\subsubsection{Image Analysis}

The same methods described in Section 4.2.1.8 were utilized to analyze each en face BBI image of the six scaffolds.

\subsubsection{Statistical Analysis}

To determine if there was a significant difference in the number of cells adhered to a noncoated or coated scaffold, a student's t-test was used where $\alpha$ was equal to 0.05 . 


\subsubsection{Results}

After cell counts were performed in ImageJ for all six scaffolds, it was determined that there was significantly more cells adhered to the scaffolds coated with Conditioning Media compared to a non-coated scaffold after 60 minutes of static incubation (Figure 23). The BBI images also illustrated a more confluent layer of cells throughout the coated scaffolds compared to non-coated scaffolds (Figure 24).

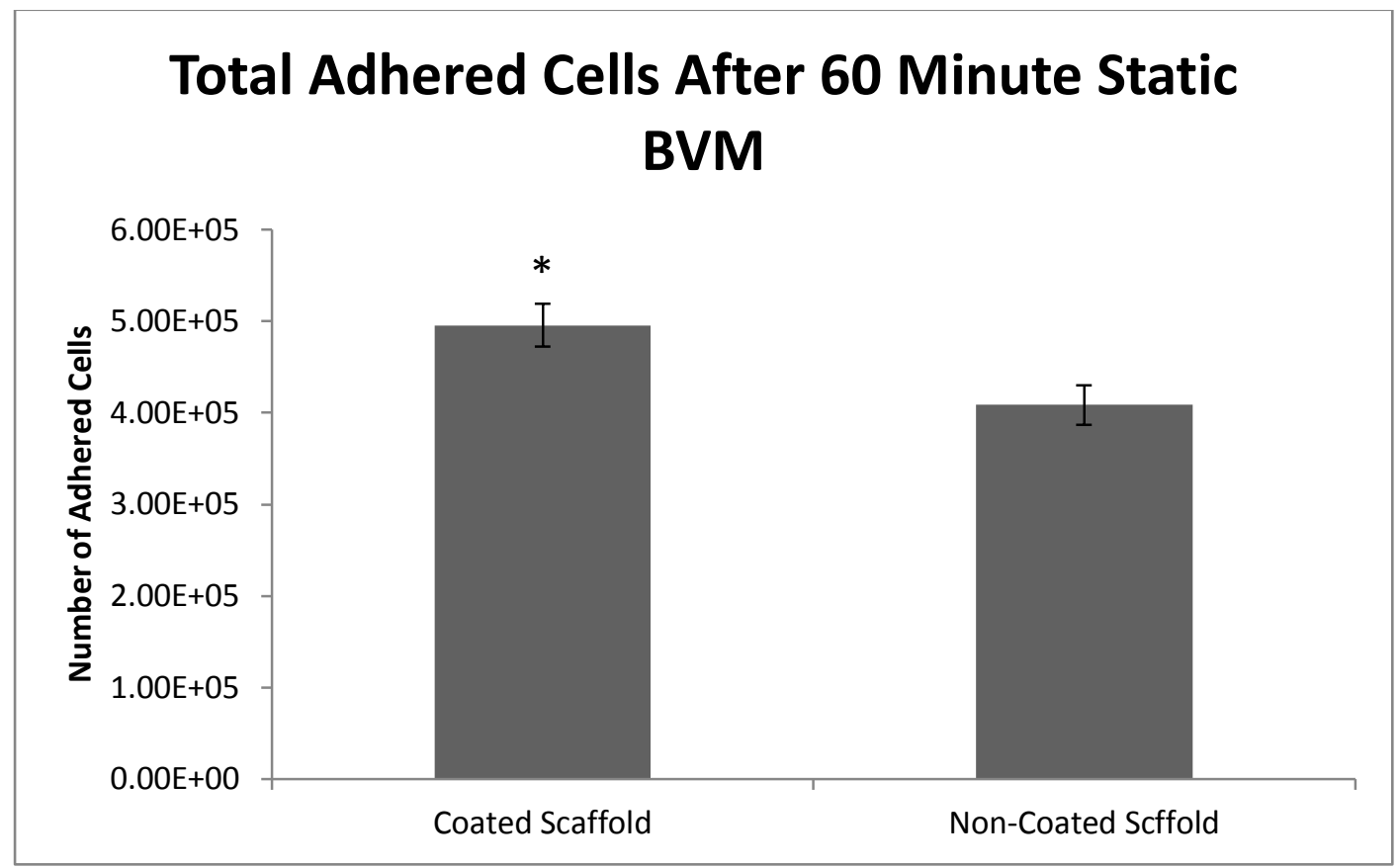

Figure 23: Number of counted cells adhered to coated and non-coated scaffolds from BBI images. $\mathrm{n}=3$. $* \mathrm{p}<0.05$ 

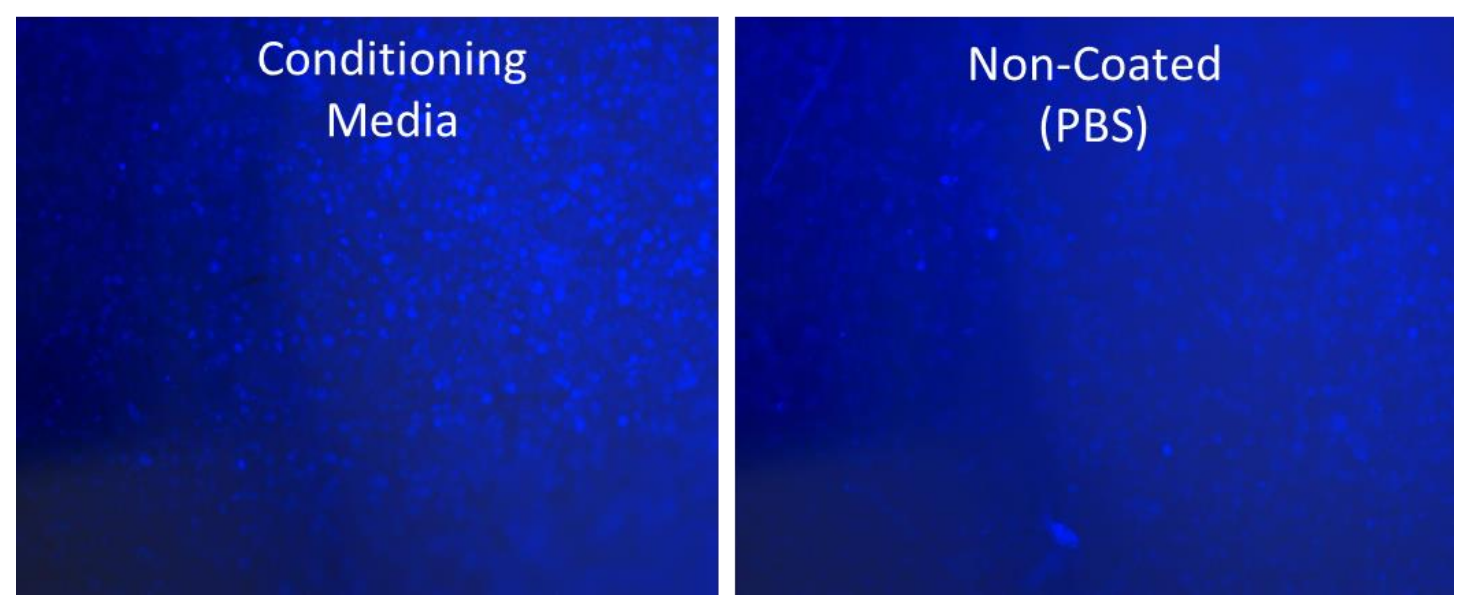

Figure 24: Representative images of Conditioning Media coated and non-coated scaffolds at 10x. The scaffolds coated with Conditioning Media had better cell coverage that scaffolds that were not pre-coated

\subsubsection{Discussion}

In order to successfully determine which pre-coating is the most effective in increasing endothelial cell adhesion in a BVM, a protocol had to be established to compare the coatings to one another. The results from this proof-of-concept study indicate that performing cell counts on BBI images in ImageJ was sufficient to detect a significant difference in the number of cells adhered between the coated and non-coated scaffolds. This method also allows for a qualitative form of analysis in which coating effectiveness can also be evaluated by the relative cell coverage, in addition to the cell counts. The results of this study indicate that the use of Conditioning Media, the pre-coating currently implemented in to the BVM, significantly increased the number of cells adhered to the scaffold. This result verifies the need for a precoating and the dynamic conditioning stages. However, as previously stated, one of the limitations of the current BVM system is the lack of cell attachment after flow exposure. This raises a few questions: Is the increase in cell adhesion due to the pre-coatings increasing the number of cells that adhere initially? Do the pre-coatings reduce the number of cells that are lost after the scaffolds are exposed to physiologic shear forces, or is it a combination of the two? With these questions in mind, two comparison studies were designed to determine the mechanism of 
action of the pre-coatings as well as to determine if Conditioning Media or ProNectin-F was the most effective coating in increasing cell adhesion when implemented in to the BVM system. 


\section{CHAPTER 5: BVM PRE-COATING COMPARISON STUDIES}

As previously stated, ProNectin-F was consistently found to be successful clinically in increasing endothelial cell adhesion in a TEVG $[52,54,59]$. In some of these studies, it was concluded that the cells were able to create a stronger attachment to the materials that were coated with ProNectin-F when compared to other materials because significantly less cells "washed off" the material once it was exposed to flow $[50,77]$. It was hypothesized that less cells detached following flow exposure because the cells had undergone receptor mediated cell adhesion and cytoskeletal remodeling [48, 77-79]. When the ECM peptides in ProNectin-F or Conditioning Media are adsorbed to the polymer surface, the cells bind specific amino acid sequences of these molecules via integrin receptors, initiating signaling cascades such as cells spreading, proliferation and differentiation [79] . As described in Chapter 1, when the interactions between the membrane integrins and ECM proteins do not occur, endothelial cells will undergo apoptosis [58]. Therefore, when adding endothelial cells to the scaffold of a BVM, it is important to ensure that receptor mediated adhesion occurs to both increase the number of cells adhered as well as activate the crucial pathways that are necessary for cell viability. When utilizing pre-coatings in a BVM, there are two potential stages in which they can play a role in increasing endothelial cell adhesion: increasing the number of cells that adhere initially, prior to flow exposure; or reducing the number of cells that are lost after the BVM is exposed to physiologic shear forces. Hence, two comparison studies were designed to determine which stage Conditioning Media and ProNectin-F act to increase cell adhesion, as well as to determine which coating was more effective in increasing overall cell adhesion in a BVM.

\subsection{Static BVM Coating Comparison Study}

As previously stated, there are two stages in the BVM setup in which Conditioning Media and ProNectin-F can act to increase endothelial cell adhesion. The first was increasing the number of cells that adhere to scaffold initially after pressure sodding and before fluid flow exposure. To determine if pre-coatings increased the number of cells adhered after pressure 
sodding, a comparison study was designed to quantify the number of endothelial cells adhered to a non-coated, Conditioning Media coated and ProNectin-F coated PLGA scaffolds after 60 minutes of static incubation. This study also served to determine what type of cell adhesion was occurring (receptor mediated/non-receptor mediated) and determine if the extent of cell spreading could be quantified. The full protocol for this setup can be found in Appendix B.4.

\subsubsection{Methods}

\subsubsection{Cell Selection and Cell Culture}

The same methods described in the 6-well plate experiments in Chapter 2 were utilized to select, and thaw P4 HUVECs (Section 2.2.1.2). The HUVECs were expanded to P8 and were used once the flasks were $80 \%$ confluent.

\subsubsection{Preparation of PLGA Scaffolds}

Three 15 wt\% PLGA scaffolds were electrospun by another student using previously developed methods. Nine $4 \mathrm{~cm}$ sections were cut from the scaffolds and sutured to luer lock fittings on each side with a silk suture. The scaffolds were then sterilized in $70 \% \mathrm{EtOH}$ for 30 minutes. After sterilization, each scaffold was syringe-rinsed with PBS. The three scaffolds to be pre-coated with Conditioning Media were syringe-primed (Section 4.2.1.2) with Conditioning Media. The three scaffolds that were non-coated were flushed with only PBS. The three scaffolds to be pre-coated with ProNectin-F were syringe primed with ProNectin-F diluted in HUVEC media.

\subsubsection{Preparation of Bioreactors}

Bioreactor media and Conditioning Media were warmed to $37^{\circ} \mathrm{C}$ in a water bath. Using aseptic technique, bioreactor media was added to each bioreactor that housed a coated scaffold. DCF-PBS was added to the bioreactors that housed non-coated scaffolds. The media reservoirs for the coated scaffolds were filled with Conditioning Media or ProNectin-F diluted in HUVEC media, while the reservoirs for non-coated scaffolds were filled with DCF-PBS. The rinsed and 
primed scaffolds were then inserted in to the bioreactors. The bioreactors with the scaffolds and media reservoirs were then placed in a large incubator and hooked up to a peristaltic pump.

\subsubsection{Dynamic Conditioning}

Each bioreactor was primed using the peristaltic pump to remove all air from the systems. After priming, transluminal flow was restricted, forcing Conditioning Media, ProNectin-F or DCF-PBS through the pores of the scaffolds at 150rpm. The dynamic conditioning of the scaffolds was continued for 20 minutes.

\subsubsection{Pressure Sodding of HUVECs}

The same methods described in Section 4.2.1.5 were utilized to sod the HUVECs to each scaffold.

\subsubsection{Static Incubation and Harvesting of Scaffolds}

After 60 minutes of static incubation, the same methods described in section 4.2.1.6 were utilized to harvest the coated and non-coated scaffolds from the bioreactors.

\subsubsection{Fluorescent Microscopy}

The same methods for a BBI stain described in Section 4.2.1.7 were utilized to quantify the number of endothelial cells adhered to each scaffold after 60 minutes of static incubation. To indirectly assess the type and strength of the cell adhesion, a rhodamine phalloidin (Em $\lambda 570$ nm) stain was used. The protocol for the rhodamine phalloidin stain can be found in Appendix C.2. Images of each scaffold were obtained using an Olympus fluorescent microscope.

\subsubsection{Image Analysis}

The same methods described in Section 4.2.1.8 were utilized to analyze each en face BBI image. ImageJ was also used to analyze the rhodamine phalloidin images to quantify cell spreading. The freehand selection tool was utilized to trace all cells in focus with clearly distinguishable borders (Figure 25). The measure function within ImageJ Analysis was then used to quantify the traced perimeter of the cell. The measured perimeters were then averaged to obtain an average cell perimeter for that image. This was repeated for the eight images representing each 
scaffold. These eight values were then averaged to obtain an average cell perimeter for each scaffold. Like the BBI image analysis, a Ranchi Ruling was used to convert the value from pixels to $\mu \mathrm{m}$.

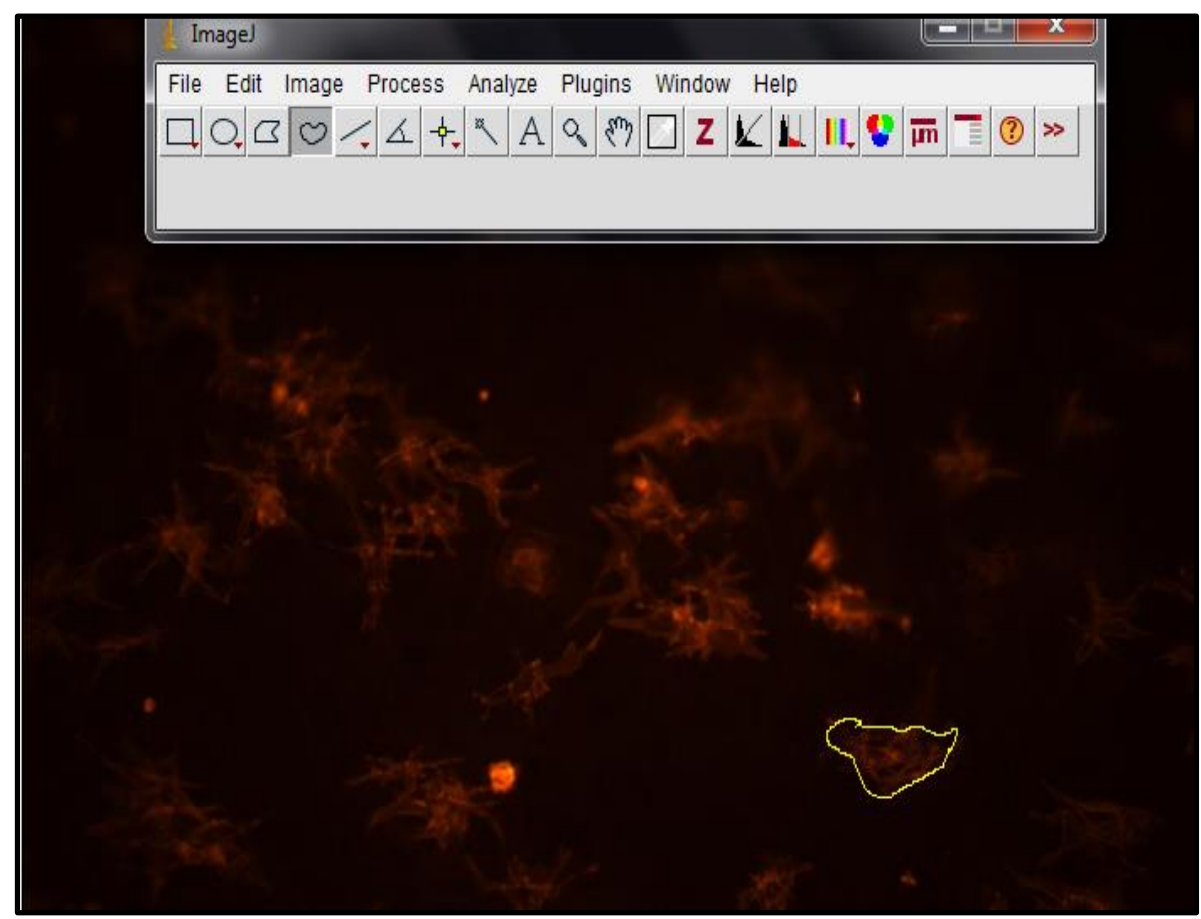

Figure 25: Illustration of rhodamine phalloidin image analysis using freehand tracing in ImageJ.

\subsubsection{Statistical Analysis}

To determine if there was a significant difference in the number of cells adhered to a noncoated or coated scaffold, ANOVA and students t-test was used where $\alpha$ was equal to 0.05 .

\subsubsection{Results}

As seen in Figure 26, after 60 minutes of static incubation, there were significantly more endothelial cells adhered to PLGA scaffolds coated with Conditioning Media and ProNectin-F compared to the non-coated control. However, there was not a significant difference in the number of endothelial cells adhere to PLGA scaffolds coated with Conditioning Media or ProNectin-F after 60 minutes of static incubation. As illustrated in Figure 27, the scaffolds that 
were pre-coated with Conditioning Media or ProNectin-F had a more confluent endothelial cell layer compared to the non-coated control.

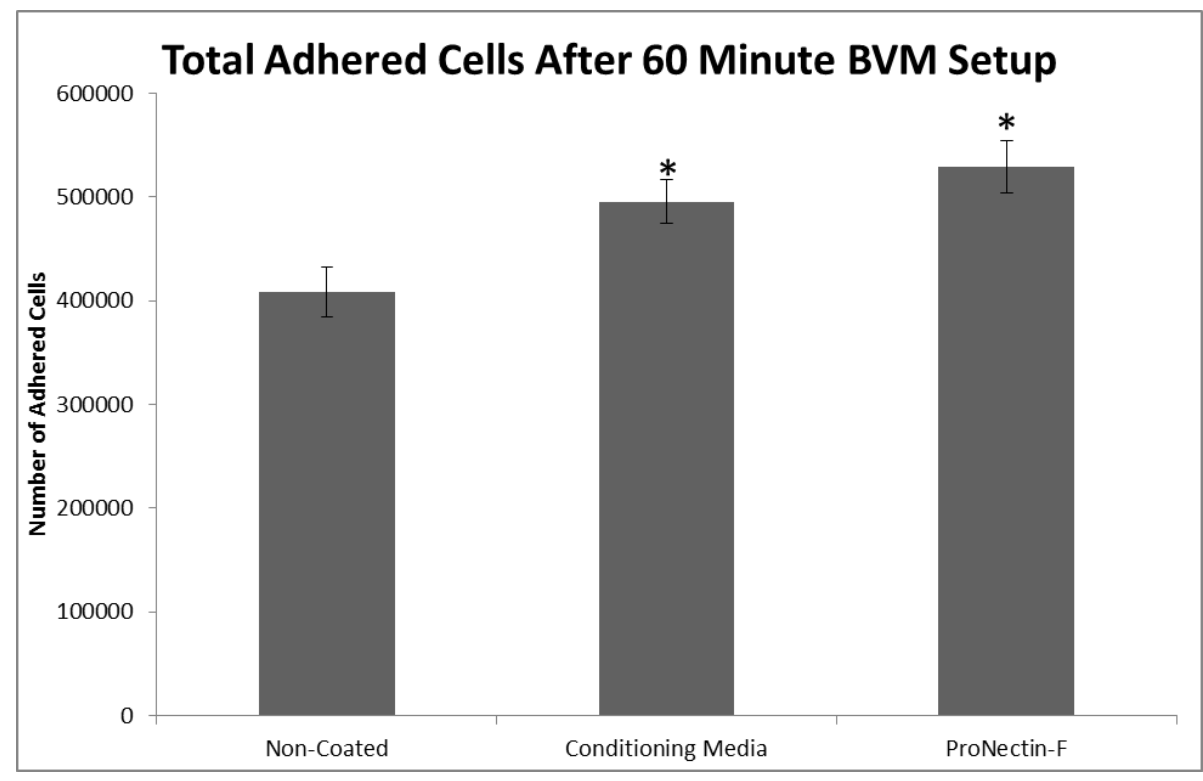

Figure 26: Number of endothelial cells adhered to scaffolds that were non-coated, coated with Conditioning Media or coated with ProNectin-F after 60 minutes of static incubation in a BVM. $n=3 . * p<0.05$ compared to non-coated
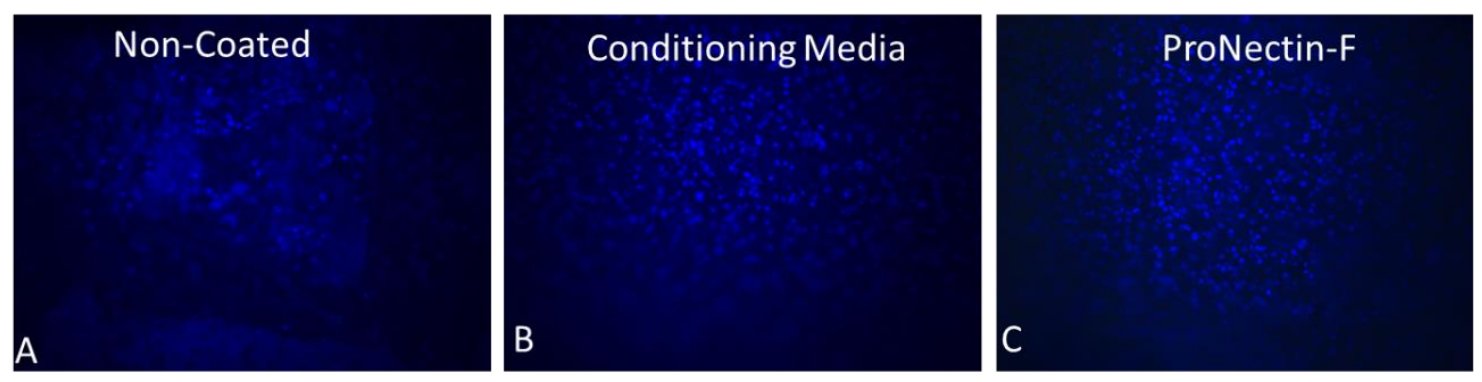

Figure 27: Representative BBI images of non-coated, Conditioning Media coated and ProNectin-F coated scaffolds after 60 minutes static incubation in a BVM.

As seen in Figure 28, the cells adhered to scaffolds coated with Conditioning Media or ProNectin-F had significantly larger cell perimeters compared to non-coated scaffold. In addition, it was found that cells adhered to scaffolds coated with ProNectin-F had significantly larger cell perimeters than cells adhered to scaffolds coated with Conditioning Media. These results were 
confirmed qualitatively. As seen in Figure 29, the cells adhered to coated scaffolds had undergone cell spreading and changed shape whereas the cells adhered to non-coated scaffolds did not.

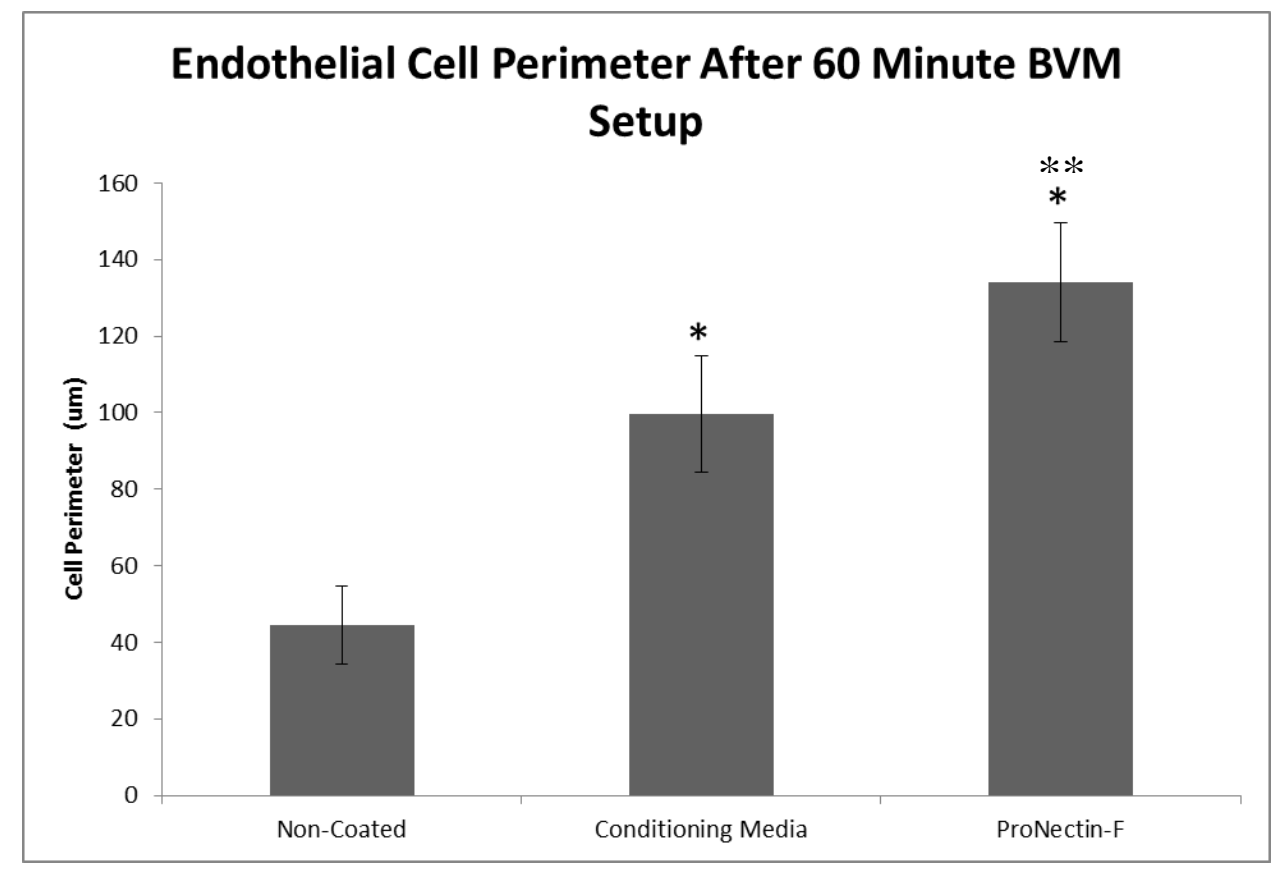

Figure 28: Endothelial cell perimeters of cells adhered to non-coated, Conditioning Media coated and ProNectin-F coated scaffolds after 60 minutes of static incubation in a BVM. $n=3$. $* p<0.05$ compared to non-coated scaffolds. $* * p<0.05$ compared to Condition
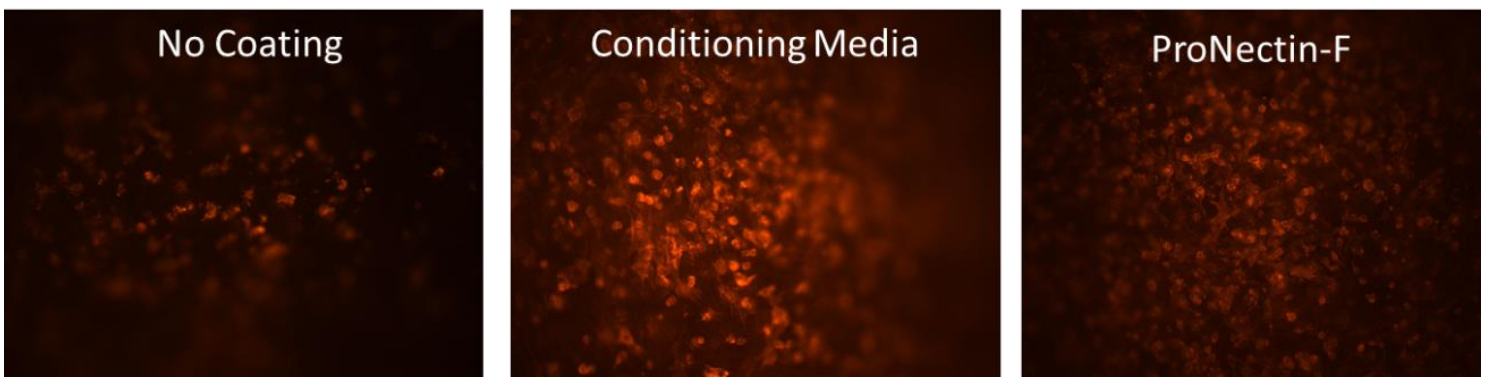

Figure 29: Representative rhodamine phalloidin images of non-coated, Conditioning Media coated and ProNectin-F coated scaffolds after 60 minutes of static incubation in a BVM

\subsubsection{Discussion}

As seen in the BBI images (Figure 27) and quantitative image analysis (Figure 26), precoating PLGA scaffolds with Conditioning Media and ProNectin-F resulted in significantly more 
cells adhered after 60 minutes of static incubation in a BVM. This indicates that the pre-coatings do play a role in increasing the initial number of cells that adhere to a PLGA scaffold after pressure sodding, which is consistent with the results from the proof of concept study. But as previously stated, there was not a significant difference in the number of cells adhered to scaffolds coated with Conditioning Media or ProNectin-F, indicating that Conditioning Media was just as effective as ProNectin-F in increasing the number of endothelial cells adhered after 60 minutes of static incubation. However, as seen in the rhodamine phalloidin images (Figure 29) and quantitative image analysis (Figure 28), the cells that adhered to scaffolds coated with ProNectin-F underwent more cell spreading, indicating a stronger attachment to the scaffold [58]. This was thought to have occurred in response to the multitude of proteins in Conditioning Media that are adsorbed to the scaffold surface. As previously stated, proteins that play a role in cell adhesion, such as fibronectin and laminin, make up a small percentage of serum [58,64]. Hence, there are fewer proteins for the integrins on the cell membranes to bind to and initiate cell spreading signaling cascades when Conditioning Media is used as a pre-coating. In comparison, ProNectin-F is made up of the RGD cell attachment epitope from fibronectin interspersed between structural peptides, resulting in more interactions between the cell membrane integrins and the adhesion peptides, initiating more cell spreading signaling cascades and creating a stronger cell attachment [80]. As previously stated, one of the current limitations of the BVM is the lack of cell adhesion after exposure to physiologic fluid flow. Therefore, the extensive cell spreading observed in ProNectin-F coated scaffolds may decrease the number of cells lost after fluid flow exposure.

\subsection{Dynamic BVM Comparison Study}

The second stage that pre-coatings can act to increase cell adhesion in a BVM is reducing the number of cells lost after flow exposure. To determine if Conditioning Media and ProNectin-F prevented cell loss after flow exposure, and if one coating was more efficient than the other in doing so, a second comparison study was designed. This comparison study sought to 
quantify and compare cell spreading and number of cells adhered to scaffolds that were coated with Conditioning Media, ProNectin-F and PBS (non-coated). The full protocol used for this setup can be found in Appendix B.5.

\subsubsection{Methods}

\subsubsection{Cell Selection and Cell Culture}

The same methods described in the 6-well plate experiments in Chapter 2 were utilized to select, and thaw P4 HUVECs (Section 2.2.1.2). The HUVECs were expanded to P8 and were used once the flasks were $80 \%$ confluent.

\subsubsection{Preparation of PLGA Scaffolds}

The same methods described in Section 5.1.1.2 were utilized to prepare the PLGA scaffolds for the dynamic comparison study.

\subsubsection{Preparation of Bioreactors}

The same methods described in Section 5.1.1.3 were utilized to prepare the PLGA scaffolds for the dynamic comparison study.

\subsubsection{Dynamic Conditioning}

The same methods described in Section 5.1.1.4 were utilized to condition and pre-coat the scaffolds in the dynamic comparison study.

\subsubsection{Pressure Sodding of HUVECs}

The same methods described in Section 4.2.5 were utilized to sod the HUVECs to each scaffold.

\subsubsection{Incubation, Flow Exposure and Harvesting of Scaffolds}

After 60 minutes of static incubation, the scaffolds were exposed to 10rpm of transluminal flow. After this, the transluminal flow was increased by $15 \mathrm{rpm}$ every hour until 90rpm was reached (took about 6 hours). After 60 minutes at 90rpm, the scaffolds were harvested from the bioreactors using the methods described in Section 4.1.6. 


\subsubsection{Fluorescent Microscopy}

The same methods described in Section 5.1.1.7 were utilized to stain and image the scaffolds for the dynamic comparison study.

\subsubsection{Image Analysis \\ Quantitative}

The same methods described in Section 5.2.1.8 were utilized to quantify cell spreading and the number of cells adhered to the scaffolds used in the dynamic comparison study.

\section{Qualitative}

After being exposed to fluid flow, the cells in the rhodamine phalloidin images had less distinct borders, making it more difficult to quantify cell spreading. Hence, to supplement the quantitative image analysis, two qualitative forms of analysis were utilized. The first of which was to count the number of traceable cells in each image. As previously stated, the cells traced in the rhodamine phalloidin images for quantitative images had to be in focus and have a defined border. Assuming that there was a positive correlation between cell coverage and number of traceable cells, this measure could supplement both the cell counts from the BBI images and the traces from the rhodamine phalloidin images. The second qualitative measure used was a scale of cell coverage. A 10 point scale was used for each image where a 10 was $100 \%$ of the image was covered cells and a 1 was $0-1 \%$ of the image was covered by cells (Figure 30).
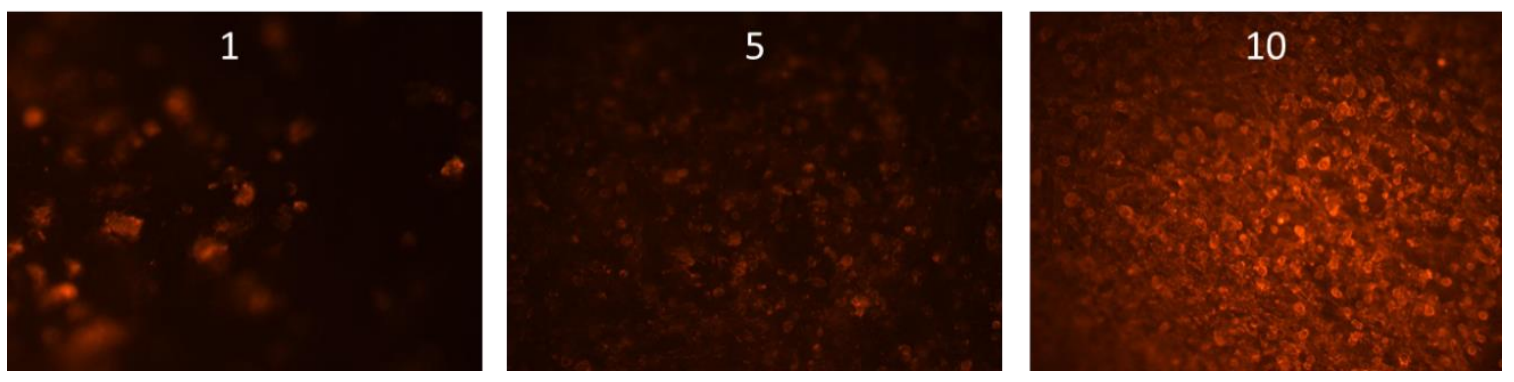

Figure 30: Rhodamine phalloidin images representing a 1, 5 and 10 on the qualitative cell coverage scale

\subsubsection{Statistical Analysis}


To determine if there was a significant difference in the number of cells adhered to a noncoated or coated scaffold, ANOVA and students t-test was used where $\alpha$ was equal to 0.05 .

\subsubsection{Results}

As seen in Figures 31 and 32, there were significantly more cells adhered to scaffolds coated with Conditioning Media o ProNectin-F than non-coated scaffolds after 60 minutes of transluminal flow at $90 \mathrm{rpm}$. There was not a significant difference in the number of cells adhered to Conditioning Media versus ProNectin-F coated scaffolds. After quantitative analysis of the rhodamine phalloidin images, it was found that the cells adhered to Conditioning Media and ProNectin-F coated scaffolds had significantly larger traced perimeters when compared to the non-coated control scaffolds (Figures 33,34). The supplemental qualitative rhodamine phalloidin image analysis resulted in more cells traced and higher coverage scores for Conditioning Media and ProNectin-F images compared to non-coated images, while the number of cells traced and coverage scores for Conditioning Media and ProNectin-F images were very similar (Tables 6,7).

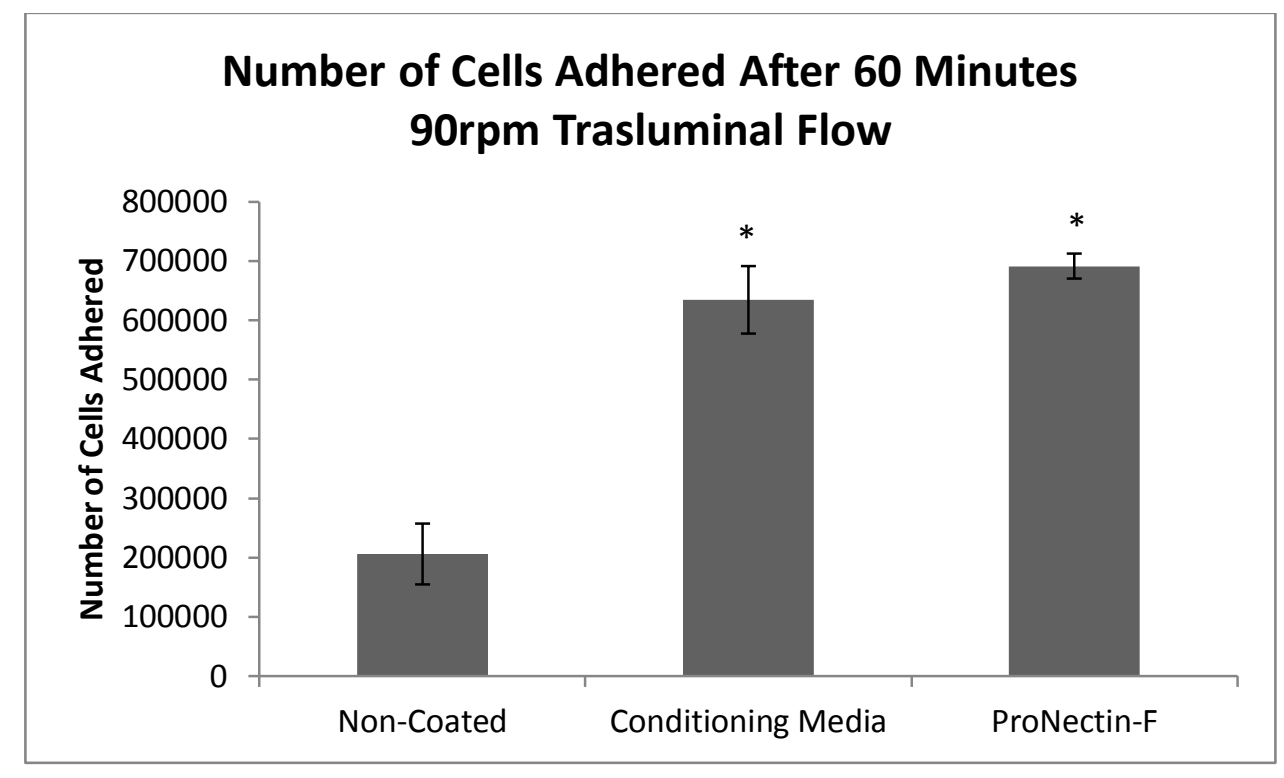

Figure 31: Results of BBI image analysis for cells adhered to non-coated, Conditioning Media coated and ProNectin-F coated scaffolds after 60 minutes of transluminal flow at 
90rpm. $\mathrm{n}=3 . * \mathrm{p}<0.05$ compared to non-coated control
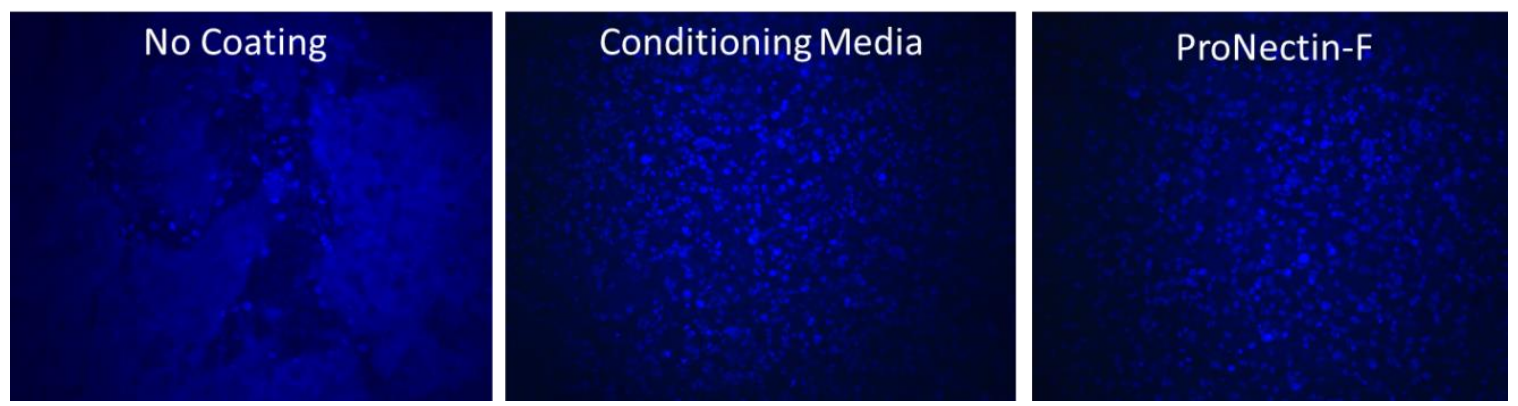

Figure 32: Representative BBI images of non-coated, Conditioning Media coated and ProNectin-F coated scaffolds after 60 minutes of transluminal flow at 90 rpm

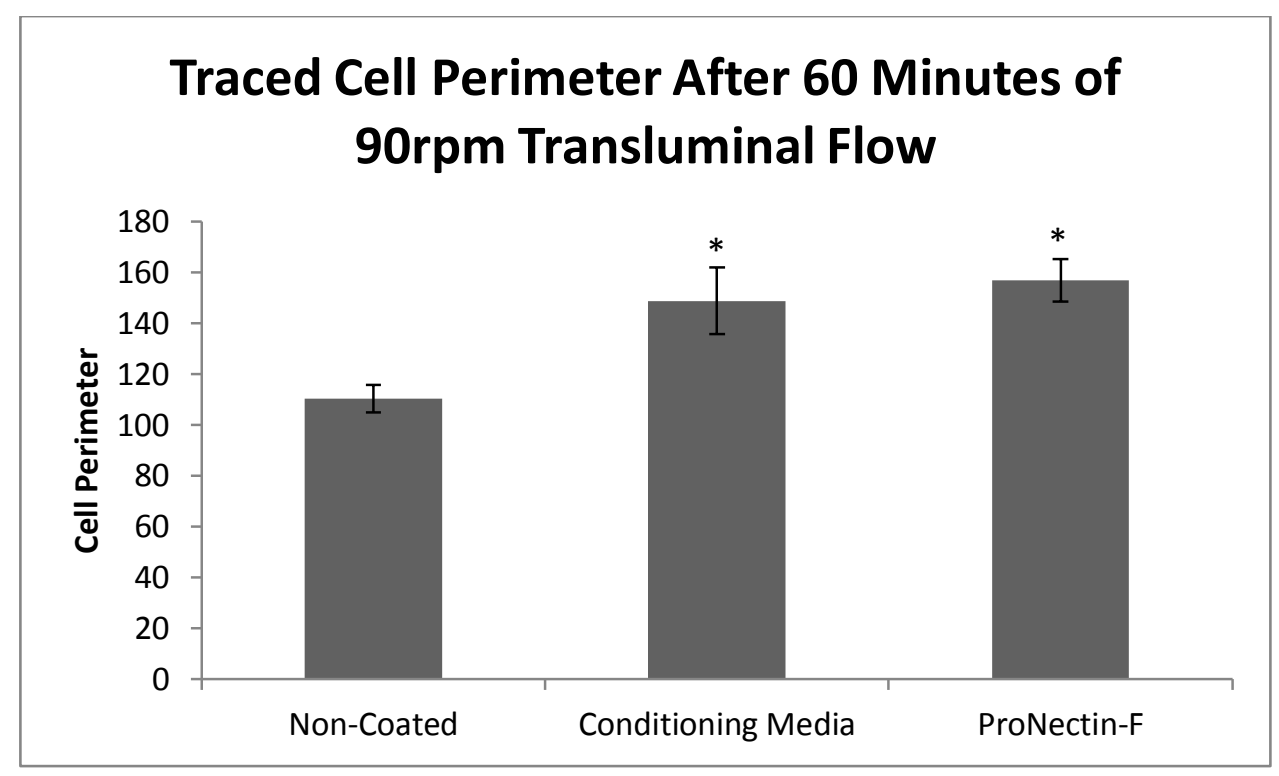

Figure 33: Results of traced cell perimeters from rhodamine phalloidin image analysis for non-coated, Conditioning Media coated and ProNectin-F coated scaffolds after 60 minutes of transluminal flow at $90 \mathrm{rpm} . \mathrm{n}=3 .{ }^{*} \mathbf{p}<0.05$ compared to non-coated control 

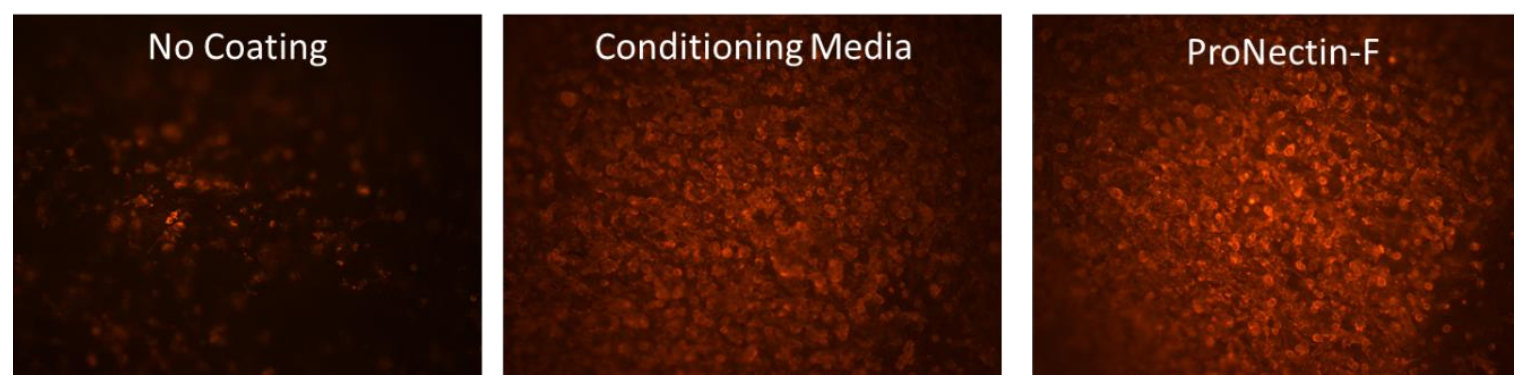

Figure 34: Representative rhodamine phalloidin images of non-coated Conditioning Media coated and ProNectin-F coated scaffolds after 60 minutes of trasnluminal flow at 90rpm

Table 7: Summary of the number of cells traced in rhodamine phalloidin images for noncoated, Conditioning Media and ProNectin-F rhodamine phalloidin images

\begin{tabular}{|c|c|c|}
\hline \multicolumn{3}{|c|}{ Number of Traces } \\
\hline Non-Coated & Conditioning Media & ProNectin-F \\
\hline 20.3 & 35.6 & 37.0 \\
\hline
\end{tabular}

Table 8: Summary of cell coverage scores of non-coated, Conditioning Media and ProNectin-F rhodamine phalloidin images

\begin{tabular}{|c|c|c|}
\hline \multicolumn{3}{|c|}{ Qualitative Coverage Score (1-10) } \\
\hline Non-Coated & Conditioning Media & ProNectin-F \\
\hline 2.7 & 7.3 & 7.6 \\
\hline
\end{tabular}

\subsubsection{Discussion}

The limitation of the BVM system that was studied for this thesis was the lack of cells adhered to PLGA scaffolds after exposure to fluid flow. This thesis sought to determine if utilizing a different pre-coating could overcome this limitation and increase the number of cells adhered as well as determine which coating was the most efficient in doing so. The results of the dynamic comparison study indicate Conditioning Media is as effective as ProNectin-F in retaining cell attachment after fluid flow exposure. It was concluded that the coatings encouraged receptor mediated cell adhesion because cell spreading and changes in cell shape were not observed on non-coated scaffolds. The cells adhered to non-coated scaffolds remained "balled 
up" indicating non-receptor mediated cell adhesion. The Conditioning Media and ProNectin-F rhodamine phalloidin images and qualitative image analysis also illustrate that the scaffolds were well covered after 60 minutes of transluminal flow exposure at 90rpm. These images also suggest a slight change in cell morphology in the direction of flow, while it was not extensively studied or quantified for this thesis.

In the static comparison study it was found that the cells adhered to ProNectin-F coated scaffolds were significantly more spread out than cells adhered to Conditioning Media coated scaffolds. Therefore, these results indicate that given more time (7 additional hours) and flow exposure, the cells adhered to Conditioning Media coated scaffolds were as spread out as cells adhered to ProNectin-F coated scaffolds. Hence, although the cell adhered to ProNectin-F coated scaffolds had larger perimeters after flow exposure, indicating a stronger attachment, the cells adhered to Conditioning Media coated scaffolds were able to undergo more cell spreading and remain attached after flow exposure.

\subsection{Discussion of BVM Pre-coating Experiments}

An interesting result of the comparison studies was the enhancement of cell spreading of the cells adhered to Conditioning Media coated scaffolds after exposure to flow conditions. It is possible that due to competitive protein adsorption and less interactions between cell membrane integrins and the ECM proteins on Conditioning Media coated scaffolds, that it takes more time for the change in cell shape and cell spreading to occur. Studies examining the dynamics and mechanics of endothelial cell spreading found that the rate and the extent of cell spreading increases with the density of the ligand substrate[81]. The exposure to shear stress may also play a role in the observed increase in cell spreading for Conditioning Media coated scaffolds. Studies that have compared the transcriptional profiles in endothelial cells exposed to prolonged laminar shear stress or turbulent flow compared to static controls found an upregulation in gene products involved in cytoskeletal remodeling, survival, and antioxidation [82]. These studies also found 
that in addition to the upregulation of various transcription factors, shear stress also activates integrins and increases their affinity for ECM proteins [82]. Compared to static controls, endothelial cells exposed to physiologic shear stresses had a significant increase in the number of integrin receptors and their reattachment to the ECM. Therefore, it is possible that although the cells adhered to Conditioning Media coated scaffolds are less spread out in static conditions, once they are exposed to transluminal flow these mechanisms are activated and the cells undergo more extensive cytoskeletal remodeling and form stronger attachments.

As previously stated, Conditioning Media is the pre-coating that is currently implemented in the BVM system for which low numbers of attached cells have been observed $[5,73,75]$. However, the results of this dynamic comparison study indicate a relatively well covered scaffold when Conditioning Media was used as a pre-coating. This difference can be attributed to a multitude of factors. In this dynamic comparison study, the dynamic conditioning stage was reduced from overnight to twenty minutes due to values repeatedly cited in literature $[50,52,54$, 59] . In these studies, optimum cell adhesion was found after 10-45 minutes of coating incubation $[50,52,54,59]$. Therefore, by utilizing a more optimal coating incubation period, the coatings may have been more effective than when they are allowed to incubate overnight. Also, the length of transluminal flow exposure was reduced from 3-7 days to 7 hours. While it is possible that a longer time point for flow exposure would result in a higher number of cells lost, many studies examining the effects of flow on endothelial cell retention to a TEVG found that the majority of cell loss usually occurred within the first 45 minutes to two hours once physiologic flow was reached and was insignificant after 24 hours [83, 84].

Finally, another factor that may contribute to the increased cell retention when Conditioning Media was used as a pre-coating is variation between researchers. The cell retention in a BVM may be influenced by the experience of the researcher (how many times they have set up a BVM), efficiency of the cell harvesting and sodding stages, and proper priming and 
conditioning. Because this thesis required a large number of BVM setups and specifically investigated the need to consider harvesting and sodding process efficiency, more successful setups may have been a result of these experiences.

In conclusion, the studies in this Chapter indicate that Conditioning Media is as efficient as ProNectin-F in increasing endothelial cell retention as well as encouraging receptor mediated cell adhesion and cell spreading after exposure to transluminal flow. As discussed in Section 4.1, the cost to use ProNectin-F as a pre-coating in the BVM system is 30 times the cost of implementing Conditioning Media. Therefore, because Conditioning Media is extremely cost efficient, as well as effective, it appears to be the most appropriate pre-coating to be implemented in to the BVM system. 


\section{CHAPTER 6: DISCUSSION AND CONCLUSIONS}

\subsection{Overview and Summary}

One in three adults is diagnosed with cardiovascular disease in the United States and it is currently the leading cause of death in developing countries [6]. These astounding statistics solidify the need for the development and use of effective therapies to treat cardiovascular disease and its symptoms. One of the most effective and widely used therapies to date is intravascular stents [1]. However, as previously stated, stent designs are constantly being modified to increase their effectiveness and prevent thrombotic events [2]. The evaluation of new stent designs and their functionality require bench, in vitro and in vivo testing [85]. Currently, bench testing provides a controlled environment to evaluate specific properties such as mechanical durability, fatigue and expansion [85]. In vitro testing consists of the initial evaluation of biocompatibility via methods such as cytotoxicity testing [85]. In vivo testing investigates the sensitivity, inflammatory response, and systemic effects of the device in a living organism [85]. All three phases of testing are required to complete an analysis of the safety and effectiveness of the device before it can be studied and implanted in humans. However, there is currently a large gap between in vitro and in vivo testing that if bridged, could create a more efficient testing process for medical devices. The BVM seeks to bridge this gap for intravascular devices by providing an in vitro model that represents a physiologic system that is both cost and time efficient. The development of the BVM will allow for a more thorough initial analysis of stents due to its ability to mimic key aspects of a native vessel in vitro.

Currently the BVM utilizes a PLGA scaffold, which has been shown to be biocompatible and support the attachment and proliferation of endothelial cells, essentially mimicking the intima of the native artery [86]. While PLGA is a proven scaffold material for tissue engineering, it has limitations that need to be overcome for it to be successful in the BVM system $[17,39,41,86]$. One of these limitations is that because it is a synthetic polymer scaffold, it is devoid of any 
biological components, which limits cell adhesion. Without a confluent endothelial cell layer throughout the lumen of the scaffold, the interactions observed between the device and the BVM will be difficult to assess. To address the limitation of the lack of endothelial cell adhesion to PLGA scaffolds in a BVM, Conditioning Media (serum enhanced media) has been utilized to precoat the scaffolds prior to adding cells. However, after exposure to flow conditions, the cells were not retained and a confluent endothelial layer was not achieved. To address the lack of cell adhesion in the current BVM system, different pre-coatings were evaluated and compared to one another to determine which was most efficient in increasing endothelial cell adhesion in a BVM.

The lack of cell adhesion after flow exposure is a limitation that is shared by Tissue Engineered Vascular Grafts [3, 37, 44, 55]. To overcome this limitation, the lumen of grafts has been pre-coated with various ECM proteins, improving endothelial cell adhesion and retention after flow exposure [50, 52-54]. Pre-coatings that have been utilized in previous studies include collagen, laminin, fibronectin, serum and the ECM in its entirety. Clinically, fibronectin is the peptide sequence that has been most successfully used for improving cellular attachment and retention [52-55, 77]. Giudiceandre et al. found that fibronectin significantly improved cellular attachment and retention as compared with uncoated grafts of ePTFE, Dacron and MyoLink [48]. Thompson et al. conducted a comparative study that found fibronectin significantly enhanced cellular attachment compared to collagen, gelatin, laminin, and albumin [87]. However, Hess et al. found that combinations of fibronectin and collagen, fibronectin and laminin, and fibronectin and ECM were superior in enhancing endothelial cell adhesion compared to fibronectin, laminin, and collagen alone [88]. Because fibronectin has been proven successful in increasing endothelial cell attachment to TEVGs, it was chosen to be evaluated for implementation in the BVM system.

To improve the endothelial cell attachment and retention in the BVM, this thesis characterized ProNectin-F (engineered fibronectin) and Conditioning Media (current BVM precoating) and compared their ability to increase endothelial cell attachment to 6-well plates and 
PLGA scaffolds in the BVM. The following discussion summarizes the work performed in this thesis.

The first step of this thesis was to characterize the effects of ProNectin-F and Conditioning Media in a more efficient and controlled setting using 6-well plates. To do this, a protocol was developed to quantify the number of endothelial cells adhered to a pre-coated well utilizing the Bioscience Nexcelom Cellometer. After four rounds of protocol development, the final protocol included a centrifugation and re-suspension stage, decreasing the cell suspension volume such that automated counts could be obtained for both adhered and non-adhered cells in pre-coated 6-well plates. This protocol was then utilized in 6-well plate incubation time studies and coating comparison studies.

Before evaluating the effectiveness of Conditioning Media and ProNectin-F in increasing endothelial cell adhesion in 6-well plates, the coating and incubation times were analyzed to determine their effects on cell adhesion. The results of these studies indicated that varying the amount of time that the coated surfaces are incubated prior to adding cells does not affect the number of cells that adhered to the coated surface. However, an increasing trend was observed for the number of cells that adhered to the coated surface as the cell incubation time increased. Hence, it was concluded that the time that the cells incubate on the coated surface played a more dominant role in increasing cell adhesion in 6-well plate experiments. Therefore, in the 6-well plate comparison studies a coating incubation time of twenty minutes was used while the cell incubation time was varied in attempt to optimize cell adhesion.

To gain initial insight and data concerning the effectiveness of Conditioning Media and ProNectin-F in increasing endothelial cell adhesion, a comparison study was designed to quantify the number of cells adhered to coated and non-coated wells after 60 and 90 minutes of incubation. After both 60 and 90 minutes of incubation, there were significantly more cells adhered to wells coated with Conditioning Media or ProNectin-F compared to non-coated wells. However, no 
significant difference was found in the number of cells adhered to Conditioning Media coated wells versus ProNectin-F coated wells at either time point. As previously stated, the 6-well plate experiments served as a controlled environment to gain initial insight into the effects of the precoatings on cell adhesion. These conditions did not represent that of a dynamic vessel in which factors such as vessel geometry and shear forces can effect cell attachment. Therefore, the precoatings were implemented in the BVM system to determine which was more effective in increasing adhesion and retaining endothelial cells.

One of the projected benefits of a fully endothelialized BVM is that it will help to create a more cost efficient approval testing process for intravascular devices. Therefore, if pre-coatings are to be implemented in to the BVM it is important that they are also relatively cost efficient. Hence, before implementing the ProNectin-F in to BVM setups, a cost analysis was performed to compare it to the current pre-coating, Conditioning Media. It was determined that implementing ProNectin-F in the BVM setup is 30 times more expensive than using Conditioning Media as a pre-coating ( $\$ 166.46$ vs. \$5.21). However, ProNectin-F was documented as a very successful precoating in increasing endothelial cell adhesion to polymer scaffolds of tissue engineered grafts $[53,54,77]$. Hence, both coatings were utilized in BVM setups for comparison studies to determine which coating was most effective in encouraging cell adhesion.

Utilizing a pre-coating in the BVM system potentially serves to both increase initial endothelial cell attachment as well as prevent cell loss once the BVM is exposed to flow conditions. Two comparison studies were designed to compare the effectiveness of ProNectin-F and Conditioning Media in performing both of these functions. A static comparison study was first conducted to determine which coating was more efficient in increasing the initial endothelial cell attachment to a PLGA scaffold prior to flow exposure. In addition to quantifying the number of cells adhered via BBI staining, the strength of the attachment was also quantified via rhodamine phalloidin staining. It was found that significantly more cells adhered to scaffolds coated with Conditioning Media or ProNectin-F, but there was not a significant difference in the 
number of cells adhered to Conditioning Media versus ProNectin-F coated scaffolds prior to flow exposure. As expected, because the pre-coatings encourage receptor-mediated cell adhesion, the cells adhered to coated scaffolds had significantly larger perimeters, indicating a stronger attachment. Interestingly, the cells adhered to ProNectin-F coated scaffolds had significantly larger perimeters than cells adhered to Conditioning Media coated scaffolds, suggesting a stronger attachment.

To determine if the cells were in fact making stronger attachments to coated scaffolds, a dynamic comparison study was conducted to determine which coating was more effective in reducing the number of cells lost after exposure to transluminal flow. After 60 minutes of transluminal flow at 90rpm, significantly more cells remained adhered to coated scaffolds when compared to non-coated scaffolds. Again, after analyzing the BBI images, there was not a significant difference in the number of cells that remained adhered to scaffolds pre-coated with Conditioning Media or ProNectin-F. However, after analyzing the rhodamine phalloidin images it was found that there was no longer a significant difference in the perimeter of cells adhered to Conditioning Media or ProNectin-F coated scaffolds. Therefore, the comparison studies combined indicated that Conditioning Media is as effective as ProNectin-F in increasing initial cell attachment and retaining cell attachment after flow exposure in the BVM.

\subsection{Challenges and Limitations}

There were some key limitations in implementing and comparing the effectiveness of pre-coatings in the BVM. One limitation was the inability to account for all of the cells added to the system through image analysis and non-adhered cell counts. While it was not necessary for the aims of this thesis, the inability to account for all the cells added made it difficult to compare the calculated cell densities to values found in literature for pre-coated vascular grafts (usually documented as $\%$ adhered). In addition to comparing cell densities to pre-coated TEVGs, it will also be important to be able to compare the cell density of the BVM to cell densities of native vessels. Being able to compare adhered cell densities is important because the ultimate goal of the 
BVM is to model a native endothelium in vitro. Therefore, in order to be considered an adequate testing platform for intravascular devices, values such as cell density should be comparable to documented in vivo values.

Another limitation of this study was the difficulty in clearly defining the cytoskeletons of individual cells during the analysis of the rhodamine phalloidin images. While about 30 cells per image had distinguishable borders, being able to trace all the cells in the rhodamine phalloidin images would increase the accuracy of the cell spreading analysis. The rhodamine phalloidin protocol had not been optimized for en face staining of PLGA scaffolds, which may have contributed to the lack of definition of the stained cytoskeleton.

\subsection{Future Work}

\subsubsection{Comparison Studies with Coating Combinations}

It was stated in literature that fibronectin was more efficient in increasing cell adhesion when combined with other ECM proteins such as collagen and laminin compared to fibronectin alone [52-54]. While ProNectin-F and Conditioning Media effectively increased cell attachment and retention to PLGA scaffolds when compared to non-coated scaffolds, a completely confluent monolayer throughout the scaffold was not observed. Therefore, a combination coating could be implemented to further improve cell attachment and retention in the BVM system. Another combination that can be considered is ProNectin-F and Conditioning Media. In the experiments for this thesis, ProNectin-F was diluted in HUVEC cell culture media. However, in future studies ProNectin-F could be diluted in Conditioning Media, possibly combining their effects while making ProNectin-F more cost-efficient.

\subsubsection{Utilizing the ECM as a Pre-Coating}

A multitude of proteins in the ECM play a role in cell adhesion [58]. Therefore, rather than using a single adhesion protein or a combination of two, the ECM in its entirety could be implemented in to the BVM system as a pre-coating to enhance cell attachment and retention. 
Aubrey Smith, a previous researcher in our lab, developed an ECM pre-coating of decellularized porcine vessels that were homogenized and dissolved such that it could be applied to scaffolds and other materials. In the future, this coating could be characterized and implemented in to the BVM system as a pre-coating to determine its effectiveness in increasing endothelial cell adhesion.

\subsubsection{Rhodamine phalloidin Stain and Imaging Protocol for PLGA}

The rhodamine phalloidin protocol provides a range of concentrations acceptable for staining cell cytoplasm. An optimal concentration should be determined for en face staining of PLGA scaffolds for a more consistent and defined stain. With the optimization of this protocol, more cells can be accurately traced in each image, resulting in a more complete quantitative analysis of cell spreading in the BVM. Also, imaging the scaffolds at a higher magnification could result in more clearly defined cell borders, enhancing the cell tracing capabilities during image analysis. Finally, there were challenges when a dual stain of rhodamine phalloidin and BBI was conducted. Therefore, during rhodamine phalloidin staining optimization, the simultaneous staining with BBI should also be included.

\subsubsection{Effects of Pre-Coatings on Gene Expression}

As discussed in previous sections, when endothelial cells are exposed to shear, integrin binding and activation activates multiple signaling cascades including the upregulation of genes required for cytoskeletal remodeling, and downregulating genes linked to proliferation and apoptosis. Multiple researchers in our lab are currently working to determine endothelial gene expression in the BVM. Therefore, these methods can be applied to determine how cell coatings and receptor-mediated cell adhesion affect gene expression within the BVM and how these expression profiles compare to the native vessel.

\subsubsection{Evaluating Receptor Mediated Cell Adhesion}

While the occurrence of cell spreading on coated scaffolds in the BVM indicated that receptor mediated cell adhesion could be occurring, it is important to confirm this with further 
studies. To verify that the observed cell spreading is the result of integrin-ECM protein interactions, a monoclonal antibody specific to ligand-occupied integrins could be used. Jalali et al. conducted a study to evaluate the interactions between endothelial cell integrins and ECM proteins during exposure to fluid flow [89]. A monoclonal antibody, HUST-21 was utilized to bind specifically to ligand occupied integins followed by the addition of FITC-conjugated goat anti-mouse IgG for fluorescent imaging [89]. This type of stain could be utilized in our BVM system to confirm the interaction between integrins and ECM proteins and that receptor mediated cell adhesion is occurring on coated scaffolds.

\subsubsection{Effects of Pre-Coatings on Smooth Muscle Cells}

To develop a physiologically relevant BVM, cellularizing the scaffold with two native cell types would more closely mimic the native artery. Smooth muscle cells could be sodded to the coated scaffold in combination with endothelial cells to create a more accurate in vitro testing platform. It would therefore be beneficial to determine the effects that Conditioning Media and ProNectin-F have on smooth muscle cell attachment in the BVM. This project is currently underway in our laboratory.

\subsection{Conclusions}

The potential of the BVM to be used for the pre-clinical evaluations of intravascular devices is great. However, before this model can be utilized for this purpose, further optimization of the BVM must be completed. A confluent endothelial lining in the lumen of the BVM scaffold is crucial for this model to be physiologically relevant. Pre-coatings have the ability to increase endothelial cell adhesion to synthetic polymers, such as PLGA, and retain attachment after flow exposure. This research provided extensive documentation of the comparison of Conditioning Media and ProNectin-F as pre-coatings in 6-well plates and the BVM. The results of these studies indicate that Conditioning Media is as effective as ProNectin-F in increasing endothelial cell attachment and retaining attachment after flow exposure. Conditioning Media is also extremely cost-efficient making it more appropriate for the BVM system. However, neither of these 
coatings achieved a $100 \%$ confluent layer, therefore additional coatings, combinations of coatings, or the ECM should be evaluated to continue to optimize cell adhesion and retention in the BVM. 


\section{LIST OF REFERENCES}

1. Waksman, R., Drug-eluting stents: From bench to bed. Cardiovascular Radiation Medicine, 2002. 3(3-4): p. 226-241.

2. Palmaz, J.C., Intravascular Stents: tissue-stent interactions and design considerations. American Journal of Roentgenology 1993. 160(3): p. 613-618.

3. Kristen O'Halloran Cardinal, G.T.B., Heidi Hofer, Jennifer Kehlet Barton, and Stuart K. Williams., Tissue-engineered vascular grafts as in vitro blood vessel mimics for the evaluation of endothelialization of intravascular devices Tissue Engineering, 2006. 12(12): p. 3431-3438.

4. Kristen O'Halloran Cardinal, S.K.W., Assessment of the intimal response to a proteinmodified stent in a tissue-engineered blood vessel mimic Tissue Engineering Part A, 2009. 15(12): p. 3869-3876.

5. Delagrammaticas, D.E., Development of an In-Vitro Tissue Engineered Blood Vessel Mimic Using Human Large Vessel Cell Sources. 2009.

6. Véronique L. Roger, M., MPH, FAHA; , et al., Executive Summary: Heart Disease and Stroke Statistics - 2011 Update. Circulation, 2011. 10(123): p. 459-463.

7. Thomas Thom; Nancy Haase; Wayne Rosamond, P.V.J.H., MSPH, FAHA; John Rumsfeld, MD, PhD, FAHA; Teri Manolio, MD, PhD, FAHA; Zhi-Jie Zheng, MD, PhD*; Katherine Flegal, PhD*; Christopher O'Donnell, MD, MPH, FAHA;Steven Kittner, MD; Donald LloydJones, MD; David C. Goff Jr, MD, PhD, FAHA; Yuling Hong, MD, MSC, PhD, FAHA; Robert Adams, MD; Gary Friday, MD, MPH; Karen Furie, MD, MPH; Philip Gorelick, MD, MPH; Brett Kissela, MD; John Marler, MD; James Meigs, MD; Veronique Roger, MD; Stephen Sidney, MD, MPH; Paul Sorlie, PhD; Julia Steinberger, MD, MSC; Sylvia WasserthielSmoller, PhD; Matthew Wilson, MD;Philip Wolf, MD, Heart Disease and Stroke Statistics-2006 Update. Circulation, 2006(105): p. 85-151.

8. MEMBERS, W.G., et al., Heart Disease and Stroke Statisticsâ€"2010 Update: A Report From the American Heart Association. Circulation. 121(7): p. e46-e215.

9. Brown, B.G., E.L. Bolson, and H.T. Dodge, Arteriographic assessment of coronary atherosclerosis. Review of current methods, their limitations, and clinical applications. Arteriosclerosis, Thrombosis, and Vascular Biology, 1982. 2(1): p. 2-15.

10. Naghavi, M., et al., From vulnerable plaque to vulnerable patient a call for new definitions and risk assessment strategies: part I. Circulation, 2003. 108(14): p. 16641672.

11. Smith, S.C., et al., AHA/ACC Guidelines for Secondary Prevention for Patients With Coronary and Other Atherosclerotic Vascular Disease: 2006 UpdateEndorsed by the National Heart, Lung, and Blood Institute. Journal of the American College of Cardiology, 2006. 47(10): p. 2130-2139.

12. Sterman, W.D., et al., Methods and systems for performing thoracoscopic coronary bypass and other procedures, 1998, Google Patents.

13. Yusuf, S., et al., Effect of coronary artery bypass graft surgery on survival: overview of 10-year results from randomised trials by the Coronary Artery Bypass Graft Surgery Trialists Collaboration. The Lancet, 1994. 344(8922): p. 563-570.

14. FitzGibbon, G.M., et al., Coronary bypass graft fate: long-term angiographic study. Journal of the American College of Cardiology, 1991. 17(5): p. 1075-1080.

15. Conte, M.S., The ideal small arterial substitute: a search for the Holy Grail? The FASEB journal, 1998. 12(1): p. 43-45. 
16. Berry, J.P. and D. Annis, Method of manufacturing synthetic vascular grafts, 1989, Google Patents.

17. Zdrahala, R.J., Small caliber vascular grafts. Part I: state of the art. Journal of biomaterials applications, 1996. 10(4): p. 309-329.

18. Salacinski, H.J., et al., The mechanical behavior of vascular grafts: a review. Journal of biomaterials applications, 2001. 15(3): p. 241-278.

19. Kannan, R.Y., et al., Current status of prosthetic bypass grafts: a review. Journal of Biomedical Materials Research Part B: Applied Biomaterials, 2005. 74(1): p. 570-581.

20. Chinn, J.A., et al., Blood and tissue compatibility of modified polyester: thrombosis, inflammation, and healing. Journal of biomedical materials research, 1998. 39(1): p. 130-140.

21. Pawlowski, K.J., et al., Endothelial cell seeding of polymeric vascular grafts. Front Biosci, 2004. 9: p. 1412-1421.

22. Serruys, P.W., et al., Comparison of coronary-artery bypass surgery and stenting for the treatment of multivessel disease. New England Journal of Medicine, 2001. 344(15): p. 1117-1124.

23. Demer, L.L., et al., Method and device for performing transluminal angioplasty, 1987, Google Patents.

24. Landzberg, B.R., W.H. Frishman, and K. Lerrick, Pathophysiology and pharmacological approaches for prevention of coronary artery restenosis following coronary artery balloon angioplasty and related procedures. Progress in cardiovascular diseases, 1997. 39(4): p. 361.

25. Faxon, D.P., et al., Restenosis following transluminal angioplasty in experimental atherosclerosis. Arteriosclerosis, Thrombosis, and Vascular Biology, 1984. 4(3): p. 189195.

26. Mehran, R., et al., Mechanisms and results of balloon angioplasty for the treatment of in-stent restenosis. The American journal of cardiology, 1996. 78(6): p. 618.

27. Jendersee, B. and R. Lashinski, Stent delivery and deployment method, 1998, Google Patents.

28. Serruys, P.W., et al., A comparison of balloon-expandable-stent implantation with balloon angioplasty in patients with coronary artery disease. New England Journal of Medicine, 1994. 331(8): p. 489-495.

29. Lowe, H.C., S.N. Oesterle, and L.M. Khachigian, Coronary in-stent restenosis: current status and future strategies. Journal of the American College of Cardiology, 2002. 39(2): p. 183-193.

30. Carrozza, J.P., et al., Restenosis after arterial injury caused by coronary stenting in patients with diabetes mellitus. Annals of internal medicine, 1993. 118(5): p. 344-349.

31. Cutlip, D.E., et al., Beyond Restenosis Five-Year Clinical Outcomes From SecondGeneration Coronary Stent Trials. Circulation, 2004. 110(10): p. 1226-1230.

32. Hansson, G.r.K., Inflammation, atherosclerosis, and coronary artery disease. New England Journal of Medicine, 2005. 352(16): p. 1685-1695.

33. lakovou, I., et al., Incidence, predictors, and outcome of thrombosis after successful implantation of drug-eluting stents. JAMA: the journal of the American Medical Association, 2005. 293(17): p. 2126-2130.

34. Leon, M.B., et al., A clinical trial comparing three antithrombotic-drug regimens after coronary-artery stenting. New England Journal of Medicine, 1998. 339(23): p. 16651671. 
35. Finn, A.V., et al., Vascular responses to drug eluting stents importance of delayed healing. Arteriosclerosis, Thrombosis, and Vascular Biology, 2007. 27(7): p. 1500-1510.

36. Nakazawa, G., et al., One Step Forward and Two Steps Back With Drug-ElutingStentsFrom Preventing Restenosis to Causing Late Thrombosis and Nouveau Atherosclerosis. JACC: Cardiovascular Imaging, 2009. 2(5): p. 625-628.

37. Mitchell, S.L. and L.E. Niklason, Requirements for growing tissue-engineered vascular grafts. Cardiovascular Pathology, 2003. 12(2): p. 59-64.

38. Williams, P.L., Gray\&s anatomy. Vol. 38. 1995: Churchill livingstone New York.

39. Teebken, O.E. and A. Haverich, Tissue engineering of small diameter vascular grafts. European journal of vascular and endovascular surgery, 2002. 23(6): p. 475-485.

40. Hoerstrup, S.P., et al., Tissue engineering of small caliber vascular grafts. European journal of cardio-thoracic surgery, 2001. 20(1): p. 164-169.

41. Ratcliffe, A., Tissue engineering of vascular grafts. Matrix Biology, 2000. 19(4): p. 353357.

42. Hibino, N., et al., Late-term results of tissue-engineered vascular grafts in humans. The Journal of thoracic and cardiovascular surgery. 139(2): p. 431-436. e2.

43. L'Heureux, N., et al., Technology insight: the evolution of tissue-engineered vascular graftsâ€"from research to clinical practice. Nature Clinical Practice Cardiovascular Medicine, 2007. 4(7): p. 389-395.

44. Heyligers, J., et al., Improving small-diameter vascular grafts: from the application of an endothelial cell lining to the construction of a tissue-engineered blood vessel. Annals of vascular surgery, 2005. 19(3): p. 448-456.

45. Seifalian, A.M., et al., Improving the clinical patency of prosthetic vascular and coronary bypass grafts: the role of seeding and tissue engineering. Artificial organs, 2002. 26(4): p. 307-320.

46. Alobaid, N., et al., Single stage cell seeding of small diameter prosthetic cardiovascular grafts. Clinical hemorheology and microcirculation, 2005. 33(3): p. 209-226.

47. Pullens, R.A., et al., Endothelialization of tissue engineered vascular grafts.

48. Salacinski, H., et al., Optimal endothelialisation of a new compliant poly (carbonateurea) urethane vascular graft with effect of physiological shear stress. European journal of vascular and endovascular surgery, 2000. 20(4): p. 342-352.

49. Yazdani, S.K., Bioreactor Preconditioning of Tissue Engineered Blood Vessels. 2008: ProQuest.

50. Krijgsman, B., et al., An assessment of covalent grafting of RGD peptides to the surface of a compliant poly (carbonate-urea) urethane vascular conduit versus conventional biological coatings: its role in enhancing cellular retention. Tissue Engineering, 2002. 8(4): p. 673-680.

51. Vara, D.S., et al., Cardiovascular tissue engineering: state of the art. Pathologie Biologie, 2005. 53(10): p. 599-612.

52. Salacinski, H., et al., Cellular engineering of vascular bypass grafts: role of chemical coatings for enhancing endothelial cell attachment. Medical and Biological Engineering and Computing, 2001. 39(6): p. 609-618.

53. Kesler, K.A., et al., Enhanced strength of endothelial attachment on polyester elastomer and polytetrafluoroethylene graft surfaces with fibronectin substrate. Journal of vascular surgery, 1986. 3(1): p. 58-64.

54. Vohra, R., et al., Fibronectin coating of expanded polytetrafluoroethylene (ePTFE) grafts and its role in endothelial seeding. Artificial organs, 1990. 14(1): p. 41-45. 
55. Walluscheck, K., et al., Improved endothelial cell attachment on ePTFE vascular grafts pretreated with synthetic RGD-containing peptides. European journal of vascular and endovascular surgery, 1996. 12(3): p. 321-330.

56. Bengtsson, L. and K. RÃ $¥$ degran, $A$ new and simple technique to achieve a confluent and flow resistant endothelium on vascular ePTFE-grafts using human serum. European Journal of Vascular Surgery, 1994. 8(2): p. 182-187.

57. HÂ: gerstrand, A., L. Bengtsson, and C. Gillis, Serum proteins provide a matrix for cultured endothelial cells on expanded polytetrafluoroethylene vascular grafts. Scandinavian Cardiovascular Journal, 1993. 27(1): p. 21-26.

58. Bä̈?Ãi kovÃ i, L., et al., Cell adhesion on artificial materials for tissue engineering. Physiol Res, 2004. 53(Suppl 1): p. S35-S45.

59. Sipehia, R., G. Martucci, and J. Lipscombe, Transplantation of human endothelial cell monolayer on artificial vascular prosthesis: the effect of growth-support surface chemistry, cell seeding density, ECM protein coating, and growth factors. Artificial Cells, Blood Substitutes and Biotechnology, 1996. 24(1): p. 51-63.

60. Kent, K.C., A. Oshima, and A.D. Whittemore, Optimal seeding conditions for human endothelial cells. Annals of vascular surgery, 1992. 6(3): p. 258-264.

61. Re, F., et al., Inhibition of anchorage-dependent cell spreading triggers apoptosis in cultured human endothelial cells. The Journal of cell biology, 1994. 127(2): p. 537-546.

62. Defilippi, P., et al., Actin cytoskeleton organization in response to integrinâ€?mediated adhesion. Microscopy research and technique, 1999. 47(1): p. 67-78.

63. Dekker, A., et al., Adhesion of endothelial cells and adsorption of serum proteins on gas plasma-treated polytetrafluoroethylene. Biomaterials, 1991. 12(2): p. 130-138.

64. Van Wachem, P., et al., The influence of protein adsorption on interactions of cultured human endothelial cells with polymers. Journal of biomedical materials research, 1987. 21(6): p. 701-718.

65. Vohra, R., et al., Comparison of different vascular prostheses and matrices in relation to endothelial seeding. British journal of surgery, 1991. 78(4): p. 417-420.

66. Parikh, S.A. and E.R. Edelman, Endothelial cell delivery for cardiovascular therapy. Advanced drug delivery reviews, 2000. 42(1): p. 139-161.

67. Ma, Z., et al., Grafting of gelatin on electrospun poly (caprolactone) nanofibers to improve endothelial cell spreading and proliferation and to control cell orientation. Tissue Engineering, 2005. 11(7-8): p. 1149-1158.

68. Panetti, T., et al., Extracellular matrix molecules regulate endothelial cell migration stimulated by lysophosphatidic acid. Journal of Thrombosis and Haemostasis, 2004. 2(9): p. 1645-1656.

69. Balcells, M. and E.R. Edelman, Effect of preâ€? ?adsorbed proteins on attachment, proliferation, and function of endothelial cells. Journal of cellular physiology, 2002. 191(2): p. 155-161.

70. Rashid, S., et al., Engineering of bypass conduits to improve patency. Cell proliferation, 2004. 37(5): p. 351-366.

71. Hubbel, J.A., S.P. Massia, and P.D. Drumheller, Surfaceâ€国grafted Cellâ€雨inding Peptides in Tissue Engineering of the Vascular Grafta. Annals of the New York Academy of Sciences, 1992. 665(1): p. 253-258.

72. Teebken, O., et al., Tissue engineering of vascular grafts: human cell seeding of decellularised porcine matrix. European journal of vascular and endovascular surgery, 2000. 19(4): p. 381-386. 
73. Mark, K., IMPLEMENTATION OF PHYSIOLOGIC PRESSURE CONDITIONS IN A BLOOD VESSEL MIMIC BIOREACTOR SYSTEM.

74. System, B.N.C.A.T.-C.C., http://www.nexcelom.com/Cellometer-Auto-T4/index.html.

75. Chavez, R.D., Development of In Vitro Tissue Engineered Blood Vessel Mimics in Complex Geometries for Coronary Stent Testing.

76. Pena, T.R., Preparation and Characterization of Electrospun Poly (D, L-lactide-coglycolide) Scaffolds for Vascular Tissue Engineering and the Advancement of an In Vitro Blood Vessel Mimic. Master's Theses and Project Reports, 2009: p. 152.

77. Truskey, G.A. and J.S. Pirone, The effect of fluid shear stress upon cell adhesion to fibronectin-treated surfaces. Journal of biomedical materials research, 1990. 24(10): $p$. 1333-1353.

78. Malek, A.M. and S. Izumo, Mechanism of endothelial cell shape change and cytoskeletal remodeling in response to fluid shear stress. Journal of Cell Science, 1996. 109(4): p. 713726.

79. Dimmeler, S., et al., Shear stress inhibits apoptosis of human endothelial cells. FEBS letters, 1996. 399(1): p. 71-74.

80. ProNectin-F, A New Dimension in Mammalian Cell Attachment 2000.

81. Reinhart-King, C.A., M. Dembo, and D.A. Hammer, The dynamics and mechanics of endothelial cell spreading. Biophysical journal, 2005. 89(1): p. 676-689.

82. Shyy, J.Y.-J. and S. Chien, Role of integrins in endothelial mechanosensing of shear stress. Circulation research, 2002. 91(9): p. 769-775.

83. Yow, K.H., et al., Tissue engineering of vascular conduits. British journal of surgery, 2006. 93(6): p. 652-661.

84. Rosenman, J., et al., Kinetics of endothelial cell seeding. Journal of vascular surgery, 1985. 2(6): p. 778-784.

85. Dhruva, S.S., L.A. Bero, and R.F. Redberg, Strength of study evidence examined by the FDA in premarket approval of cardiovascular devices. JAMA: the journal of the American Medical Association, 2009. 302(24): p. 2679-2685.

86. E Niklason, L. and R. S Langer, Advances in tissue engineering of blood vessels and other tissues. Transplant immunology, 1997. 5(4): p. 303-306.

87. Thompson, M., et al., Effect of pulsatile shear stress on endothelial attachment to native vascular surfaces. British journal of surgery, 1994. 81(8): p. 1121-1127.

88. Hess, F., et al., Seeding of enzymatically derived and subcultivated canine endothelial cells on fibrous polyurethane vascular prostheses. Biomaterials, 1992. 13(10): p. 657663.

89. Jalali, S., et al., Integrin-mediated mechanotransduction requires its dynamic interaction with specific extracellular matrix (ECM) ligands. Proceedings of the National Academy of Sciences, 2001. 98(3): p. 1042-1046. 


\title{
APPENDIX A: 6-WELL PLATE PROTOCOLS AND EXPERIMENTAL DETAILS
}

\section{A.1 6-Well Plate Protocol \#1}

\author{
Six-Well Plate Coating Protocol
}

Date:

Material:

Cell Type:

\section{Prep Five Days Prior}

1. Prep T-75 flask for thawed cells with $20 \mathrm{ml}$ of HUVEC media, allow to incubate for at least $30 \mathrm{~min}$

2. Thaw 1 vial of HUVECs for T-75 flask

3. Pass cells in to T-75 flask

4. Feed cells day after thawing

5. If T-75 is confluent, pass cells in to T-225

6. Make sure T-225 is $80 \%$ confluent prior to set up date

\section{Set Up Day}

8. Obtain 3 six-well plates

a. Label wells 1-18
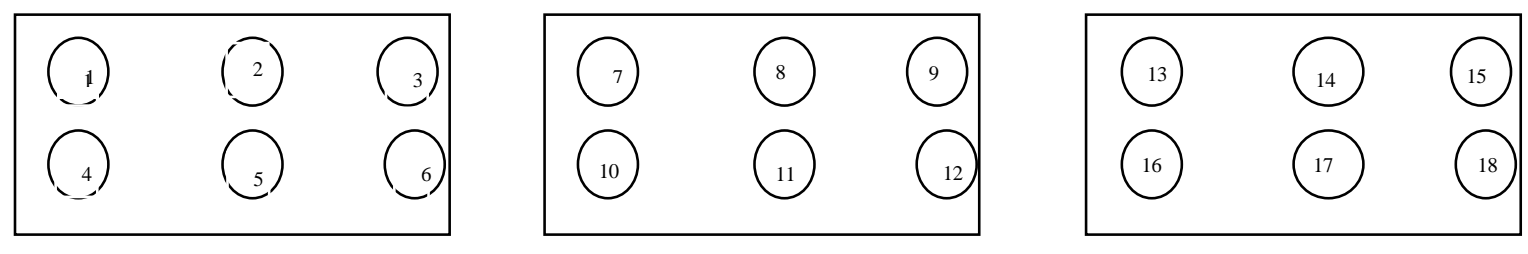

$$
\begin{aligned}
& \text { 1,7,3: No Coating } \\
& \text { 2,8,14: Conditioning Media } \\
& \text { 3,9,15: HUVEC Media } \\
& \text { 4, 10, 16: ProNectin-F+HUVEC Media } \\
& \text { 5, 11,17: ProNectin-F +PBS } \\
& \text { 6, 12,18: HUVEC Media w/5 Minute Cell Incubation }
\end{aligned}
$$

7. Preparation of Wells

a. Add $1.5 \mathrm{ml}$ of Conditioning Media in to wells 2, 8 and 14

b. Add 1.5ml of HUVEC Media in to wells 3, 9 and 15 and 6, 12, 18 .

c. Add $1.5 \mathrm{ml}$ of ProNectin-F+HUVEC Media in to wells 4, 10 and 16

d. Add $1.5 \mathrm{ml}$ of ProNectin-F + PBS in to wells 5, 11 and 17

e. Incubate coated wells for 20 minutes

8. Add Cells to Wells

a. Aspirate coatings

b. Add $1 \mathrm{ml}$ of HUVEC media to each well

c. Add $9 \mathrm{ml}$ of trypsin to T-225 containing HUVECS

d. Deactivate with $27 \mathrm{ml}$ of HUVEC media, count sample from T-225:

i. Total of $36 \mathrm{ml}$ for 18 wells, $2.0 \mathrm{ml}$ for each well.

ii. Be extremely thorough in breaking up clumps and rinsing

e. Add $2.0 \mathrm{ml}$ of cell solution to each well

f. Incubate wells $6,12,18$ for 5 minutes 
g. Incubate remaining wells for 15 minutes

8. Count Non-Adhered Cells in Each Well

a. Pipet all media from wells in to three new 6 well plates (make sure to label wells)

b. Take counts of non-adhered cells

\section{A.2 6-Well Plate Coating Protocol \#2}

Six-Well Plate Coating Protocol

Date:

Material:

Cell Type:

\section{Prep Five Days Prior}

1. Prep T-75 flask for thawed cells with $20 \mathrm{ml}$ of HUVEC media, allow to incubate for at least $30 \mathrm{~min}$

2. Thaw 1 vial of HUVECs for T-75 flask

3. Pass cells in to T-75 flask

4. Feed cells day after thawing

5. Make sure T-225 is $80 \%$ confluent prior to set up date

\section{Set Up Day}

8. Obtain 1 six-well plate

a. Label wells 1-6

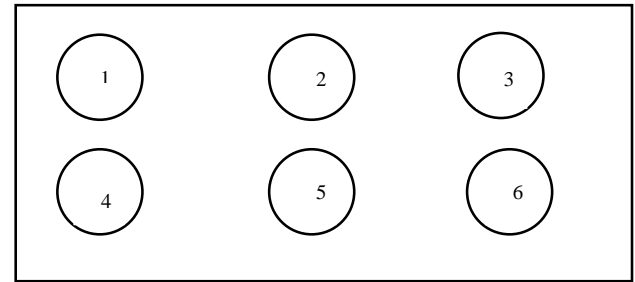

1: No Coating

2: Conditioning Media

3: ProNectin-F+HUVEC Media

4: ProNectin-F+HUVEC Media

5: HUVEC Media

6: HUVEC Media

7. Well Preparation

a. Add $1.5 \mathrm{ml}$ of each coating to their designated wells

b. Incubate for 20 minutes

8. Add Cells to Wells

a. Aspirate coatings

b. Add $1 \mathrm{ml}$ of HUVEC media to each well

c. Add $3 \mathrm{ml}$ of trypsin to T-75 containing HUVECs

d. Deactivate with $9 \mathrm{ml}$ of HUVEC media, count sample from T-75: cells.

i. Total of $12 \mathrm{ml}$ for 6 wells, $2.0 \mathrm{ml}$ for each well.

ii. Be extremely thorough in breaking up clumps and rinsing

e. Add $2.0 \mathrm{ml}$ of cell solution to each well

f. Incubate wells for 5 minutes

8. Counting and Imaging Cells in Individual Wells

a. Pipet all media from wells in to a new 6 well plate (make sure to label wells)

b. Take counts of non-adhered cells 


\section{A.3 6-Well Plate Coating Protocol \#3}

Six-Well Plate Coating Protocol

Date:

Material:

Cell Type:

\section{Prep Five Days Prior}

1. Prep T-75 flask for thawed cells with $20 \mathrm{ml}$ of HUVEC media, allow to incubate for at least $30 \mathrm{~min}$

2. Thaw 1 vial of HUVECs for T-75 flask

3. Pass cells in to T-75 flask

4. Feed cells day after thawing

5. Make sure T-225 is $80 \%$ confluent prior to set up date

\section{Set Up Day}

8. Obtain 1 six-well plate

a. Label wells 1-6

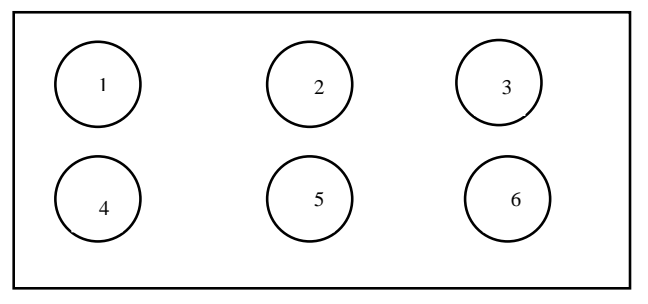

1: No Coating

2: Conditioning Media

3: ProNectin-F+HUVEC Media

4: ProNectin-F+HUVEC Media

5: HUVEC Media

6: HUVEC Media

7. Well Preparation

a. Add $1.5 \mathrm{ml}$ of each coating to their designated wells

b. Incubate for 20 minutes

8. Add Cells to Wells

a. Aspirate coatings

b. Add $1 \mathrm{ml}$ of HUVEC media to each well

c. Add $3 \mathrm{ml}$ of trypsin to T-75 containing HUVECs

d. Deactivate with $9 \mathrm{ml}$ of HUVEC media, count sample from T-75:

i. Total of $12 \mathrm{ml}$ for 6 wells, $2.0 \mathrm{ml}$ for each well.

ii. Be extremely thorough in breaking up clumps and rinsing

e. Add $2.0 \mathrm{ml}$ of cell solution to each well

f. Incubate wells for 5 minutes

8. Counting and Imaging Cells in Individual Wells

a. Pipet all media from wells in to a new 6 well plate (make sure to label wells)

b. Take counts of non-adhered cells

b. Add $1 \mathrm{ml}$ of trypsin to each well

c. Deactivate trypsin with $2 \mathrm{ml}$ of HUVEC media in each well

d. Use $1000 \mu \mathrm{L}$ pipet to mix and break up clumps 
e. Take $20 \mu \mathrm{L}$ sample from each well for adhered cell counts

\section{A.4 6-Well Plate Coating Protocol \# 4}

Six-Well Plate Coating Protocol

Date:

Material:

Cell Type:

\section{Prep Five Days Prior}

1. Prep T-75 flask for thawed cells with $20 \mathrm{ml}$ of HUVEC media, allow to incubate for at least $30 \mathrm{~min}$

2. Thaw 1 vial of HUVECs for T-75 flask

3. Pass cells in to T-75 flask

4. Feed cells day after thawing

5. Make sure T-225 is $80 \%$ confluent prior to set up date

Set Up Day

8. Obtain 1 six-well plate

a. Label wells 1-6

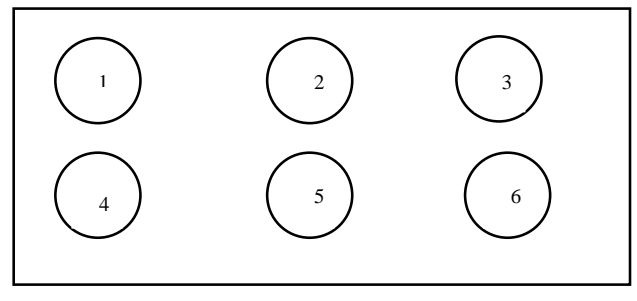

1: No Coating

2: Conditioning Media

3: ProNectin-F+HUVEC Media

4: ProNectin-F+HUVEC Media

5: HUVEC Media

6: HUVEC Media

7. Well Preparation

a. Add $1.5 \mathrm{ml}$ of each coating to their designated wells

b. Incubate for 20 minutes

8. Add Cells to Wells

a. Aspirate coatings

b. Add $1 \mathrm{ml}$ of HUVEC media to each well

c. Add $3 \mathrm{ml}$ of trypsin to T-75 containing HUVECs

d. Deactivate with $9 \mathrm{ml}$ of HUVEC media, count sample from T-75: cells.

i. Total of $12 \mathrm{ml}$ for 6 wells, $2.0 \mathrm{ml}$ for each well.

ii. Be extremely thorough in breaking up clumps and rinsing

e. Add $2.0 \mathrm{ml}$ of cell solution to each well

f. Incubate wells for 5 minutes

8. Counting and Imaging Cells in Individual Wells

a. Pipet all media from wells in to a new 6 well plate (make sure to label wells)

b. Take counts of non-adhered cells

b. Add $1 \mathrm{ml}$ of trypsin to each well

c. Deactivate trypsin with $2 \mathrm{ml}$ of HUVEC media in each well 
d. Centrifuge media from each well on level 4 for 4 minutes

e. Aspirate media until close to bottom of conical

f. Re-suspend cells in $0.5 \mathrm{ml}$ of HUVEC media

g. Take sample from each conical to count.

\title{
A.5 6-Well Plate Experiment: Varying Coating and Cell Incubations Protocol
}

\author{
Six-Well Plate Coating Protocol
}

Date:

Material:

Cell Type:

\section{Prep Five Days Prior}

1. Prep T-75 flask for thawed cells with $20 \mathrm{ml}$ of HUVEC media, allow to incubate for at least $30 \mathrm{~min}$

2. Thaw 1 vial of HUVECs for T-75 flask

3. Pass cells in to T-75 flask

4. Feed cells day after thawing

5. If T-75 is confluent, pass cells in to T-225

6. Make sure T-225 is $80 \%$ confluent prior to set up date

\section{Set Up Day}

8. Obtain 3 six-well plates

a. Label wells 1-12

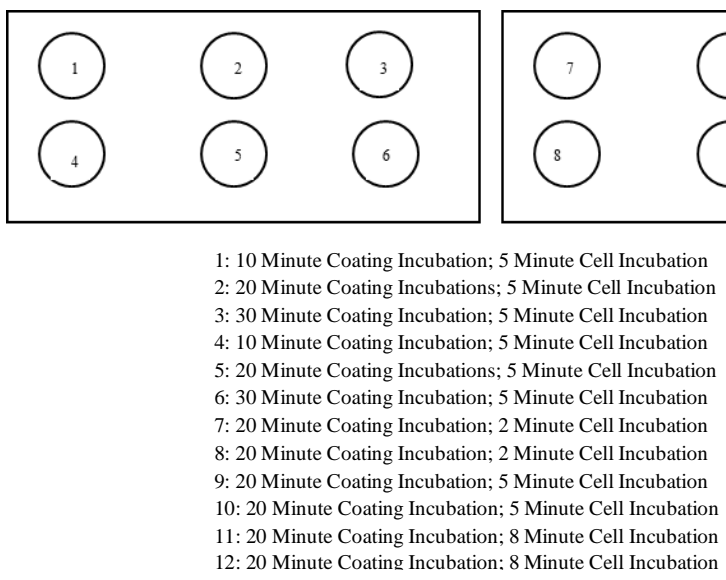

7. Varying Coating Incubation Time

a. Add $1.5 \mathrm{ml}$ of Conditioning Media in to wells 3 and 6

b. Incubate for 10 minutes

c. Add $1.5 \mathrm{ml}$ of Conditioning Media in to wells 2, 5, 7, 8, 9, 10, 11, 12.

d. Incubate for 10 minutes

e. Add $1.5 \mathrm{ml}$ of Conditioning Media in to wells 1 and 4

f. Incubate for 10 minutes

8. Add Cells to Wells

a. Aspirate coatings

b. Add $1 \mathrm{ml}$ of HUVEC media to each well

c. Add $9 \mathrm{ml}$ of trypsin to T-225 containing HUVECS

d. Deactivate with $27 \mathrm{ml}$ of HUVEC media, count sample from T-225:
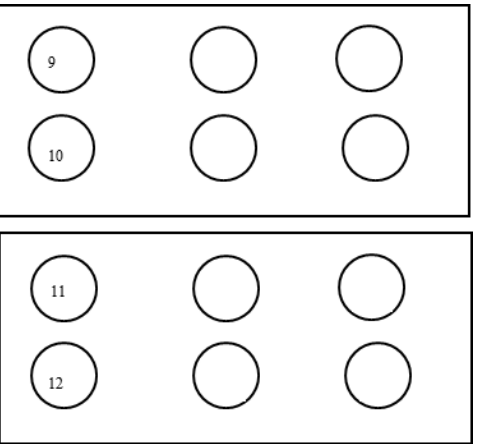

i. Total of $36 \mathrm{ml}$ for 12 wells, $3.0 \mathrm{ml}$ for each well. cells. 
ii. Be extremely thorough in breaking up clumps and rinsing

e. Add $3.0 \mathrm{ml}$ of cell solution to each well

f. Incubation

1. Wells 7 and 8 incubate for two minutes

2. Wells 9,10 and 1-6 incubate for five minutes

3. Wells 11 and 12 incubate for 8 minutes

8. Counting and Imaging Cells in Individual Wells

a. Pipet all media from wells in to two new 6 well plates (make sure to label wells); take counts of nonadhered cells

b. Add $1 \mathrm{ml}$ of trypsin to each well as they finish cell incubation period, let sit for 5 minutes

c. Deactivate trypsin with $2 \mathrm{ml}$ of HUVEC media in each well

d. Centrifuge media from each well on level 4 for 4 minutes

e. Aspirate media until close to bottom of conical

f. Re-suspend cells in $0.5 \mathrm{ml}$ of HUVEC media

g. Take sample from each conical to count. 


\title{
A.6 6-Well Plate Experiments: Comparison Study Protocol
}

\author{
Six-Well Plate Coating Protocol
}

Date:

Material:

Cell Type:

\section{Prep Five Days Prior}

1. Prep T-75 flask for thawed cells with $20 \mathrm{ml}$ of HUVEC media, allow to incubate for at least $30 \mathrm{~min}$

2. Thaw 1 vial of HUVECs for T-75 flask

3. Pass cells in to T-75 flask

4. Feed cells day after thawing

5. If T-75 is confluent, pass cells in to T-225

6. Make sure T-225 is $80 \%$ confluent prior to set up date

\section{Set Up Day}

7. Obtain 4 six-well plates

a. Label wells 1-18
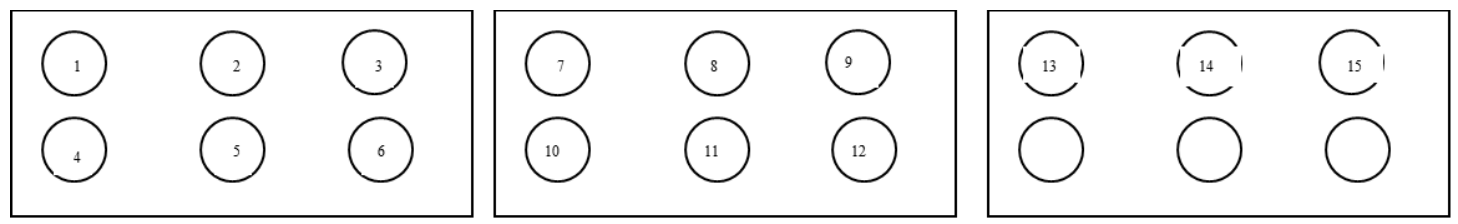

1: Conditioning Media: 60 Minute Incubation

2: Conditioning Media: 60 Minute Incubation

3: Conditioning Media: 60 Minute Incubation

4: ProNectin F: 60 Minute Incubation

5: ProNectin F: 60 Minute Incubation

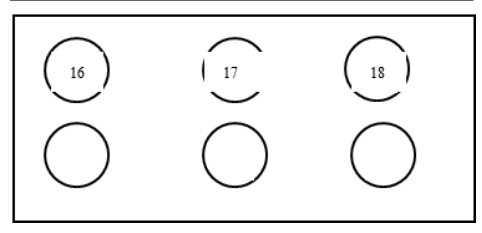

6: ProNectin F: 60 Minute Incubation

7: Conditioning Media: 90 Minute Incubation

8: Conditioning Media: 90 Minute Incubation

9: Conditioning Media: 90 Minute Incubation

10: ProNectin F: 90 Minute Incubation

11: ProNectin F: 90 Minute Incubation

12: ProNectin F: 90 Minute Incubation

13: No Coating: 60 Minute Incubation

14: No Coating: 60 Minute Incubation

15: No Coating: 60 Minute Incubation

16: No Coating: 90 Minute Incubation

17: No Coating: 90 Minute Incubation

18: No Coating: 90 Minute Incubation

\section{Well Preparation}

a. Add $1.5 \mathrm{ml}$ of each coating to designated wells

b. Incubate for 20 minutes

9. Add Cells to Wells

a. Aspirate coatings

b. Add 1ml of HUVEC media to each well

c. Add $9 \mathrm{ml}$ of trypsin to T-225 containing HUVECS

d. Deactivate with $27 \mathrm{ml}$ of HUVEC media, count sample from T-225: cells.

i. Total of $36 \mathrm{ml}$ for 18 wells, $2.0 \mathrm{ml}$ for each well.

ii. Be extremely thorough in breaking up clumps and rinsing

e. Add $2.0 \mathrm{ml}$ of cell solution to each well 
f. Incubation wells for designated cell incubation periods

10. Counting and Imaging Cells in Individual Wells

a. Pipet all media from wells in to two new 6 well plates (make sure to label wells); take counts of nonadhered cells

b. Add $1 \mathrm{ml}$ of trypsin to each well as they finish cell incubation period, let sit for 5 minutes

c. Deactivate trypsin with $2 \mathrm{ml}$ of HUVEC media in each well

d. Centrifuge media from each well on level 4 for 4 minutes

e. Aspirate media until close to bottom of conical

f. Re-suspend cells in $0.5 \mathrm{ml}$ of HUVEC media

g. Take sample from each conical to count. 


\section{APPENDIX B: BVM PROTOCOLS AND EXPERIMENTAL DETAILS}

\section{B.1 Analysis of Pre-Coatings In a BVM: Protocol \#1}

Study Title:

Purpose:

Material:

Diameter:

Length:

Cell Type:

Prep the day before

1. Make media:

a. Bioreactor Media (Human Complete w/o ECGS w/ antibiotics)

b. Conditioning Media (1:6 solution of FBS:M199 + antibiotics)

PLGA (1x)

2. Sterilize grafts $30 \min 70 \% \mathrm{EtOH}$

i. Using syringe and cap flush luminaly and transmuraly with PBS

ii. Perform same flush procedure with Conditioning Media

3. Place small WM pump in hood

a. Fill coated vessel chambers with Bioreactor media (Be sure tubes are closed!)

4. Insert sterile grafts into biochambers. And place lid on chamber.

5. Using a syringe, flush lumen with Conditioning Media, ProNectin-F or PBS to prime graft

6. Clamp lumen and continue to prime graft

i. Repeat for all vessels

7. Prime 2-port reservoirs with Conditioning Media, ProNectin-F or PBS

8. Attach primed biochamber to 2-port reservoir and condition graft for 20 minutes

a. Flow through lumen first to remove air, then clamp lumen and condition transmurally on $150 \mathrm{rpm}$ setting

Set-up day: BVM sodding

9. Take corresponding number of primed biochambers and reservoirs to hood

10. Attach outlet of reservoir to inlet stopcock of biochamber

a. Leave reservoir inlet unattached and biochamber outlet facing trough

11. Record BVM numbers (or chamber ID):

12. Harvest cells

a. Apply Trypsin, deactivate with media

b. Take $100 \mathrm{uL}$ from total $\mathrm{mL}$ cells

Counts: 
13. $\mathrm{X}=\mathrm{x} 2000 \mathrm{x}($ cell $\mathrm{mL} \times .10)$

total number of cells $=$

14. Pellet cell suspension (on 4 for 4 min)

15. Resuspend in ___ $\mathrm{mL}$ Bioreactor Media

16. Sod each graft with ___ $\mathrm{mL}$ cell solution

a. Cells per graft $=$

b. Sodding density $=\quad$ cells $/ \mathrm{cm} 2$

17. Chase with 1-3mL HUVEC Media

18. Attach biochamber outlet to reservoir inlet

19. Bring BVMs to large incubator

20. Place on small WM pump - leave lumen clamped!!

21. Immediately begin transmural flow at $10 \mathrm{rpm}$, and maintain for 10 minutes

22. Turn off pump and allow scaffolds in incubate for 60 minutes

23. Harvest scaffolds from bioreactors and fix in histachoice 


\section{B.2: Analysis of Pre-Coatings In a BVM: Protocol \#2}

Study Title:

Purpose:

Material:

Diameter:

Length:

Cell Type:

\section{Prep the day before}

1. Make media:

a. Bioreactor Media (Human Complete w/o ECGS w/ antibiotics)

PLGA (1x)

b. Conditioning Media (1:6 solution of FBS:M199 + antibiotics)

2. Sterilize grafts $30 \mathrm{~min} 70 \% \mathrm{EtOH}$

i. Using syringe and cap flush luminaly and transmuraly with PBS

ii. Perform same flush procedure with Conditioning Media

3. Place small WM pump in hood

a. Fill coated vessel chambers with Bioreactor media PBS (Be sure tubes are closed!)

4. Insert sterile grafts into biochambers. And place lid on chamber.

5. Using a syringe, flush lumen with Conditioning Media, ProNectin-F or PBS to prime graft

6. Clamp lumen and continue to prime graft

i. Repeat for all vessels

7. Prime 2-port reservoirs with Conditioning Media, ProNectin-F or PBS

8. Attach primed biochamber to 2-port reservoir and condition graft for 20 minutes

a. Flow through lumen first to remove air, then clamp lumen and condition transmurally on $150 \mathrm{rpm}$ setting

\section{Set-up day: BVM sodding}

9. Take corresponding number of primed biochambers and reservoirs to hood

10. Attach outlet of reservoir to inlet stopcock of biochamber

a. Leave reservoir inlet unattached and biochamber outlet facing trough

11. Record BVM numbers (or chamber ID):

12. Harvest cells

a. Apply Trypsin, deactivate with media

b. Take 100uL from total ___ $\mathrm{mL}$ cells

Counts: 
13. $\mathrm{X}=\mathrm{x} 2000 \mathrm{x}($ cell $\mathrm{mL} \times .10)$

total number of cells $=$

14. Pellet cell suspension (on 4 for 4 min)

15. Resuspend in ___ $\mathrm{mL}$ Bioreactor Media

16. Sod each graft with ___ $\mathrm{mL}$ cell solution

a. Cells per graft $=$

b. Sodding density $=\quad$ cells $/ \mathrm{cm} 2$

17. Chase with 1-3mL HUVEC Media

18. Attach biochamber outlet to reservoir inlet

19. Bring BVMs to large incubator

20. Place on small WM pump - leave lumen clamped!!

21. Immediately begin transmural flow at $10 \mathrm{rpm}$, and maintain for 10 minutes

22. Turn off pump and allow scaffolds in incubate for 60 minutes

23. Harvest scaffolds from bioreactors and fix in histachoice 


\section{B.3 Proof-of-Concept Study Protocol \\ Study Information}

Study Title:

Purpose:

Material:

Diameter:

Length:

Cell Type:

\section{Prep the day before}

1. Make media:

a. Bioreactor Media (Human Complete w/o ECGS w/ antibiotics)

PLGA (1x)

b. Conditioning Media (1:6 solution of FBS:M199 + antibiotics)

2. Sterilize grafts $30 \mathrm{~min} 70 \% \mathrm{EtOH}$

i. Using syringe and cap flush luminaly and transmuraly with PBS

1. Repeat for non-coated scaffolds

ii. Perform same flush procedure with Conditioning Media for coated scaffolds

3. Place small WM pump in hood

4. Fill coated vessel chambers with Bioreactor media, non-coated fill with PBS (Be sure tubes are closed!)

5. Insert sterile grafts into biochambers. And place lid on chamber.

6. Using a syringe, flush lumen with Conditioning Media, or PBS to prime graft

7. Clamp lumen and continue to prime graft

i. Repeat for all vessels

8. Prime 2-port reservoirs with Conditioning Media, or PBS

9. Attach primed biochamber to 2-port reservoir and condition graft for 20 minutes

a. Flow through lumen first to remove air, then clamp lumen and condition

transmurally on $150 \mathrm{rpm}$ setting

\section{Set-up day: BVM sodding}

10. Take corresponding number of primed biochambers and reservoirs to hood

11. Attach outlet of reservoir to inlet stopcock of biochamber

a. Leave reservoir inlet unattached and biochamber outlet facing trough

12. Record BVM numbers (or chamber ID):

13. Harvest cells

a. Apply Trypsin, deactivate with media

b. Take $100 \mathrm{uL}$ from total $\mathrm{mL}$ cells

Counts: 
14. $\mathrm{X}=$ x 2000 x (cell mL x .10)

total number of cells $=$

15. Pellet cell suspension (on 4 for $4 \mathrm{~min}$ )

16. Resuspend in _ $\quad \mathrm{mL} \mathrm{HUVEC} \mathrm{media} \mathrm{or} \mathrm{PBS}$

17. Sod each graft with ___ $\mathrm{mL}$ cell solution
a. Cells per graft $=$
b. Sodding density $=$
cells/cm2

18. Chase with 1-3mL HUVEC Media

19. Attach biochamber outlet to reservoir inlet

20. Bring BVMs to large incubator

21. Place on small WM pump - leave lumen clamped!!

22. Immediately begin transmural flow at $10 \mathrm{rpm}$, and maintain for 10 minutes

23. Turn off pump and allow scaffolds in incubate for 60 minutes

24. Harvest scaffolds from bioreactors and fix in histachoice 


\section{B.4 Static BVM Pre-Coating Comparison Study}

Study Title:

Purpose:

Material:

Diameter:

Length:

Cell Type:

\section{Prep the day before (uncoated)}

1. Make media:

a. Bioreactor Media (Human Complete w/o ECGS w/ antibiotics)

b. Conditioning Media (1:6 solution of FBS:M199 + antibiotics)

PLGA (1x)

2. Sterilize grafts $30 \mathrm{~min} 70 \% \mathrm{EtOH}$

i. Using syringe and cap flush luminaly and transmuraly with PBS

ii. Perform same flush procedure with Conditioning Media for Conditioning Media coated scaffolds

iii. Perform same flush procedure with ProNectin-F+HUVEC media

3. Place small WM pump in hood

a. Fill coated vessel chambers with Bioreactor media, ProNectin-F+HUVEC media, or non-coated fill with PBS (Be sure tubes are closed!)

4. Insert sterile grafts into biochambers. And place lid on chamber.

5. Using a syringe, flush lumen with Conditioning Media, ProNectin-F or PBS to prime graft

6. Clamp lumen and continue to prime graft

i. Repeat for all vessels

7. Prime 2-port reservoirs with Conditioning Media, ProNectin-F or PBS

8. Attach primed biochamber to 2-port reservoir and condition graft for 20 minutes

a. Flow through lumen first to remove air, then clamp lumen and condition transmurally on $150 \mathrm{rpm}$ setting

\section{Set-up day: BVM sodding}

9. Take corresponding number of primed biochambers and reservoirs to hood

10. Attach outlet of reservoir to inlet stopcock of biochamber

a. Leave reservoir inlet unattached and biochamber outlet facing trough

11. Record BVM numbers (or chamber ID):

12. Harvest cells

a. Apply Trypsin, deactivate with media

b. Take $100 \mathrm{uL}$ from total $\mathrm{mL}$ cells

Counts: 
13. $\mathrm{X}=$ x 2000 x (cell mL x .10)

total number of cells $=$

14. Pellet cell suspension (on 4 for $4 \mathrm{~min}$ )

15. Resuspend in ___ $\mathrm{mL}$ Bioreactor Media

16. Sod each graft with ___ $\mathrm{mL}$ cell solution

a. Cells per graft $=$

b. Sodding density $=\quad$ cells $/ \mathrm{cm} 2$

17. Chase with 1-3mL HUVEC Media

18. Attach biochamber outlet to reservoir inlet

19. Bring BVMs to large incubator

20. Place on small WM pump - leave lumen clamped!!

21. Immediately begin transmural flow at $10 \mathrm{rpm}$, and maintain for 10 minutes

22. Turn pump off and incubate for 60 minutes

23. Harvest scaffolds from bioreactors 


\section{B.5 Dynamic BVM Pre-Coating Comparison Study}

Study Title:

Purpose:

Material:

Diameter:

Length:

Cell Type:

\section{Prep the day before (uncoated)}

1. Make media:

a. Bioreactor Media (Human Complete w/o ECGS w/ antibiotics)

b. Conditioning Media (1:6 solution of FBS:M199 + antibiotics)

PLGA (1x)

2. Sterilize grafts $30 \mathrm{~min} 70 \% \mathrm{EtOH}$

i. Using syringe and cap flush luminaly and transmuraly with PBS

ii. Perform same flush procedure with Conditioning Media for Conditioning Media coated scaffolds

iii. Perform same flush procedure with ProNectin-F+HUVEC media

3. Place small WM pump in hood

4. Fill coated vessel chambers with Bioreactor media, ProNectin-F+HUVEC media, or non-coated fill with PBS (Be sure tubes are closed!)

5. Insert sterile grafts into biochambers. And place lid on chamber.

6. Using a syringe, flush lumen with Conditioning Media, ProNectin-F or PBS to prime graft

7. Clamp lumen and continue to prime graft

i. Repeat for all vessels

8. Prime 2-port reservoirs with Conditioning Media, ProNectin-F or PBS

9. Attach primed biochamber to 2-port reservoir and condition graft for 20 minutes

a. Flow through lumen first to remove air, then clamp lumen and condition transmurally on $150 \mathrm{rpm}$ setting

\section{Set-up day: BVM sodding}

10. Take corresponding number of primed biochambers and reservoirs to hood

11. Attach outlet of reservoir to inlet stopcock of biochamber

a. Leave reservoir inlet unattached and biochamber outlet facing trough

12. Record BVM numbers (or chamber ID):

13. Harvest cells

a. Apply Trypsin, deactivate with media

b. Take $100 \mathrm{uL}$ from total $\mathrm{mL}$ cells

Counts: 
14. $\mathrm{X}=$ x 2000 x (cell mL x .10)

total number of cells $=$

15. Pellet cell suspension (on 4 for $4 \mathrm{~min}$ )

16. Resuspend in ___ mL Bioreactor Media

17. Sod each graft with ___ $\mathrm{mL}$ cell solution

a. Cells per graft $=$

b. Sodding density $=\quad$ cells $/ \mathrm{cm} 2$

18. Chase with 1-3mL HUVEC Media

19. Attach biochamber outlet to reservoir inlet

20. Bring BVMs to large incubator

21. Place on small WM pump - leave lumen clamped!!

22. Immediately begin transmural flow at $10 \mathrm{rpm}$, and maintain for 1 hour

a. Started on pump at: ___ (time)

23. Unclamp lumen and maintain 10rpm luminal flow for 1 hour

24. Increase flow by $10-15 \mathrm{rpm}$ each hour at a time to reach $90 \mathrm{rpm}$ by the end of the day

25. Harvest scaffolds from bioreactors 


\section{APPENDIX C: STAINING PROTOCOLS AND EXPERIMENTAL DETAILS}

\section{C.1 BBI Staining Protocol}

1. Wrap nonsterile $15-\mathrm{mL}$ conicals in foil. Thoroughly label conicals for all samples.

2. Make BBI solution. Always keep stock solution wrapped in foil!

a. Use small tube of stock solution and dilute 1:1000 with milli-Q water $(10 \mu \mathrm{L}$ stock solution in $10 \mathrm{~mL}$ water). Use pipette aid from room 209 hood for milli-Q water; spray pipette aid before placing back in hood.

b. Mix by inverting.

3. Put on safety glasses. Cut samples with blade or scissors, being careful to not disrupt cell lining inside lumen (squeezing, touching, and scraping can all disrupt lining and ruin experiment).

4. Use washed forceps to place samples in corresponding 15-mL conicals that contain BBI solution. Carefully keep track of samples. Leave foil on conicals.

a. Let samples soak for at least 15 minutes (longer is better).

5. Put away extra stock solution. Clean up preparation area.

6. With permission or help from Dr. Cardinal, use fluorescent microscope to obtain en face images. Take forceps to use at microscope.

a. Log into notebook (fluorescence; initials; date; time and lamp hours).

b. Turn turret to setting 4 .

c. Turn on Olympus lamp (green switch).

d. Turn on Optiscan wheels (black switch).

e. Turn on camera (black switch).

f. Set filter wheel 1 to 1 , and set filter wheel 2 to 1 .

g. Open shutter: o

h. Set Prior keypad to shutter S1.

i. Dial objectives to desired magnification (typically $4 \mathrm{x}$ and 10x for BBI images).

j. Set thin bar to icon of eye and camera.

k. Sign into computer by clicking Kristen's account (password can be obtained from Kristen).

1. Click QCapture Pro (on desktop).

m. Click camera icon at top of QCapture Pro window:

n. Place slide on microscope. Place sample on slide.

o. See image.

p. Manually adjust microscope to clarify image.

q. If scaffold is too wet, carefully blot end of scaffold on Kim wipe.

r. Take pictures. Save pictures if desired (labeled with sample info, initials, and magnification).

s. Quit QCapture Pro. Log out of computer.

t. Shut down microscope by switching off Olympus lamp, switching off Optiscan wheels, switching off camera (on top of microscope), closing shutter, and setting thin bar to icon of eye.

u. Log out of notebook. 

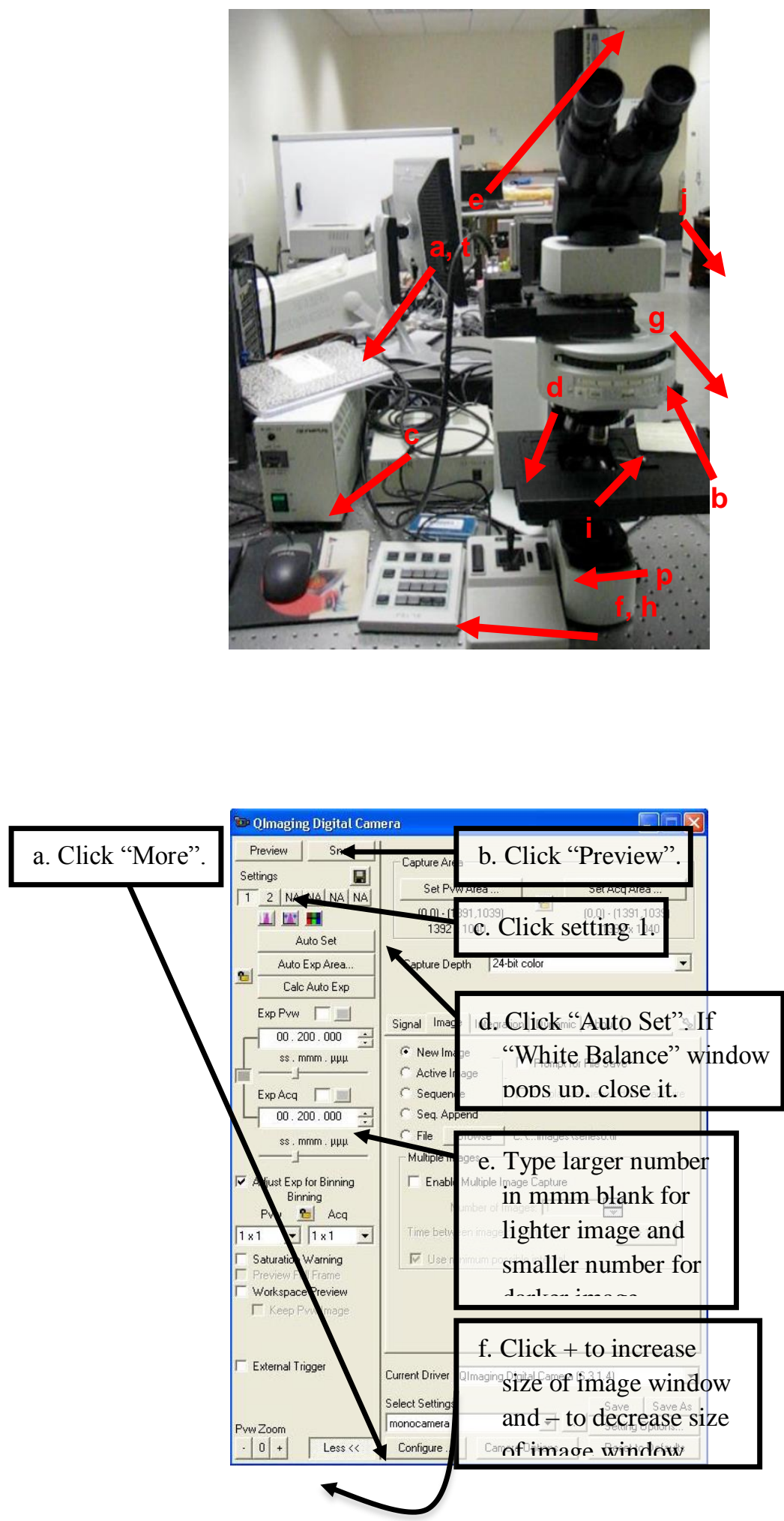


\section{C.2 Rhodamine phalloidin Staining Protocol}

1. Wash cells twice with prewarmed phosphate-buffered saline, $\mathrm{pH} 7.4$ (PBS).

2. Fix the sample in $3.7 \%$ formaldehyde solution in PBS for 10 minutes at room temperature. Note: Methanol can disrupt actin during the fixation process. Therefore, it is best to avoid any methanol containing fixatives. The preferred fixative is methanol-free formaldehyde.

3. Wash two or more times with PBS.

4. Place each coverslip in a glass petri dish and extract it with a solution of acetone at $\equiv-$ $20^{\circ} \mathrm{C}$ or $0.1 \%$ Triton X-100 in PBS for 3 to 5 minutes.

5. Wash two or more times with PBS.

6. When staining with any of the fluorescent phallotoxins, dilute $5 \mu \mathrm{L}$ methanolic stock solution into $200 \mu \mathrm{L}$ PBS for each coverslip to be stained. To reduce nonspecific background staining with these conjugates, add $1 \%$ bovine serum albumin (BSA) to the staining solution. It may also be useful to pre-incubate fixed cells with PBS containing $1 \%$ BSA or with the Image-iT ${ }^{\mathrm{TM}} \mathrm{FX}$ signal enhancer (I36933) for 20-30 minutes prior to adding the phallotoxin staining solution. When staining with biotin-XX phalloidin (B7474), dilute $10 \mu \mathrm{L}$ of the methanolic stock solution into $200 \mu \mathrm{L}$ PBS for each coverslip to be stained. When staining more than one coverslip, adjust volumes accordingly. For a stronger signal, use 2 or 3 units per coverslip.

7. Place the staining solution on the coverslip for 20 minutes at room temperature (generally, any temperature between $4^{\circ} \mathrm{C}$ and $37^{\circ} \mathrm{C}$ is suitable). To avoid evaporation, keep the coverslips inside a covered container during the incubation.

8. Wash two or more times with PBS.

9. When using biotin-XX phalloidin, incubate for 30 minutes with $100 \mu \mathrm{L}$ of a $10 \mu \mathrm{g} / \mathrm{mL}$ solution of fluorescent or enzyme-conjugated streptavidin dissolved in $100 \mathrm{mM}$ Tris- $\mathrm{HCl}$, $\mathrm{pH} 7.5,150 \mathrm{mM} \mathrm{NaCl}, 0.3 \%$ Triton X-100 and 1\% BSA. Incubate for 15 minutes at room temperature. After incubation, wash the coverslip with PBS. To develop enzyme activity, follow a procedure recommended for the specific enzyme.

10. For long-term storage, the cells should be air dried and then mounted in a permanent mountant such as ProLong® Gold reagent or Cytoseal. Specimens prepared in this manner retain actin staining for at least six months when stored in the dark at $2-6^{\circ} \mathrm{C}$. 
